Claremont Colleges

Scholarship @ Claremont

Spring 2021

\title{
Where can I find services that will help me meet my basic needs?: Developing a geospatial tool to support college students experiencing basic needs insecurities
}

\author{
Elizabeth Rowen \\ Claremont Graduate University
}

Follow this and additional works at: https://scholarship.claremont.edu/cgu_etd

\section{Recommended Citation}

Rowen, Elizabeth. (2021). Where can I find services that will help me meet my basic needs?: Developing a geospatial tool to support college students experiencing basic needs insecurities. CGU Theses \& Dissertations, 224. https://scholarship.claremont.edu/cgu_etd/224. doi: 10.5642/cguetd/224

This Open Access Dissertation is brought to you for free and open access by the CGU Student Scholarship at Scholarship @ Claremont. It has been accepted for inclusion in CGU Theses \& Dissertations by an authorized administrator of Scholarship @ Claremont. For more information, please contact scholarship@cuc.claremont.edu. 
Where can I find services that will help me meet my basic needs?

Developing a geospatial tool to support college students experiencing basic needs insecurities.

By

Elizabeth Rowen

Claremont Graduate University

2021 
(C) Copyright Elizabeth Rowen, 2021

All rights reserved 


\title{
Approval of the Dissertation Committee
}

This dissertation has been duly read, reviewed, and critiqued by the Committee listed below, which hereby approves the manuscript of Elizabeth Rowen as fulfilling the scope and quality requirements for meriting the degree of Doctor of Philosophy in Political Science.

\author{
Melissa Rogers, Co-Chair \\ Claremont Graduate University \\ Associate Professor of International Studies
}

Brian Hilton, Co-Chair

Claremont Graduate University

Clinical Full Professor of Information Systems and Technology

Guillermo Douglass-Jaimes

Pomona College

Assistant Professor of Environmental Analysis 


\begin{abstract}
Where can I find services that will help me meet my basic needs?: Developing a geospatial tool
\end{abstract}

to support college students experiencing basic needs insecurities

By

\title{
Elizabeth Rowen
}

Claremont Graduate University: 2021

College students in California are unable to meet their basic needs for survival, leaving students across the state without consistent access to food, housing, and health care. Emergency programs and services, both public and private, exist on most college campuses to address students' basic needs. Unfortunately, due to the stigmatization of basic needs insecurities and a lack of widespread knowledge about these services, students who need help meeting their basic needs are not connecting with the programs and services on campus that can help them. This dissertation contends that college students experiencing homelessness, housing insecurity, and food insecurity would benefit from the use of a mobile application that assists users in finding and accessing on-campus and off-campus services, such as housing services, food services, health care services, financial services, personal care services, and LGBTQ+ student services. Using the frameworks of design science research, public participatory GIS, and critical GIS and tools such as Esri's QuickCapture, Esri’s Web App Builder, React Native Listings, Termly, ATLAS.ti, Qualtrics, and Google Forms, this dissertation illustrates the design, development, implementation, and evaluation of a model of a mobile application, the Campus Cares Community App, that connects student users with basic needs services.

The dissertation includes a literature review of all of the studies conducted on college students' experiences with basic needs insecurities in the U.S. and California and a review of the public policies shaping college students' experiences with basic needs insecurities. The literature 
review shows that despite the increased empirical examination of college students' experiences with basic needs insecurities in recent years, there have been few uses of geospatial tools, methods, or artifacts to support research about this topic or development of solutions to address this problem. Geospatial methods can help researchers to document, describe, and analyze data about students' experiences with basic needs insecurities because these conditions are experienced geographically. Many applied geospatial tools can be useful in addressing this problem because these tools provide user-friendly, cost-effective methods for connecting people with other people, locations, and institutions. In addition, the dissertation presents a comprehensive explanation of the iterative process of designing and developing a model of a mobile application in consultation with important stakeholders and potential users, such as students and staff who work with students experiencing basic needs insecurities. Three iterative cycles were performed, during which processes such as: reviewing existing tools to support service navigation, collecting information about software and applications for designing the application, selecting and testing multiple programs and applications, creating a model of an application showing proof of concept of the idea, brainstorming ideas for the app with potential users, naming the application, and developing a template of the application occurred. The evaluation of the model of the mobile application employed the System Usability Scale (SUS) and five open-ended questions to assess the usability of the application. The five participants who responded to the survey containing the SUS and the evaluative open-ended questions found the Campus Cares Community App to be usable and useful. The participants also shared ideas for improvements and revisions to the application which can be applied in future iterative cycles. A mobile application to support students experiencing basic needs insecurities is feasible, usable, and beneficial. College administrators can consider implementing the Campus Cares Community 
App on their campuses as an additional instrument of mitigation to support students experiencing basic needs insecurities. 


\section{Acknowledgements}

I would like to express sincere gratitude to my dissertation committee for their guidance, encouragement, kindness, and excellent feedback. I am grateful to co-Chair Brian Hilton for his flexibility, innovative leadership, patience, and generosity in sharing so much time and knowledge with me. I thank co-Chair Melissa Rogers for her enthusiastic support of my ideas and goals, analytical feedback, and lightning-fast response times. I really appreciate Guillermo Douglass-Jaimes' elevating feedback, compassion, and creativity. It is not hyperbolic to note that I feel like I had the most magnificent dissertation committee. It was a joy and an honor to be able to work with these three amazing people.

The mobile application that is described in this dissertation would not exist without the expertise, time, and energy expended by Wenxing Luo, who built the application and dedicated countless hours to this project. To merely say "thank you" feels like an understatement but these are the best words that I can think of to express my immense gratitude! Thank you for being so patient, thoughtful, and generous with your time and intelligence. Also, I am grateful to Haibo Yan for his help in developing the mobile application and getting the engine of the project started.

This project would not have been possible without input from numerous students, staff, and faculty at Copper Mountain College, College of the Desert, and Claremont Graduate University who shared ideas, experiences, and resources that fueled this project. Thank you for sharing your creativity, brilliance, and vulnerability with me. Thank you to the Claremont Graduate University Graduate Student Council (GSC) for believing in this project and supporting it financially through the GSC Material Award. Additionally, I am especially grateful to Chant'e Catt for her early, enthusiastic participation and continued encouragement. Also, a big "thank 
you" to Chant'e for sharing so many excellent resources and tools with me! Furthermore, I want to thank Dr. Linda Perkins for her effusive support, compassion, and magnanimity throughout my time in graduate school. I have learned so much about scholarship, teaching, and activism from Dr. Perkins and I would not have made it to this stage of my educational journey without her guidance.

It is imperative to say a huge, mountain-sized "thank you" to my parents, Dorothy and John, for their fierce, unconditional love and for supporting all of my ideas, no matter how eccentric! I am continuously inspired by my parents' selflessness, wisdom, optimism, and funloving spirits, all of which they shared with me throughout this dissertation process. I am also so grateful to Halimah, Lotfi, Mariem, and Salma for their kindness, encouragement, helpful advice, and great senses of humor. I owe a debt of gratitude - and tons of hugs - to all of my friends for cheering me on throughout this process, with special thanks to Emily, Jamie, Joyce, Abiola, Hafsa, and Vung. Thank you for listening to me, laughing with me, inspiring me, advising me, hiking with me, and believing in me - sometimes when I was not so keen on believing in myself. Misty Copeland says that "anything is possible when you have the right people there to support you". This quote captures my feelings about the dissertation process and the people who made the impossible feel possible. Thank you! 


\section{Table of Contents}

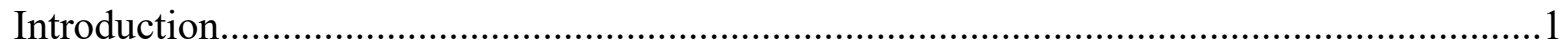

Review of the Literature on College Students' Experiences with Basic Needs Insecurities....11

Developing an Application that Connects College Students to Services that Address Basic Needs

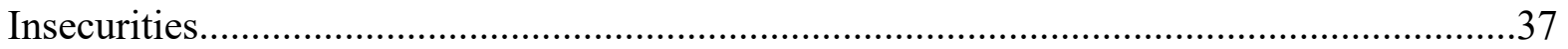

Evaluating the Campus Cares Community Application.......................................................75

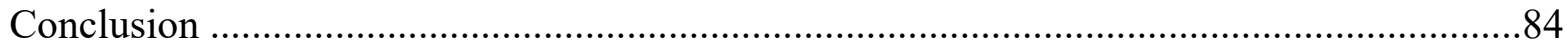

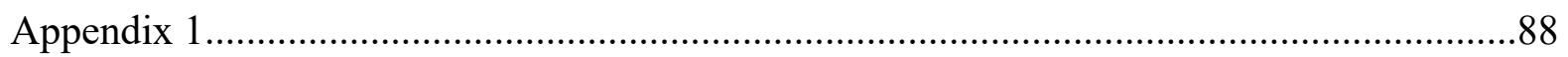

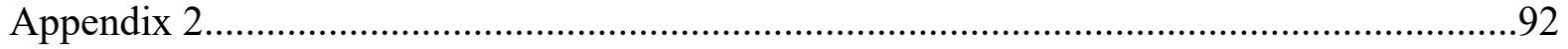

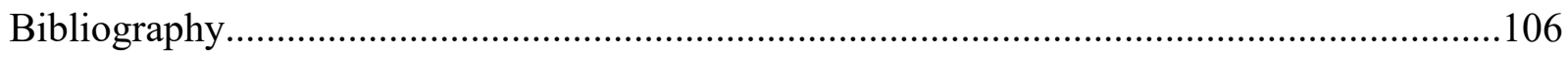




\section{Introduction}

"Education is the great equalizer of our time. It gives hope to the hopeless and creates chances for those without." —Kofi Annan, former UN Secretary General

Education is often conceptualized as an equalizer, particularly in the context of economic inequality. Research from the field of applied economics shows that at the country level, the expanse of national educational opportunities is associated with a reduction in national levels of income inequality (Coady and Dizioli 2017, 2018). Students who decide to pursue college degrees often make their decisions based on economic concerns. They assume that a college degree will give them increased economic opportunities and career options throughout their lives (Bowen 2018). However, many students find that the financial pressures and burdens associated with pursuing a college degree are debilitating (Haney 2015, Grabmeier 2015, Crutchfield and Maguire 2018), thus calling into question the potential for social mobility.

In California, there is a growing number of college students who are vulnerable to experiencing homelessness, housing insecurity, and food insecurity. About $25 \%$ of community college students in California experienced homelessness in 2017. Approximately $11 \%$ of California State University students experienced homelessness from July 2017-July 2018 (Anderson 2018). Roughly 50\% of California community college students reported experiencing food insecurity and $60 \%$ of California community college students reported experiencing housing insecurity from 2016-2018 (Goldrick-Rab et al. 2019). In the University of California (UC) system, it is estimated that approximately $5 \%$ of systemwide undergraduate students experienced homelessness and approximately $48 \%$ of systemwide undergraduate students experienced food insecurity, in 2016 (Restmeyer 2018). 
Research on student homelessness in California shows that there are some groups of college students who are especially vulnerable to experiencing homelessness, housing insecurity, and food insecurity. For example, students of color, non-traditional students (students age 25 years or older), LGBTQ+ students, first generation college students, students who are former foster youth, students who have been incarcerated, and students who are immigrants are often at risk of experiencing homelessness, housing insecurity, and food insecurity as a result of systemic housing inequities (Ringer 2015, Au and Hyatt 2017, Goldrick-Rab, Richardson, and Hernandez 2017, Mello 2018, Crutchfield and Maguire 2018, Restmeyer 2018, Goldrick-Rab et. al. 2019).

The term used to describe the conditions of homelessness, housing insecurity, and food insecurity simultaneously is "basic needs insecurities". Basic needs insecurities are "hardship[s] in terms of at least three aspects of basic physiological needs: food, shelter, and medical care" (Assistant Secretary for Planning and Evaluation 2004). College students in California are unable to meet their basic needs for survival and they would benefit from the development of an application that helps them find, locate, access, and use on-campus and off-campus services.

\section{Problem Statement}

Most college campuses in California make support services available to students experiencing basic needs insecurities including access to free shower facilities, food banks, food pantries, housing navigation support, mental health services, health clinics for physical health needs, CalFresh recruitment programs, Educational Opportunity Program (EOP) offices, and CalWorks offices (Au and Hyatt 2017, Crutchfield and Maguire 2018, Restmeyer 2018, Goldrick-Rab et. al. 2019). While campus staff are responsible for administering and providing on-campus services, local, state, and federal government agencies and non-profit organizations 
lead the administration of off-campus services. Off-campus services available, such as food banks, shelters, and non-profit organizations are often available in close in proximity to campuses and offer services that would help students meet their basic needs (Crutchfield and Maguire 2018).

However, students are not always aware of how to find basic needs services, nor when to access them. For example, students are often left wondering when are the hours of operation of the services? And, where are these services located on campus and off campus? Students who do find information about these services use word-of-mouth referrals to find information about these services (Mello 2018). On-campus services are often publicized during orientation week (Au and Hyatt 2017). However, due to a variety of factors including the stigma associated with discussing one's housing or food insecure status, students may fail to learn about the existence, location, or operating hours of these services and therefore remain or become homeless (Mello 2018).

A 2018 report on service utilization among Cal State University students found:

"CalFresh and campus emergency food pantry use increased with students who reported low and very-low food security; however, utilization rates were still very low" (Crutchfield and Maguire 2018). The report indicates that only $22 \%$ of students who need food services are utilizing services (Crutchfield and Maguire 2018). One of the policy recommendations that emerged from the comprehensive mixed-methods study that was sponsored by the California State University Office of the Chancellor encourages researchers to: "identify and institute creative campaigns to develop a campus culture of awareness and response to support students who experience significant material hardships" (Crutchfield and Maguire 2018). This project directly responds to the policy recommendation of creating an innovative way to spread information about the services available to students who are experiencing basic needs insecurities in a way that fosters 
a supportive and encouraging experience with finding and using on-campus and off-campus services. The main objective of this dissertation is to design a model for a geospatial tool in the form of an application that can be used to enhance students' opportunities to identify and access services on their campuses that are designed to address basic needs insecurities. The application will also be designed with the intention of reducing stigma for students who are experiencing homelessness, housing insecurity, and food insecurity.

\section{Research Questions}

The questions that will guide this project are:

1. Which public policies and institutional policies, programs, and services at colleges and universities have been designed and implemented to address the basic needs insecurities experienced by college students in California?

2. How useful are Geographic Information Systems (GIS) methods for developing tools that college students can use to identify and access services on campus?

3. How can the development of geospatial tools support college students who are impacted by homelessness, housing insecurity, and food insecurity incorporate "geographies of hope and care" (Pavlovskaya 2018) and become effective tools for social transformation?

\section{Methodology and Structure}

Geographic Information Systems (GIS) methods and techniques can be used to help mitigate the negative effects of housing inequality on undergraduate students in California. This dissertation uses geospatial applications for reducing basic needs insecurities for college students in California. 
In order to analyze the public policies, political and educational institutions, and additional constraints that impact experiences of basic needs insecurities for students in California, a review of the academic literature and public policy initiatives on students' experiences with basic needs insecurities was conducted. Thus, this first chapter addresses the first research question: which public policies and institutional policies, programs, and services at colleges and universities have been designed and implemented to address homelessness, housing insecurity, and food security as it is experienced by college students?

The second chapter contains a description of the design of an application that will help facilitate the connection between students who are homeless, at risk of becoming homeless, housing insecure, and food insecure and the available services on campuses. This project is taking an inclusive view of homelessness, housing insecurity, and food insecurity and the tool will be designed to support students who are experiencing varying degrees of homelessness, housing insecurity, and food insecurity. The literature on design theory, critical GIS, public participation GIS (PPGIS), and geospatial modeling tools are also examined in this chapter in order to determine which tools and frameworks are the most effective for building an application that can assist students in the process of finding the location and hours of operation of services on their campuses without exacerbating the stigma that is associated with experiencing homelessness, housing insecurity, and food insecurity.

It is necessary to create an application that students who are experiencing basic needs insecurities can use to find the services that they need on-campus and off-campus. Students can search for the service or good that they need and find where it is located on campus, when they can access this service, and any information that they will need to bring with them to access the service (e.g., Student ID card, CA ID card, etc.). Students can also search for off-campus 
services that are administered by local non-profit organizations and local government agencies (e.g., city, county, or state social services and homeless services). This chapter addresses the second research question and the third research question that guide this project: what is the utility of Geographic Information Systems (GIS) methods for developing tools that students can use to identify and access homeless services on campus?; and how can the development of geospatial tools support students who are impacted by housing inequality incorporate "geographies of hope and care" (Pavlovskaya 2018, Harvey 2018) and become effective tools for social transformation? GIS tools have the potential to support students experiencing basic needs insecurities by giving students the opportunity to find services without disclosing that they are homeless, housing insecure, or food insecure, thus reducing feelings of stigma or hesitancy about using services. The aspects of confidentiality, independent service navigation, and personal agency associated with these geospatial tools represents exciting possibilities for showing how geospatial artifacts can empower students with hope, care, and respect.

The third chapter contains a test of the application to assess the application's strengths, weaknesses, and utility. This chapter addresses the second research question and the third research question for this project: What is the utility of Geographic Information Systems (GIS) methods for developing tools that students can use to identify and access homeless services on campus?; and how can the development of geospatial tools support students who are impacted by housing inequality incorporate "geographies of hope and care" (Pavlovskaya 2018, Harvey 2018) and become effective tools for social transformation?

Students who are experiencing homelessness, housing insecurity, and food insecurity may be more vulnerable to higher education attrition due to increased stress and anxiety (Mello 2018, Au and Hyatt 2017). Therefore, it is necessary to find tangible ways of supporting students 
who are experiencing homelessness with their housing, food, hygiene, and health needs so that they can complete their degrees and have more economic and educational opportunities in the future.

\section{Defining Key Terms}

While there are many definitions of "homeless youth" that are active in shaping public policy discussions and decision-making processes in the U.S., the definitions that best apply to this examination of homeless and housing insecure college students are the definitions developed by the Department of Education and the Runaway and Homeless Youth Act (RHYA). These definitions best capture the realities of homelessness for undergraduate students in California. These definitions are also used as the basis of defining "homeless youth" for many institutional, state, and federal policies targeting undergraduate students who are experiencing homelessness, housing insecurity, and food insecurity. Therefore, these definitions should guide this research. This section of the project presents definitions of key terms and provides justification for the use of these definitions of key terms, for this research project including definitions of: "homeless youth", "housing inequality", "housing insecurity", and "food insecurity".

The U.S. Department of Education defines homeless children and youths as those "individuals who lack a fixed, regular, and adequate nighttime residence" (Subtitle VII-B of the McKinney-Vento Homeless Assistance Act). This definition allows for a broad, inclusive understanding of homelessness experienced by undergraduate students, as students who are experiencing homelessness at undergraduate institutions in California experience a wide array of nighttime sleeping arrangements ranging from sleeping in vehicles to "couch surfing" to sleeping on the streets to staying in shelters and motels (Mello 2018, Au and Hyatt 2017). 
The definition produced by the U.S. Department of Education does not include an age limitation, so it is useful for conceptualizing homelessness as it is experienced by "nontraditional" students who may be older in age than college students who started their college degrees immediately following a high school graduation. Over one-third of college students in the State of California are considered non-traditional students, as they are above the age of 25 (Mello 2019). Ringer (2015) argues that it is imperative to distinguish between the conditions faced by younger, traditional and older, non-traditional college students. Ringer finds that older, non-traditional college students are more likely than their younger peers to experience challenges that may require different strategies for resiliency:

Public institutions with high levels of diversity may include especially high numbers of non-traditional students, including those who are (a) classified as "independent" on their FAFSA; (b) are parents; (c) have delayed enrollment; (d) entered college with a GED rather than a high school diploma; and (e) who attend school part time and/or work full-time. Many non-traditional students simultaneously face more than one, or all, of these challenges... Students in this group may have entered school with a pattern of unstable housing due to unemployment, and enrolled in college to become more competitive job applicants (p. 113-114).

The Runaway and Homeless Youth Act defines homeless youth as individuals who are "less than 21 years of age...for whom it is not possible to live in a safe environment with a relative and who have no other safe alternative living arrangement” (42 U.S.C. §5732a). While this definition contains an age limitation which limits its applicability to non-traditional students, it does highlight the unstable, insecure, unsafe, and stressful nature of homelessness for young adults. Goldrick-Rab, Richardson, and Hernandez (2017) find that certain populations of undergraduate students such as former foster youth, students from immigrant families, students of color, students who are women, and LGBTQ+ identifying students may be more vulnerable to experiencing homelessness while in college if it is not possible for them to live in a safe and 
stable environment with relatives. Therefore, this definition adds a necessary component of security for understanding the safety-related complexities associated with homelessness as it is experienced by undergraduate students.

Another concept that is intertwined with youth homelessness is housing inequality. Homelessness, housing insecurity, and food insecurity are all by-products of housing inequality. Broadly defined, "housing inequality" is a type of economic inequality in which significant disparities in housing quality, affordability, and accessibility exist in a society (Albouy and Zabek 2016). Housing inequality intersects with -- and is often the result of race, gender, class, sexual orientation, age, and ability bias (Kattari et. al. 2016, Albouy and Zabek 2016, Lareau 2014, Griffin 2012, Sen 2009, Wilson 2006, Uehara 1994). Understanding the concept of "housing inequality" provides a strong foundation for understanding how large, interconnected economic systems and political institutions can create the conditions under which youth homelessness flourishes.

In addition, developing an understanding of the concept of "housing insecurity" is necessary in order to determine the context surrounding the specific experiences of youth who are experiencing homelessness and youth who are at risk of becoming homeless in college. The concept of "housing insecurity" describes a set of challenges associated with unstable and insecure housing, including (but not limited to): the need to move frequently and quickly, the inability to pay housing costs such as rent and utilities, and a lack of safety and security in living arrangements (Goldrick-Rab, Richardson, and Hernandez 2017). Students who experience housing insecurity are frequently at risk of becoming homeless (Ringer 2015, Hallett and Freas 2018). 
Since many college students who are experiencing homelessness and who are at risk of becoming homeless also experience food insecurity, it is also necessary to present a definition of this concept. "Food insecurity" is defined as "the limited or uncertain availability of nutritionally adequate and safe foods, or the ability to acquire such foods in a socially acceptable manner. The most extreme form is often accompanied with physiological sensations of hunger" (GoldrickRab, Richardson, and Hernandez 2017). Food insecurity, coupled with housing insecurity, can create a situation in which learning is extremely challenging for undergraduate students, academic performance suffers (Broton and Goldrick-Rab 2018, Maroto et. al. 2014, Chaparro et. al. 2009), and dropping out of college becomes more likely for undergraduate students (Mello 2018, Au and Hyatt 2017).

\section{Conclusion}

While the concepts of homeless youth, housing inequality, housing insecurity, and food insecurity are all interconnected, they represent distinct definitions and conditions. This introduction has defined the problem addressed by this dissertation and explained the concepts of homeless youth, housing inequality, housing insecurity, and food insecurity. The next section of this project will show how basic needs insecurities shape the economic and educational opportunities that are available to college students. 


\section{Review of the Literature on College Students' Experiences with Basic Needs Insecurities}

\section{Introduction}

This literature review analyzes the research that has been conducted on college students experiences of homelessness, housing insecurity, and food insecurity. This chapter also includes a review of the federal and state public policies and programs that impact basic needs insecurities for college students in California. There are few instances of geospatial methods, tools, and techniques being used to support research about - and service implementation for - college students who are experiencing basic needs insecurities. In addition, recurring themes in the literature on this topic indicate that tools or services designed to support students who are experiencing basic needs insecurities will require consciousness about the stigmatization of homelessness, housing insecurity, and food insecurity and students' social and psychological needs. Furthermore, there are some students - such as students of color, non-traditional students, students who are former foster youth, LGBTQ+ students, and low-income students - who are more vulnerable to experiencing basic needs insecurities than others. Finally, while institutional programs and public policies have presented some policies and services designed to ameliorate basic needs insecurities among college students, these services are still under-utilized by students. The patterns presented in this literature review show that a geospatial application that connects students to services has the potential to increase service utilization among students and help decrease students' experiences of basic needs insecurities.

\section{College Students Experiencing Basic Needs Insecurities}

The literature on college students who are experiencing homelessness, housing insecurity, and food insecurity comes from a multitude of sources, disciplines, and authors who have 
employed a variety of approaches to analyzing these issues in their research. Some of the research that has been conducted focuses on breadth by examining all of these phenomena concurrently in a holistic manner, while other studies focus instead on depth by analyzing one particular aspect intently. Research on student experiences of homelessness, housing insecurity, and food insecurity in the U.S. emerged in 2009, the earliest year in which an article about these topics was published (Berg-Cross and Green 2009). While two (2) research projects present data about graduate students' experiences with basic needs insecurities (Berg-Cross and Green 2009, UC GFI 2017), the majority of the research that has been conducted investigates the experiences of undergraduate students.

\section{Geospatial Methods, Tools, and Artifacts}

The literature reviewed in this chapter was collected by using the following search terms in the databases JSTOR, EBSCO, and Google Scholar: "food insecure college students USA"; "housing insecure college students USA"; and "homeless college students USA". Sources were also compiled by retrieval from bibliographies and references pages in the studies that were found from searching the databases. Forty-two (42) sources were retrieved and are included in this literature review. Only two (2) of these sources employ geospatial methods, tools, or techniques to learn more about college students' experiences of homelessness, housing insecurity, and food insecurity. This suggests that there are underutilized opportunities for exploring: 1. how geospatial methods can be used to analyze information about college students' experiences of homelessness, housing insecurity, and food insecurity; and 2. how geospatial tools and applications can be used to support students who are experiencing these conditions. 


\section{Geographic Locations of Research Sites}

There have been eleven (11) research projects conducted on college students' experiences with basic needs insecurities in the United States of America generally. The research that has been conducted on students' experiences with basic needs insecurities has been conducted on one or more campuses of large public universities and community colleges in certain states. There have been the same number of studies conducted on undergraduate experiences with basic needs insecurities on campuses in California (16 studies) as there have been conducted on these student experiences on campuses in other states (15 studies). Table 1 shows the geographic locations analyzed by the 42 sources included in this literature review.

Table 1. Geographic locations of studies about basic needs insecurities

\begin{tabular}{|l|l|}
\hline Location(s) Investigated & Number of Research Projects Produced \\
\hline United States of America & 11 \\
\hline California & 16 \\
\hline U.S. States other than California & 15 \\
\hline & Total: 42 \\
\hline
\end{tabular}

All (15 sources) of the studies that have been conducted on students' experiences with basic needs insecurities in the U.S. states other than California focus on students' experiences at one or more specific university or college campus. However, the majority of the research (11 sources) identified about California relies on data collected from multiple public college and university campuses and therefore draws conclusions about public education systems such as the California State University system and the California Community Colleges system, instead of reporting findings about basic needs insecurities on one or more specific campuses in California. 
Figure 1 displays the locations of the 31 studies that have been conducted on college students' experiences of homelessness, housing insecurity, and food insecurity in specific states. One of the studies that was conducted on student homelessness, housing insecurity, and food insecurity in California (Crutchfield and Maguire 2018) and one of the studies that was conducted on students' experiences with food (in)security in Texas (Calvez et. al. 2016) used GIS methods to analyze data and display findings. Crutchfield and Maguire (2018) investigated student experiences with basic needs insecurities in California. The authors used spatial methods to analyze the relationship between homeless students' reported locations (based on the closest intersection or cross-street to where they were staying) and food and housing security indexes that were created by the U.S. Department of Agriculture (USDA), the Department of Housing and Urban Development (HUD), and the Department of Education (DOE). The researchers noticed that "the areas around some of the CSUs in more rural locations (Humboldt State University, Cal State University Fullerton, and Cal State University Monterey Bay) showed higher levels of food insecurity while urban cities showed a complex mosaic of small areas of security next to areas of insecurity...more students were homeless in urban areas, the primary exception being rural Humboldt County" (Crutchfield and Maguire 2018, 20-22).

Additionally, the study that was conducted on students' experiences of food insecurity on the Texas A\&M University campus used geospatial and qualitative methods to assess the scale and scope of food insecurity on that campus (Calvez et. al. 2016, 4). These researchers found that students attending Texas A\&M University experienced food insecurity at 2.5 times the rate of students at other undergraduate institutions in Texas. They also found that there were substantial gaps in the university's provision of affordable and easily-accessible nutritional food to students (Calvez et. al. 2016, 11). 
Both of these research projects represent excellent uses of geospatial methods to analyze and describe homelessness, housing insecurity, and food insecurity on university campuses. However, geospatial methods and tools can and should be employed in additional research projects to study students' experiences with basic needs insecurities.

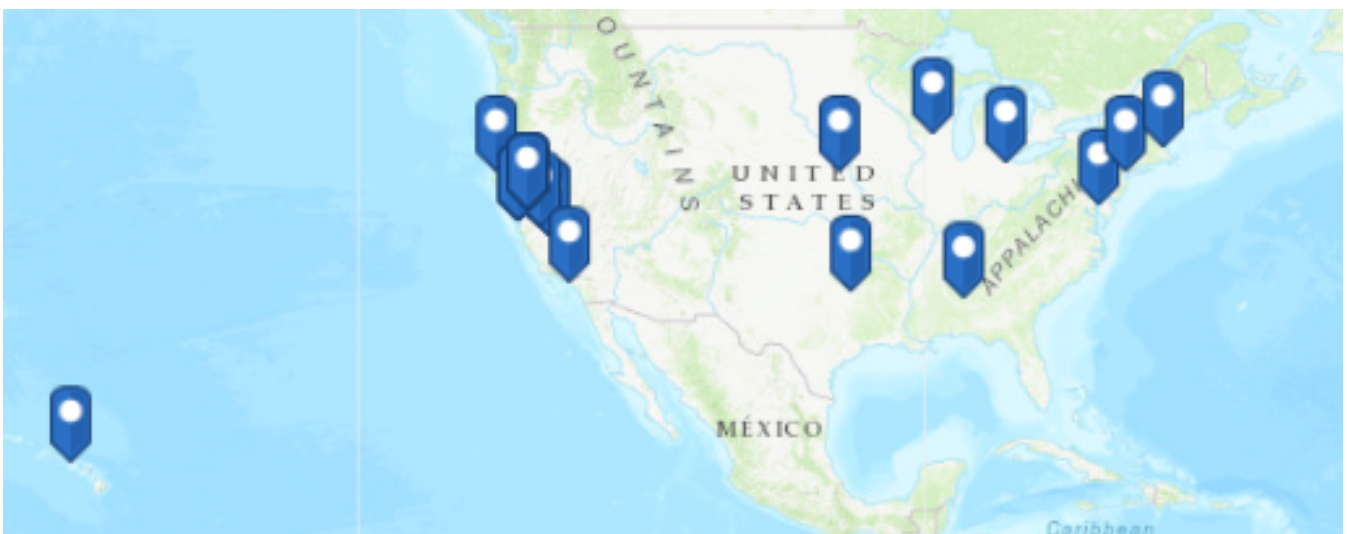

\section{Figure 1. Locations of 31 Studies Conducted on Students' Experiences with Basic Needs Insecurities in Specific U.S. States}

\section{Research Conducted on Institutions of Higher Education in California}

There have been sixteen studies of basic needs insecurities conducted on college and university campuses in the State of California. It is worthwhile to note where these studies are being conducted and reflect on the reasons why they are being conducted in these locations. Are homelessness, housing insecurity, and food insecurity more prevalent or more visible in the states -- and on the college campuses -- that are being studied? Is there more public awareness of college students' experiences with basic needs insecurities in these locations that spurs these projects? Or, is there more potent political will that exists in these locations that affects researchers' decisions to conduct studies on college and university campuses in these locations? These questions merit deliberation. 
The remainder of this literature review will focus on the sixteen research projects that have been conducted on college students' experiences with basic needs insecurities in California, as California is the location in which the model for a geospatial application has be designed, developed, and tested. Important and relevant findings from these sources will be presented in chronological order to illustrate how research about these topics has changed over time. The sources that have been published more recently tend to analyze multiple campuses and rely on larger sample sizes than the studies that were produced earlier. The earliest studies available on college students' experiences with basic needs insecurities in California focus on one university or college campus and employ smaller sample sizes.

While testing multiple hypotheses about food insecurity on one public university campus in California, Espinoza (2013) found that approximately one in three students experienced food insecurity on the unidentified California State University (CSU) campus that was examined in the study (Espinoza 2013, 42). Espinoza found that there were a variety of factors that contributed to students' different experiences with food security. Differences in food security status were found to be dependent on the basis of housing arrangements, income, self-reported health status, credit card debt, and coping strategies (Espinoza 2013, 52). Students who lived with family members were more food secure than their peers who had alternative living arrangements (e.g., students who lived in dorms, students who lived in off-campus housing with other students, students who were homeless, etc.) (Espinoza 2013, 51). The students who reported having an income of less than $\$ 10,000$ per year were more food insecure than students in all other income groups, even students reporting $\$ 0$ in annual income. Espinoza argues that this finding suggests that students reporting no annual income may be receiving financial assistance from their families or from financial aid sources which protects them from food 
insecurity. In addition, "students who had credit card debt were over two times more likely to be food insecure than those who did not have credit card debt..." (Espinoza 2013, 52). Finally, students who used coping strategies to access food were about five times less likely than their peers to experience food insecurity. Coping strategies include visiting food banks and food pantries, using soup kitchens, asking friends and family for food, stealing, and borrowing money for food (Espinoza 2013, 52-53). This last finding is especially relevant to the development of a geospatial tool to support students experiencing homelessness, housing insecurity, and food insecurity. If students who are engaging in coping strategies are more food secure than students who do not engage in coping strategies, then it would be useful to develop an application that can be used by students to cope with (and prevent) the mental and physical health strains associated with food insecurity.

Furthermore, Chappelle (2015) found that $35 \%$ of students at Humboldt State University (HSU) reported experiencing food insecurity and an additional 35\% of HSU students reported feeling at risk of becoming food insecure (Chappelle 2015, 46). The results from this study indicate that the majority of the student body (roughly $70 \%$ of students at HSU) are experiencing - or are at risk of experiencing - food insecurity. Chappelle found that students who lived alone and students who lived off campus were more food insecure than students who lived with other people (such as other students, family, or friends) and students who lived on campus (Chappelle 2015, 50). Food insecure students also reported higher levels of mental health concerns than food secure students (Chappelle 2015, 51). Students who reported being food insecure reported experiencing significant weight loss and significant weight gain (Chappelle 2015, 54). These findings suggest that food insecurity has substantive impacts on the mental health and the physical health of undergraduate students. Therefore, it is necessary to include services for 
mental health and physical health needs in the geospatial tool that is created to connect students to services.

As established by Espinoza (2013) and Chappelle (2015), housing arrangements and food insecurity are connected. Mercado (2017) documented the prevalence of food insecurity, housing insecurity, and homelessness on a community college campus in the Peralta Community College District (PCCD). Mercado found that $60.5 \%$ of PCCD students reported experiencing food insecurity within the past month. In addition, Mercado found that $83.1 \%$ of PCCD students reported experiencing housing insecurity and $30.2 \%$ of PCCD students reported experiencing homelessness within the last year (Mercado 2017, 80). The demographic variables that were most closely associated with student experiences of food insecurity, housing insecurity, and homelessness were race/ethnicity, parental education level, parenting status, and annual household income. The findings from this study show that students of color, first-generation students, and full-time students reported the highest levels of food insecurity and housing insecurity. Additionally, food insecure students were more likely to have children than food secure students (Mercado 2017, 79).

\section{Intersectionality, Stigma, and Basic Needs Insecurities}

The majority of food and housing insecure students reported that their food and housing insecure experiences had directly affected their academic performance, attendance, and enrollment (Mercado 2017, 80). It is essential to account for the relationship between forms of housing inequalities such as housing insecurity, food insecurity, and homelessness and systemic racism, sexism, and classism in the design and development of a geospatial tool to support students. 
Focusing on community college students, Gupton (2017) collected qualitative data from students at Los Angeles Community College District (LACCD) to study how invisibility impacts students who are experiencing homelessness on community college campuses. Community college students experiencing homelessness discussed the positive and negative aspects of being invisible on campus. Some students liked the anonymity associated with their invisibility. They did not feel stigmatized because their classmates and professors did not know they were homeless and they did not have to be party to counselors constantly analyzing their behavior (Gupton 2017, 19). While evading surveillance and stigma was an appealing aspect of being invisible on campus for some students, other students who experienced homeless felt that their invisibility became a liability when they needed help accessing services and did not know who or which office - to contact for assistance. The students interviewed in this study also discussed their feelings of isolation and their frustration with the staff's and the faculty's lack of knowledge about services available to students experiencing homelessness on campus (Gupton 2017, 19-20).

These findings provide further support for the need to develop a geospatial tool to assist students with the process of navigating services on campus. An application would allow students to find the services they need without disclosing their homeless or housing insecure status to others; would allow them to evade surveillance by social workers and counselors if preferred; and it would allow them to access information about services in a timely manner in an environment in which staff and faculty members may not be very knowledgeable about the services available on campus for homeless students.

It can be difficult for students to find and access services on campus that help to decrease basic needs insecurities. Au and Hyatt (2017) sought to document and analyze the supply of 
services available to students experiencing homelessness, housing insecurity, and food insecurity on public college and university campuses in California. They found that the University of California (UC) schools offer the most programs and services for students experiencing homelessness, with the highest score of $86 \%$. The California State University (CSU) schools received the second highest score of $77 \%$ for offering programs and services for students experiencing homelessness. Finally, the California Community Colleges offered the fewest services to homeless students, with the lowest score of $41 \%$. The highest rated campuses in the state were CSU Fresno and San Jose State University, as both campuses provide all of the recommended supportive services for students experiencing homelessness, housing insecurity, and food insecurity (as recommended by students experiencing homelessness) (Au and Hyatt 2017, 15).

$\mathrm{Au}$ and Hyatt note that the "percent scores are based on the resources - mental health services, child care, centers for LGBTQ and non-Caucasian identifying students, advisors and programs for foster youth and homeless students, student housing, food assistance, and discounted public transit - that each campus posted online" (Au and Hyatt 2017, 13). The authors weighted services differently to account for the disparate impact of homelessness on some groups of college students, including LGBTQ+ students, students of color, and students who are former foster youth. Au and Hyatt weighted the scores for services for LGBTQ+ students, services for students who were former foster youth, and programs that promoted racial, cultural, and/or sexual orientation diversity more than they weighted the scores for some of the other programs and services (Au and Hyatt 2017, 13).

Support for taking into account interlocking systems of oppression when designing a model for a geospatial application to connect students to services is also found in a 2018 report 
published by the California State Assembly Speaker's Office of Research and Floor Analysis. The report found that student homelessness in California was reported at higher rates among international students, African American students, Hispanic/Latinx students, American Indian students, students who are former foster youth, and LGBTQ students (Restmeyer 2018). The report also included excerpts from interviews conducted with students experiencing homelessness. Many of these interviews revealed the ways in which gender impacts students' experiences of homelessness. One female student said: “I'm scared. I live with my boyfriend but I can't break up with him because I'll be homeless. That's a horrible feeling" (Restmeyer 2018, 4). Another shared: "As a single mom I cannot afford anything more than a room for rent but the market is so competitive that no one wanted to rent to both my child and I except an elderly man who rented his poorly renovated small garage to me and then sexually harassed me when I went in and out of his house to come and go" (Restmeyer 2018, 10). The problems of homelessness, housing insecurity, and food insecurity is a problem that is raced, gendered, and classed. Therefore, it is necessary to develop solutions and ameliorative tools that take into account the ways in which housing inequalities are shaped by racial, gender, and economic inequalities.

Findings from the mixed-methods CSU Study of Basic Needs also indicate that homelessness, housing insecurity, and food insecurity are shaped by racial, gender, and economic inequality. Students who identified as Black or African-American experienced the highest average rates of homelessness than any other racial group. First generation college students and college students receiving Pell Grants had higher rates of homelessness than their peers who were not first generation students and who did not receive Pell Grants (Crutchfield and Maguire 2018, 22). The students who were interviewed and who participated in focus groups discussed the ways in which homelessness, housing insecurity, and food insecurity negatively 
impacted their physical and mental health. One student described experiencing tremors in his arms after failing to receive adequate nutrition for months (Crutchfield and Maguire 2018, 27), while another student described the profound effects of the guilt that she felt after couch-surfing at friends' homes while experiencing homelessness on her mental and emotional well-being (Crutchfield and Maguire 2018,29). This study also used geospatial methods to describe and analyze the concentration and dispersion of CSU students' experiences with homelessness and food insecurity. Crutchfield and Maguire found that the areas of California in which CSU students experienced the highest rates of homelessness were concentrated in urban areas, whereas incidents of food insecurity were more likely to be concentrated in rural areas and be more diffuse in urban areas of California (Crutchfield and Maguire 2018, 20-24). This research provides a strong guide for using geospatial methods in conjunction with other methods to document the breadth and depth of undergraduate students' experiences with homelessness, housing insecurity, and food insecurity in California.

\section{Trauma-informed Research}

Many of the studies that have been conducted on students' experiences with basic needs insecurities in California show how these conditions are shaped by various forms of inequality. However, a study conducted by Hallett and Freas (2018) on California community college students' experiences of homelessness and housing insecurity is one of the few studies that explicitly connects experiences of homelessness and housing insecurity to experiences of trauma by employing the "trauma to care perspective", a conceptual framework (Hallett and Freas 2018, 726-727). The trauma to care framework relies on a long-term approach to understand student homelessness and grounds research about homelessness in the concept that homelessness is 
traumatic. Hallett and Freas also argue that many college students approach higher education environments carrying their own histories of trauma. Therefore, any solutions or tools proposed to ameliorate homelessness as it is experienced by college students also must be traumainformed. While trauma is not deterministic and will not necessarily have a negative impact on students' experiences with higher education, it can make students more vulnerable to experiencing homelessness and housing insecurity. Hallett and Freas (2018) write:

Trauma does not determine educational outcomes. Postsecondary institutions should not assume that all students who have experienced trauma need the same support. However, institutions should intentionally acknowledge that the lived experiences of students often influence how they access education. This can enable higher education institutions to identify support services that can be offered to students who may need assistance. Ignoring the real trauma of individuals in educational institutions only pushes these students to the margins, which then points to the students as broken and blames them for being unsuccessful (p. 727).

The need for including a trauma-informed approach to research, policies, and practices targeting students experiencing homelessness and housing insecurity becomes evident when witnessing the magnitude of the problem of homelessness and housing insecurity among California community college students. A 2018 report published by the California Community Colleges Chancellor's Office found that in $2017,56 \%$ of students in California community colleges that were surveyed reported experiencing food insecurity, $35 \%$ of students experienced housing insecurity, and 14\% of students experienced homelessness (CCC 2018, 1). The report documents the multiple services available for food insecure students (e.g., CalFresh enrollment assistance, food pantries, food banks, grocery bingo, meal vouchers, etc.) and the few services available for housing insecure and homeless students on the community college campuses (mostly referrals to shelters, transitional housing programs, and public housing applications) (CCC 2018, 4-5), revealing an approach to housing services that is not informed by the trauma to care perspective. 
Another 2018 report published by California Community Colleges provides information for College Youth Homeless Liaisons, a position created by California Assembly Bill (AB) 801, the Success for Homeless Youth in Higher Education Act (CCC 2018, 9). AB 801 requires a member of the financial aid office (or another comparable administrative position) to act as a liaison between homeless students and services that they need both on- and off-campus. The report contains guidelines for College Youth Homeless Liaisons to follow when recruiting and supporting community college students who are experiencing homelessness (CCC 2018, 10). The California Homeless Youth Project also published a guide designed to provide information to College Youth Homeless Liaisons and other members of administration, staff, and faculty who are supporting students experiencing homelessness (CHYP 2018). This report describes California Assembly Bill (AB) 1228, Public Postsecondary Education: Campus Housing: Priority for Homeless Youth. AB 1228 requires CSUs and requests that CCCs and UCs give former foster youth, current homeless youth, and former homeless youth priority access to student housing, especially student housing that is available year-round (at no additional cost). The law also encourages (although does not require) colleges to make a year-round action plan with housing insecure and homeless students to help them achieve housing security (CHYP $2018,1-2)$.

This report repeatedly asserts that there is not enough awareness about services for homeless, housing insecure, and food insecure students among staff, administrators, and faculty members or among students themselves on public college and university campuses (CHYP 2018, $3)$. The themes that emerge in these institutional reports and policy briefs is that the supply of services available to homeless, housing insecure, and food insecure students is not keeping pace 
with students' demand for these services and the students' awareness about - and utilization of the services that do currently exist is low.

\section{Risk Factors and Regional Variation}

Furthermore, in 2018 two additional articles about undergraduate students' experiences with food insecurity on college and university campuses in California were published. The first article used UC campuses as sites for data collection and concluded that students' experiences of food insecurity on UC campuses was directly related to lower GPAs and poor mental health outcomes for students (Martinez et. al. 2018). The second article determined that the major risk factors for students experiencing food insecurity at the UC campuses that were included in the study were age, race and ethnicity, childhood experiences of food insecurity, living off-campus, and receipt of financial aid. They found that $40 \%$ of the student respondents in their study reported experiencing food insecurity and their lack of stable and secure sources of nutrition had substantive effects on their educational experiences, including difficulty concentrating and lower academic performance (Martinez et. al. 2018, 10). Researchers also learned that most students in their sample desired more information on cooking, budgeting, accessing services on campus, and wanted to know who (which administrator/staff member) to talk to on campus for assistance with accessing food and resources (Martinez et. al. 2018, 12), which suggests that information about services for food insecure students may not spreading rapidly enough on the UC campuses included in the study.

The 2019 report titled "California Community Colleges \#Real College Survey" includes a basic needs assessment for California community college students and displays information about regional variations in community college students' experiences of homelessness, housing 
insecurity, and food insecurity. The authors of this report found that community college students attending college in Northern California are at the highest risk of experiencing food insecurity, housing insecurity, and homelessness. Students who attend community college in the south central coast area and near the southeastern border of the state are the least likely to experience food insecurity, housing insecurity, and homelessness while attending community college (Goldrick-Rab et. al. 2019, 11). The findings about student demographics that are described in this report echo the conclusions of other research that has been conducted on student homelessness, housing insecurity, and food insecurity. For example, Goldrick-Rab et. al. find that students who are LGBTQ+ identifying experience very high rates of homelessness and housing insecurity. "These students have rates of housing insecurity and homelessness almost 10 percentage points higher than their heterosexual or non-identifying peers" (Goldrick-Rab et. al. 2019, 13).

Additionally, students who identify as Black or African American, American Indian, and Alaska Native experience the highest rates of food insecurity of any racial or ethnic group. Students who are older than 21 years and students who are parents are also more likely to experience basic needs insecurities than students who are younger than 21 and students who are not parents (Goldrick-Rab et. al. 2019, 13-15). This research also finds that very few students who are struggling to meet their basic needs are enrolled in government programs and college programs designed to support them. For example, only $22 \%$ of food insecure community college students receive Supplemental Nutrition Assistance Program (SNAP) benefits (Goldrick-Rab et. al. 2019, 22). The findings from this research provides further support for the contention that there is a disconnect between students who are insecure in their basic needs and the services that are available to support students both on- and off- campus. 
In addition, a 2019 report published by the California Research Bureau and the California State Library finds that almost all of the public higher education institutions in California distribute free groceries to students who are food insecure on a regular basis and employ at least one advisor who works with foster youth. The report also indicates that most campuses have a specific advisor for students who are experiencing housing insecurity and homelessness.

However, the authors of the study displayed in the report assert that it was outside of the scope of their study to investigate how many students are aware of the existence of these advisors (LePage and Hyatt 2019, 1-6). Findings from this study also show that the students who are the most vulnerable to housing insecurity, community college students, are also those students who are least likely to have on-campus or student housing options available at their college (LePage and Hyatt, 8-12).

There is also important information about the impact that discontinuous housing can have on students described in this report. Many students who use campus or student housing may be required to vacate that housing during school breaks, subsequently facing deadlines, additional housing costs, and the burden of navigating complex bureaucratic processes when looking for temporary housing on their own (LePage and Hyatt, 8). The findings from this study show that there are many institutional policies, procedures, and personnel decisions that impact students' experiences with basic needs insecurities. While a service navigation application may be able to provide supplementary support to students, there will need to be more substantial policy changes in order to reduce the number of students who are experiencing basic needs insecurities.

Finally, the most recent research that has been conducted on college students' experiences with basic needs insecurities emerges in the form of the California Student Aid Commission’s “2018-2019 Student Expenses and Resources Survey” report. The results of this 
survey indicate that students are heavily cost-constrained by the non-tuition costs associated with college, such as housing, food, transportation, and personal expenses. Students surveyed reported spending, on average, about $\$ 2000$ per month on these costs. This report also indicates that one in three students in the State of California reported experiencing food and housing insecurity (Garcia 2019, 5). Students of color and non-traditional students reported facing the greatest challenges to affordability with meeting the non-tuition costs associated with college (Garcia 2019, 6). Regionally, students living in the Northern Inland area of the state (including Butte, Lassen, Plumas, Shasta, and Siskiyou) reported the highest rates of food insecurity, while students in the Central Valley region of the state reported experiencing the highest rates of housing insecurity (Garcia 2019, 5-6). The results from this survey reaffirm the need for the development of more tools that can support students who are experiencing basic needs insecurities in California.

\section{Themes in the Literature on Basic Needs Insecurities}

The scholarly literature, policy briefs, and institutional research that has been produced on homelessness, housing insecurity, and food insecurity in California documents students' experiences with these conditions and the supply of services available to students on college and university campuses. The first recurring theme that emerges across these research projects is that many students find it difficult to find and access services on campus either due to inaccessible information about the services and programs or the stigmatization of homelessness, housing insecurity, and food insecurity. The second theme that emerges in this body of research is that there are some groups of students who are more vulnerable to experiencing homelessness, housing insecurity, and food insecurity than other students - and specialized services may be 
required to adequately address the needs of these populations of students. Students who are LGBTQ+ identifying, students of color, students who are immigrants, students who are former foster youth, students who are parents, non-traditional students, and students with mental and physical health challenges may require additional support, assistance, and encouragement when accessing services. Finally, the third theme that emerges in this research is that geospatial tools and methods have not been widely used to document, analyze, or address students' demands for services, despite the transformative potential of geospatial tools and methods.

\section{Public Policies that Impact College Students Experiencing Basic Needs Insecurities}

In addition to reviewing the academic literature on college students experiencing basic needs insecurities, it is pertinent to note that there are many public policies at the federal level and at the state level that impact experiences of homelessness, housing insecurity, and food insecurity for undergraduate students in California. Table 2 displays information about key pieces of legislation that have shaped federal and state policy responses to basic needs insecurities. The policies addressing basic needs insecurities, and the government agencies responsible for implementing these policies, will be discussed in this section of the project.

Table 2. Key Legislation Addressing Basic Needs Insecurities

\begin{tabular}{|l|l|l|l|}
\hline Title of Legislation & Jurisdiction & Objective & Target Populations \\
\hline $\begin{array}{l}\text { Runaway and } \\
\text { Homeless Youth Act }\end{array}$ & Federal & $\begin{array}{l}\text { Define homelessness } \\
\text { and provide federal } \\
\text { funds for programs } \\
\text { targeting young } \\
\text { adults experiencing } \\
\text { homelessness. }\end{array}$ & $\begin{array}{l}\text { Individuals under age } \\
\text { 21 who are } \\
\text { experiencing } \\
\text { homelessness in the } \\
\text { U.S. }\end{array}$ \\
\hline $\begin{array}{l}\text { McKinney-Vento } \\
\text { Homeless Assistance } \\
\text { Act }\end{array}$ & Federal & $\begin{array}{l}\text { Provide federal funds } \\
\text { to homeless services } \\
\text { programs. }\end{array}$ & $\begin{array}{l}\text { Individuals, families, } \\
\text { students, young } \\
\text { adults, and children }\end{array}$ \\
\hline
\end{tabular}




\begin{tabular}{|c|c|c|c|}
\hline & & & $\begin{array}{l}\text { experiencing } \\
\text { homelessness in the } \\
\text { U.S. }\end{array}$ \\
\hline Second Chance Act & Federal & $\begin{array}{l}\text { Provides federal } \\
\text { funding to programs } \\
\text { and services designed } \\
\text { to prevent recidivism } \\
\text { and homelessness } \\
\text { among formerly } \\
\text { incarcerated people. }\end{array}$ & $\begin{array}{l}\text { Adults, } 18 \text { years of } \\
\text { age or older in the } \\
\text { U.S., and families of } \\
\text { formerly incarcerated } \\
\text { adults. }\end{array}$ \\
\hline $\begin{array}{l}\text { Success for Homeless } \\
\text { Youth in Higher } \\
\text { Education Act }\end{array}$ & State of California & $\begin{array}{l}\text { Requires California } \\
\text { Community Colleges } \\
\text { and California State } \\
\text { University campuses } \\
\text { to appoint a staff } \\
\text { member to serve as a } \\
\text { Homeless and Foster } \\
\text { Student Liaison to } \\
\text { support students with } \\
\text { financial aid. Also } \\
\text { waives enrollment } \\
\text { fees for students } \\
\text { experiencing } \\
\text { homelessness. }\end{array}$ & $\begin{array}{l}\text { College students in } \\
\text { California. }\end{array}$ \\
\hline $\begin{array}{l}\text { Campus housing: } \\
\text { priority for homeless } \\
\text { youth }\end{array}$ & State of California & $\begin{array}{l}\text { Requires California } \\
\text { State University and } \\
\text { University of } \\
\text { California campuses } \\
\text { to give on-campus } \\
\text { housing priority to } \\
\text { current and former } \\
\text { foster youth. On- } \\
\text { campus housing must } \\
\text { be left open year- } \\
\text { round for student } \\
\text { occupation. }\end{array}$ & $\begin{array}{l}\text { College students who } \\
\text { are current and } \\
\text { former foster youth in } \\
\text { California. }\end{array}$ \\
\hline $\begin{array}{l}\text { Community colleges: } \\
\text { homeless students: } \\
\text { access to shower } \\
\text { facilities }\end{array}$ & State of California & $\begin{array}{l}\text { This law makes it } \\
\text { mandatory for } \\
\text { community college } \\
\text { campuses that have } \\
\text { shower facilities to } \\
\text { grant access to those } \\
\text { facilities to students } \\
\text { who are experiencing } \\
\text { homelessness. }\end{array}$ & $\begin{array}{l}\text { Community college } \\
\text { students experiencing } \\
\text { homelessness and } \\
\text { housing insecurity in } \\
\text { California. }\end{array}$ \\
\hline
\end{tabular}




\begin{tabular}{|c|c|c|c|}
\hline $\begin{array}{l}\text { Food Assistance: } \\
\text { Higher Education } \\
\text { Student }\end{array}$ & State of California & $\begin{array}{l}\text { Colleges and } \\
\text { universities in } \\
\text { California must } \\
\text { develop a Restaurant } \\
\text { Meals Program that } \\
\text { allows students who } \\
\text { are enrolled in } \\
\text { CalFresh to use their } \\
\text { electronic benefit } \\
\text { transfer (EBT) cards } \\
\text { to purchase hot meals } \\
\text { on campus. Requires } \\
\text { the State Legislature } \\
\text { to direct funding to } \\
\text { on-campus programs } \\
\text { that address food } \\
\text { insecurity, such as } \\
\text { food pantries, food } \\
\text { banks, and other } \\
\text { hunger-relief } \\
\text { programs. }\end{array}$ & $\begin{array}{l}\text { College students who } \\
\text { are experiencing food } \\
\text { insecurity in } \\
\text { California. }\end{array}$ \\
\hline
\end{tabular}

At the federal level, legislation such as the Runaway and Homeless Youth Act (34 U.S.C. ch. 111), the McKinney-Vento Homeless Assistance Act (42 U.S.C. ch. $119 \S 11301$ ), and the Second Chance Act (Pub.L. 110-199) provide funding for programs designed to support people who are experiencing homelessness across the United States. For example, the McKinney-Vento Homeless Assistance Act provides funding for formula grants for the program 'Education for Homeless Children and Youth'(Title VII-B of 42 U.S.C. ch. $119 \S 11301)$. These policies also outline the rules and regulations that guide the provision of services to children, youth, and adults who are experiencing homelessness. The definition of "homeless youth" that is used in the McKinney-Vento Act is used throughout many pieces of state-level legislation and state agency guidelines and regulations in California.

The Department of Housing and Urban Development (HUD) oversees multiple programs designed to serve people who are experiencing homelessness in the U.S. such as Housing 
Opportunities for Persons With Aids (HOPWA), Section 8 Housing Choice Vouchers, and Homeless Assistance Grants (HUD 2019). In addition to HUD, there are other federal agencies that are responsible for providing services to people who are experiencing homelessness. For example the Substance Abuse and Mental Health Services Administration (SAMSA) administers the SAMSA Homeless Services program (SAMSA 2019) and the Federal Emergency Management Agency (FEMA) administers the Emergency Food and Shelter program (FEMA 2019). There are also instances in which federal agencies work together to administer programs. For example the Veterans Association (VA) Housing Choice Vouchers program is administered jointly by HUD and the VA (VA 2019).

Data on homelessness in the United States of America is collected by the HUDadministered Point-in-Time Count which represents an annual effort to quantify the number of people who are experiencing unsheltered homelessness in communities across the country (HUD 2019). While the Point-in-Time Count procedure is federally mandated, there are some counties and states that fail to report and publish the results of their counts (NAEH 2012, 2018). The Point-in-Time Count method has been criticized for its substantial variation in count methodology year-to-year and across different communities in the U.S. It has also been criticized for focusing solely on unsheltered homelessness and failing to capture the complexities associated with sheltered homelessness. This method is also notably unreliable at capturing an accurate count of youth (people who are under the age of 24) who are experiencing homelessness, as this population tends to be more wary of homeless services providers and homeless youth may be afraid of being counted, surveilled, and stigmatized by the volunteers who collect Point-in-Time Count data (NAEH 2012). Since many students who experience homelessness fall into this age category (under 24 years of age) of youth who are experiencing 
homelessness, it is important to assert that they may be avoiding detection during the annual Point-in-Time Counts. This provides an additional barrier to accurately estimating the number of undergraduate students who are experiencing homelessness and may suggest that current results from Point-in-Times Counts are modest and represent under-estimated data (NAEH 2018).

In addition, the Free Application for Federal Student Aid (FAFSA) poses questions to student applicants about homelessness and housing security. In 2014, over 150,000 FAFSA applicants noted that they were homeless or at risk of becoming homeless. California has repeatedly had more FAFSA applicants who identify as homeless or at risk of becoming homeless than any other U.S. state, recently claiming one tenth of all homeless and housing insecure FAFSA applicants (CCC 2018). While this descriptive quantitative evidence is noteworthy, many researchers argue that the FAFSA indicators likely under-estimate student homelessness and housing insecurity because students are afraid of the consequences of reporting their homeless or housing insecure status on FAFSA forms (Goldrick-Rab et. al. 2019, Crutchfield and Maguire 2018).

In the State of California, the California Department of Housing and Community Development (HCD) is responsible for providing services to homeless and housing insecure Californians using revenue from a combination of state and federal funding sources (HCD 2018). Additionally, the Health and Human Services Agency (CHHS) is responsible for administering programs such as Medi-Cal (California's Medicaid program), CalWorks (California's Temporary Assistance to Needy Families program), and CalFresh (California's Supplemental Nutrition Assistance Program) that may be used by college students who are vulnerable to experiencing homelessness, housing insecurity, and food insecurity (Brown 2017). 
Furthermore, there have been multiple pieces of legislation that have been designed and chaptered with the explicit purpose of addressing the needs of homeless college students in California. In addition to the aforementioned Assembly Bills 801 and 1228, AB 1995, titled "Community colleges: homeless students: access to shower facilities", was chaptered in 1996. This bill makes it mandatory for community college campuses that have shower facilities to grant access to those facilities to students who are experiencing homelessness (AB 1995, 2016).

In response to demands by campus activists and advocates, AB 1747 (titled "Food Assistance: Higher Education Students") was designed to address the problem of increasing food insecurity on undergraduate campuses in California. AB 1747 created a state requirement that public and private colleges and universities within California must develop a Restaurant Meals Program. The Restaurant Meals Program allows students who are enrolled in CalFresh to use their electronic benefit transfer (EBT) cards to purchase hot meals on campus. AB 1747 also established the Public Higher Education Pantry Assistance Program Account which requires the State Legislature to direct funding to on-campus programs that address food insecurity among students such as food pantries, food banks, and other hunger-relief programs (AB 1747, 2016). In 2017, the California State Legislature allocated \$7.5 million from the state budget to support campus hunger initiatives. This funding has allowed colleges to start food pantries and mealsharing programs and sign students up for programs such as CalFresh, Medi-Cal, and CalWorks (Mello 2018).

Recently, AB 302, titled "Parking: Homeless Students", was introduced by Assembly Member Berman to require all California community college campuses that have parking facilities on campus to grant overnight access to parking lots for students who are experiencing homelessness and sleeping in their vehicles (AB 302 2019). As of September 5, 2019 the bill has 
been ordered to the inactive file at the request of State Senator Jerry Hill (LegInfo 2019), who represents Senate District 13 which is composed of San Mateo County and the northern portion of Santa Clara County (CA Senate 2019). Ordering this bill to the inactive file indicates that the bill is ready for consideration, however has been labeled "dead" or "dormant" for political or fiscal reasons (LegInfo 2019). The bill may leave the inactive file in the future, however the fate of this bill has yet to be determined.

\section{Conclusion}

In order to design a geospatial tool that can best serve college students who are experiencing homelessness, housing insecurity, and food insecurity, it is important to understand the public policy environment. The number of government programs and public policies designed to combat homelessness and other facets of housing inequality may seem large. However, it can be difficult for students who are experiencing homelessness, housing insecurity, and food insecurity to become beneficiaries of these programs if they are unaware that they are eligible to participate in these programs or if they are concerned about being stigmatized for participating in these programs (Au and Hyatt 2017, Paden 2012).

For instance, due to issues related to stigma and self-perception, it can be difficult for undergraduate students who are experiencing homelessness and housing insecurity to feel comfortable and confident identifying themselves as homeless or housing insecure (Crutchfield and Maguire 2018, Paden 2012). They often believe that these programs and services are designed to target another population and do not apply to them, resulting in a need of college and university staff and faculty to convince students that they are eligible for - and deserve to use these programs and services (Crutchfield and Maguire 2018, Au and Hyatt 2017, Paden 2012). 
Without tools for spreading information about these programs, policies, and services in a manner that illustrates how and why they are intended to support undergraduate students who are experiencing homelessness and housing insecurity, these policies and programs will lose their saliency and utility. 


\section{Developing an Application that Connects College Students to Services that Address Basic Needs Insecurities}

\section{Introduction}

College students in California are facing difficulties meeting their basic needs for survival. Basic needs insecurities are defined as "hardship in terms of at least three aspects of basic physiological needs: food, shelter, and medical care" (Assistant Secretary for Planning and Evaluation 2004). About $35 \%$ of college students in California experienced very low or low food security and 33\% of students experienced housing insecurity during the 2018-2019 school year (Garcia 2019). Approximately $25 \%$ of students attending community colleges in California experience homelessness and $11 \%$ of students attending Cal State University (CSU) schools experience homelessness (Anderson 2018). While there are on-campus and off-campus services available to students to help them meet their basic needs (e.g., food pantries, free meals, access to showers, housing assistance, etc.), many students are unaware of the existence of these services or are hesitant to use them due to the stigma associated with experiencing homelessness, housing insecurity, and food insecurity (Au and Hyatt 2017, Mello 2018, Crutchfield and Maguire 2018).

In this chapter, the process for developing a tool to support college students experiencing basic needs insecurities will be described and displayed. First, justification for developing an application to support students experiencing homelessness, housing insecurity, and food insecurity will be presented. Second, the design of this tool draws on the theories and insights from design science theory, critical GIS, and public participation GIS in order to build a useful tool for students who are experiencing basic needs insecurities. As such, this chapter contains a brief review of the literature on design science theory, critical GIS, and public participation GIS. Finally, this chapter illustrates and explicates the process and the outcome of designing a tool 
that helps students find services that will help them meet their basic needs, whether they are oncampus or off-campus.

\section{Technology Usage}

College students and young adults who are experiencing homelessness use the Internet, social media, digital tools such as applications, mobile devices, and other technologies frequently (Jones et. al. 2009, Woelfer and Hendry 2010 and 2012, Guadagno et. al. 2013). Many young adults who are experiencing homelessness use a variety of digital tools to search for employment and housing, to get directions to various locations, to document events, to tell stories, and to socialize (Woelfer and Hendry 2012, Guadagno et. al. 2013). Many college students, homeless youth, and homeless college students use social media applications to explore their identities, find services that they need, send and receive private messages, and build communities (Jones et. al. 2009, Woelfer and Hendry 2010, Guadagno et. al. 2013).

Additionally, compared to the general population, college students are more likely to be early adopters of new technologies, applications, and digital tools. "For U.S. college students, Internet technologies have become so ubiquitous as to seem invisible" (Jones et. al. 2009). This suggests that developing a model for an application that can be used for service navigation by college students who are experiencing homelessness, housing insecurity, and food insecurity would actually be used by many college students. However, a persistent digital divide ${ }^{1}$ exists in American higher education and this divide has had a disparate impact on non-traditional

\footnotetext{
1 “The phrase 'digital divide' has been used to refer to a wide variety of inequities, including differential access to, contact with, and use of ICTs [Information Communication Technologies] cross-nationally ... as well as between social and demographic groups within individual nations ... The phrase is used perhaps most commonly to refer to differences in access to ICTs" (Jones et. al. 2009).
} 
students, students of color, students who are women, and students with low incomes (Cooper 2006, Jones et. al. 2009, Goode 2010, Jesnek 2012). Therefore, it is necessary to develop digital tools that can help colleges serve and support students who are experiencing basic needs insecurities while also remaining conscious of the inequities associated with the digital divide. One of the ways to address the challenges posed by the digital divide in the design process is to build a version of the tool that can be accessed in a public space, such as a public library, or in an on-campus common area, such as a college library or computer lab. If a student does not have a smart phone or access to reliable internet, then they would still be able to find and navigate to on-campus and off-campus services using devices and technologies supplied by the college or a public library.

\section{Design Science Theory}

Information Technology (IT) research that is driven by design science theory produces, uses, and assesses artifacts that have been designed to solve complex problems. Design science theory "involves a rigorous process to design artifacts to solve observed problems, to make research contributions, to evaluate the designs, and to communicate the results to appropriate audiences. Such artifacts may include constructs, models, methods...social innovations or new properties of technical, social, or informational resources...” (Peffers et. al. 2007, 49). Design science theory presents a problem-solving framework for "wicked problems" - problems that are rife with instability and complexity that demand solutions that are flexible, creative, and collaborative (Hevner and Chatterjee 2010, 11). College students' experiences of homelessness, housing insecurity, and food insecurity are complex problems that demand solutions that are flexible, creative, and collaborative. 
Design science theory emphasizes the importance of a tool's utility to the user and focuses on the production of the artifact (Peffers et. al. 2018, 131). In addition to demanding rigorous research and meticulously designed theories to learn more about how to solve problems, researchers working in design science theory argue that the products of research should be assessed by considering the practical implications and the practical value of the products (Hevner and Chatterjee 2010,12). This methodology complements this project, as the utility (or lack thereof) of the tool that will be designed to support students who are experiencing basic needs insecurities is central to the project. The tool that has been developed must be useful to students. If the tool is not useful, then the value of the tool will be diminished. Therefore, design science theory provides a useful framework for the development of this application.

\section{Critical GIS and Public Participation GIS (PPGIS)}

Critical GIS describes mapping that "calls things into question" (Crampton 2011, 40). As its name suggests, critical GIS provides a framework for critiquing the assumptions inherent in various GIS models, critiquing the notion that GIS tools are "neutral" in their analyses, and critiquing the use of GIS to uphold systems of inequality and oppression (Pickles 1997 and 2006, Sieber 2004, Crampton 2011, Harvey 2018). The work that has been produced by using the critical GIS framework uses the tools, methods, and applications of GIS to support social transformation, decrease various forms of inequalities and marginalization, and produce new cartographies of "hope and care" (Pavlovskaya 2018, 41).

Critical GIS "opens a pragmatic plane of action by fusing progressive geographic imaginations with concrete and tangible maps" (Pavlovskaya 2018, 40). Research using critical GIS is concerned with how research questions are posed, how cartographies are developed, and 
how the omission and the inclusion of information, voices, and perspectives affects the outcomes of GIS research, tools, analyses, and artifacts (Pickles 2006, Crampton 2011, Harvey 2018). College students' experiences with basic needs insecurities are directly impacted by the relationships between inclusion and exclusion, power and marginalization, and accessibility and inaccessibility both in their lived experiences of homelessness, housing insecurity, and food insecurity (Paden 2012, Au and Hyatt 2017, Crutchfield and Maguire 2018, Goldrick-Rab et. al. 2019) and in their experiences with geospatial technologies due to inequities perpetuated by the digital divide (Cooper 2006, Jones et. al. 2009, Goode 2010, Jesnek 2012). Additionally, since the conditions of homelessness, housing insecurity, and food insecurity are very traumatic for college students (Hallett and Freas 2018), it is most productive to develop geospatial tools that are designed with a deliberate attempt to provide students with tools that encourage "hope and care" (Pavlovskaya 2018, 41), and not further marginalization.

Public participation GIS (PPGIS) focuses on supporting people in vulnerable populations by providing equitable access to geospatial tools that can assist in enhancing power and agency in public decision-making processes (Warren, 2004, Elwood 2006, Tulloch 2008, Mukherjee 2015). PPGIS can be used to promote citizen engagement, participation, and control in public planning processes (Rall et. a. 2019) and governance (Elwood 2006, Cinderby et. al. 2008, Mukherjee 2015). Critical GIS and PPGIS are interconnected theoretical frameworks. The work that is produced in PPGIS often responds to the critiques of GIS tools and technologies that have been presented by critical GIS theorists by attempting to make GIS more accessible, inclusive, equitable, and accountable to people from traditionally marginalized groups (Elwood 2006).

In accordance with the literature on PPGIS, the application has been developed with input from stakeholders who are directly impacted by basic needs insecurities, including students and 
staff who work to support students experiencing basic needs insecurities. Tulloch (2008) notes that some of the barriers to PPGIS include addressing different levels of familiarity with geospatial tools and technologies and noting that tools have a limited impact on decision-making processes and decision-makers in practice. College students and the staff and administrators who support them have different levels of knowledge and experience with using geospatial tools. They may be unfamiliar, familiar, or semi-familiar with using maps and applications. By designing this tool with input from students who are experiencing basic needs insecurities and those staff members who work with them, it is possible to support students in gaining agency when accessing services on campus and off campus.

\section{Method}

This project follows the stages of design science research (DSR), including the processes of: problem identification and motivation, defining the objectives of a solution, designing and developing the artifact, demonstration, evaluation, and communication (Peffers et. al. 2007, 5354). The project engages users and stakeholders throughout the DSR process in order to build users' needs into the design of the tool by including the perspectives of students who are experiencing basic needs insecurities (as well as the staff, faculty, and administrators who support them), in accordance with the tenets of Critical GIS and PPGIS (Elwood 2006, Tulloch 2008, Crampton 2011). Participants who were involved in this research were identified for this project and included in this project because their lived experiences and expertise regarding basic needs insecurities added value to the design process. Finally, including potential users of this tool in the design process allows students, staff, faculty, and administrators to illustrate their 
understanding of what technologies that foster "hope and care" look like in practice (Pavlovskaya 2018, 41).

\section{Problem Identification}

The artifact attempts to connect college students who are experiencing basic needs insecurities with the services that they need, on-campus and off-campus (Au and Hyatt 2017, Mello 2018). The initiation of the development of this artifact is "problem-centered" (Peffers et. al. 2007, 54), meaning that the design of this artifact begins with observing a problem that has the potential to be solved or ameliorated by an artifact. There are two categories of stakeholders who are affected by this problem. The major stakeholders include college students who are experiencing basic needs insecurities and the staff, faculty, and administrators who work with students who are experiencing basic needs insecurities in an assistive or supportive capacity. The students will be henceforth referred to as the "users" of the tool. The staff, faculty, and administrators who work with students and who would be responsible for collecting, maintaining, and administering data will be henceforth referred to as "providers".

\section{Objectives of a Solution}

The objective of the solution to this problem is to design a tool that can assist college students who are experiencing basic needs insecurities find and access free or low-cost services that they need on-campus and off-campus (e.g., housing services, food services, health care services, personal and hygiene services, etc.). The challenges in meeting this objective include determining, meeting, and accounting for variation in users' and providers' familiarity with using applications that contain geospatial components, as predicted by Tulloch (2008). 


\section{Design and Development}

There were three (3) cycles of iteration for designing and developing this application. This section will describe the design, implementation, and evaluation processes that occurred during each iterative cycle.

\section{Cycle 1}

\subsection{Design}

\subsubsection{Existing Solutions}

While designing and developing an artifact to meet this objective, examples of geospatial tools and mapping tools that support service navigation were reviewed. For example, Humboldt State University (HSU) has created a Wellbeing Map to encourage students to connect with oncampus services and off-campus services that can enhance their physical, mental, and emotional health. The tool includes lists of services, events, landmarks, and resources in sections titled "Food, Nutrition, \& Housing", "Mental Health", "Sexual Health \& Consent", "Physical Health”, "Health \& Identity", “Alcohol \& Other Drugs", "Relationships \& Belonging”, "Health \& Wellbeing Services 101", and “Adulting Skills". The Wellbeing Map is integrated into Canvas, the online learning management system that is used at HSU. Therefore, all students, staff, faculty, and administrators at HSU have access to the tool. The Wellbeing Map is a figurative map for planning how and when to access resources. It is not a literal, cartographic map. While the Wellbeing Map does not contain a geographical mapping component, there is a section of the map that provides students with information about "Landmarks", or locations on-campus and off-campus where they can find support for accessing services and resources that they need (Humboldt State University 2019). 
Furthermore, the Los Angeles Food Bank has created a mapping tool to help users identify the locations of nearby food pantries. This tool allows users to type in their zip code, select a radius of up to 15 miles and search for food pantries and food distribution within the selected parameters. Then, the closest pantries are displayed as points on a Google Map and the address, contact information, and the name of the organization distributing food appears to the left of the map (Los Angeles Food Bank 2019).

Additionally, the Environmental Systems Research Institute (Esri) has developed a Homeless Service Locator application for local governments and homeless services agencies to use to help their clients find a variety of services including housing, food, transportation, and health care services. This geospatial tool can be viewed in the WebAppViewer and includes a search bar that allows users to search for services within a designated radius (up to 20 miles) of a specific location or address. The WebAppViewer can be accessed using any web browser and there are no specialized applications or costs associated with accessing the tool. The search bar also includes categories for different services (e.g., housing, food, transportation, etc.) with designated icons so that users can search for specific services and watch as the corresponding icons for those services appear on the map in the WebAppViewer. When a user clicks on an icon that marks the location for a service on the map, the full address, name of the organization, operating hours, phone number, website, and description of the organization's service offerings appear for users to view (Esri 2019).

These examples illustrate creative uses of mapping and geospatial applications to support service navigation for people who are experiencing homelessness, housing insecurity, and food insecurity. The Los Angeles Food Bank tool and the Homeless Service Locator tool both contain 
design elements that make the use of these applications accessible to people with a wide range of familiarity with using mapping tools and geospatial applications.

When designing a tool to support service navigation for college students, it is crucial to consider the role that stigma plays in students' decision-making processes about accessing services. Students who are experiencing basic needs insecurities often feel stigmatized, ashamed, and embarrassed about their food insecure or housing insecure statuses, which leads them to resist accessing services that they need (Au and Hyatt 2017, Crutchfield and Maguire 2018). If students feel a heightened awareness of their homelessness, housing insecurity, or food insecurity while using a tool, then they may experience increased feelings of stigmatization. If certain features of a service navigation tool are prompting students to feel stigmatized, then the students may resist using the tool to access services. Therefore, it is necessary to consider stigma when designing all elements of the service navigation application.

While the pre-existing tools and applications such as the Wellbeing Map, the Homeless Service Locator, and the Los Angeles Region Food Bank Locator are designed well, they do not capture all of the needs of students who are experiencing basic needs insecurities. For instance, the Homeless Service Locator and the Los Angeles Region Food Bank Locator are very explicit about their utility as tools for addressing homelessness and food insecurity. Even the titles of the tools draw attention to their objectives. These titles may discourage students from using the tools to access services if they consciously or subconsciously feel stigmatized by these labels. One of the most brilliant design elements of the Wellbeing Map is its title. The Wellbeing Map focuses on "wellbeing", which is a general, holistic, and relatable concept, instead of focusing on basic needs insecurities explicitly. Therefore, the opportunity to decrease stigma and increase students' comfort with using the tool is enhanced. Students may not think that they need or deserve help if 
they are making comparisons between their own experiences of suffering and struggle and others' experiences of suffering and struggle (Crutchfield and Maguire 2018). Therefore, in order to design a tool that can best support college students experiencing basic needs insecurities, it is imperative to be conscious of the ways in which the titles or names of the tools can further exacerbate stigmatization.

\subsubsection{Proposed Solutions}

In order to design and develop a tool that supports service navigation without perpetuating the stigmatization of basic needs insecurities, it is necessary to first develop a tool that allows providers to add, delete, and revise the list and locations of services that are available to students on-campus and off-campus. As such, there are two tools that work together to enhance students' experiences with service navigation and utilization. The first tool allows providers to collect data about on-campus and off-campus services and the second tool allows users to locate and use on-campus and off-campus services. Both of the tools that were designed and developed during this iterative cycle rely on applications, technologies, and programs that have been created by the Esri.

\subsection{Implementation}

The first tool for capturing the location of services was built using QuickCapture, a program that allows users to collect data in the field and send the location of the observations they capture to a hosted feature layer for analysis (Esri 2019). A hosted feature layer is a digital map layer that can be accessed using ArcGISOnline, a cloud-based GIS program created by the Esri. QuickCapture was chosen as the tool to build this application because it efficiently and 
effectively records the geographic location of the service that is being recorded and it allows the providers to take a photo of the location they are capturing for reference. The photographing feature provides a helpful reminder for providers who need to remember and reference which location they captured when managing the data after capturing it. Additionally, QuickCapture can be used by staff, administrative, and faculty providers to develop an application for student users in the Web AppBuilder on ArcGIS Online efficiently because the information gathered in a QuickCapture application is recorded, and can be maintained, in a hosted feature layer on ArcGISOnline (Esri 2019).

The QuickCapture application designed and implemented for providers was built by first creating a hosted feature layer including each service (e.g., housing, food, health care, etc.) as a category within a field. Then, the hosted feature layer was saved and the QuickCapture project was built using this hosted feature layer. The directions that describe the process for creating and using this application are available in Appendix 1. This instructional guide can be used as a reference guide for providers who are creating their own versions of this application for capturing the locations of student services on their college campuses. There were two different attempts to implement the QuickCapture application for providers. The first version is depicted in Figure 2 and the second version is depicted in Figure 3. 


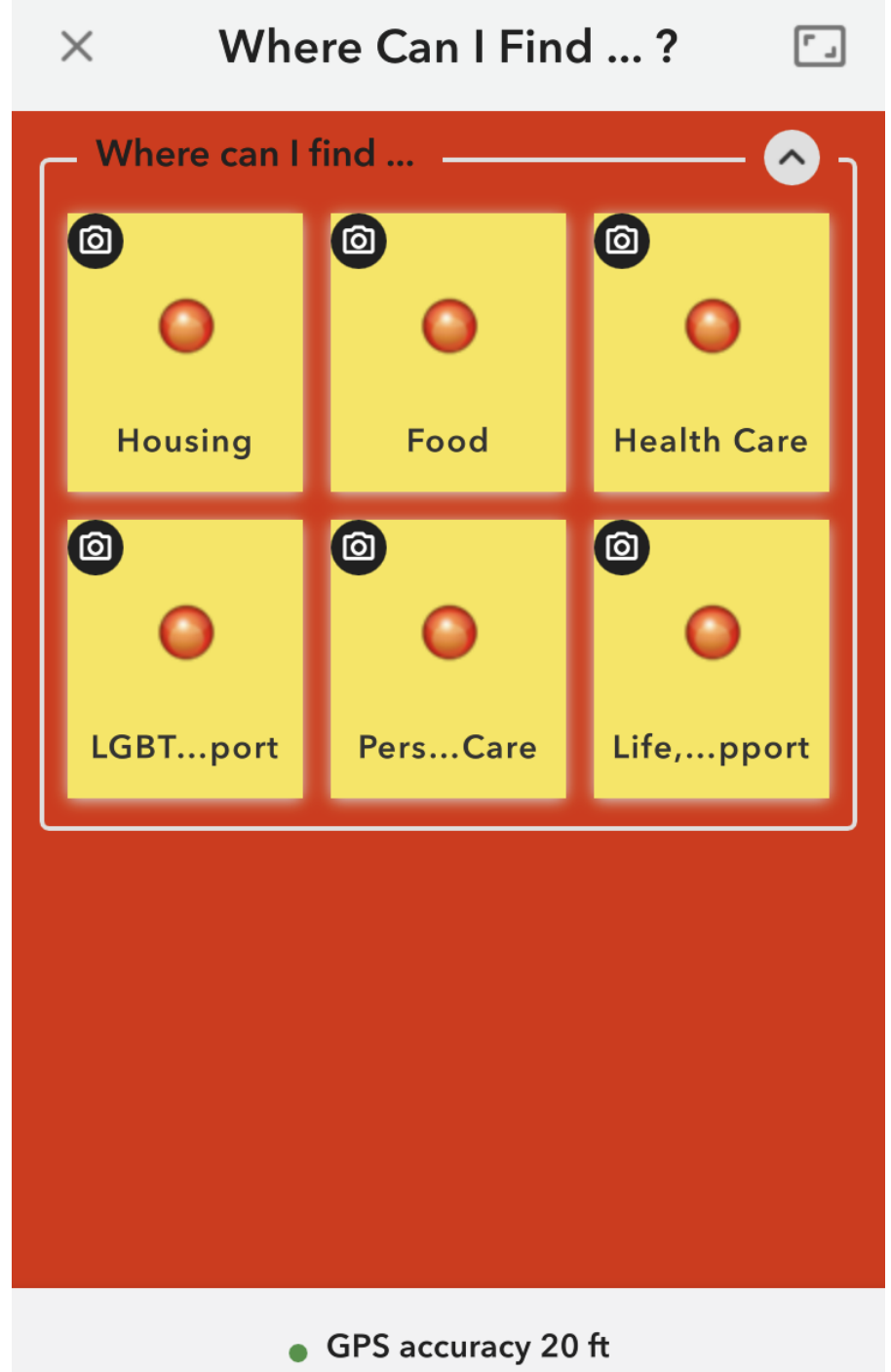

Figure 2. First iteration of mobile application development using QuickCapture 


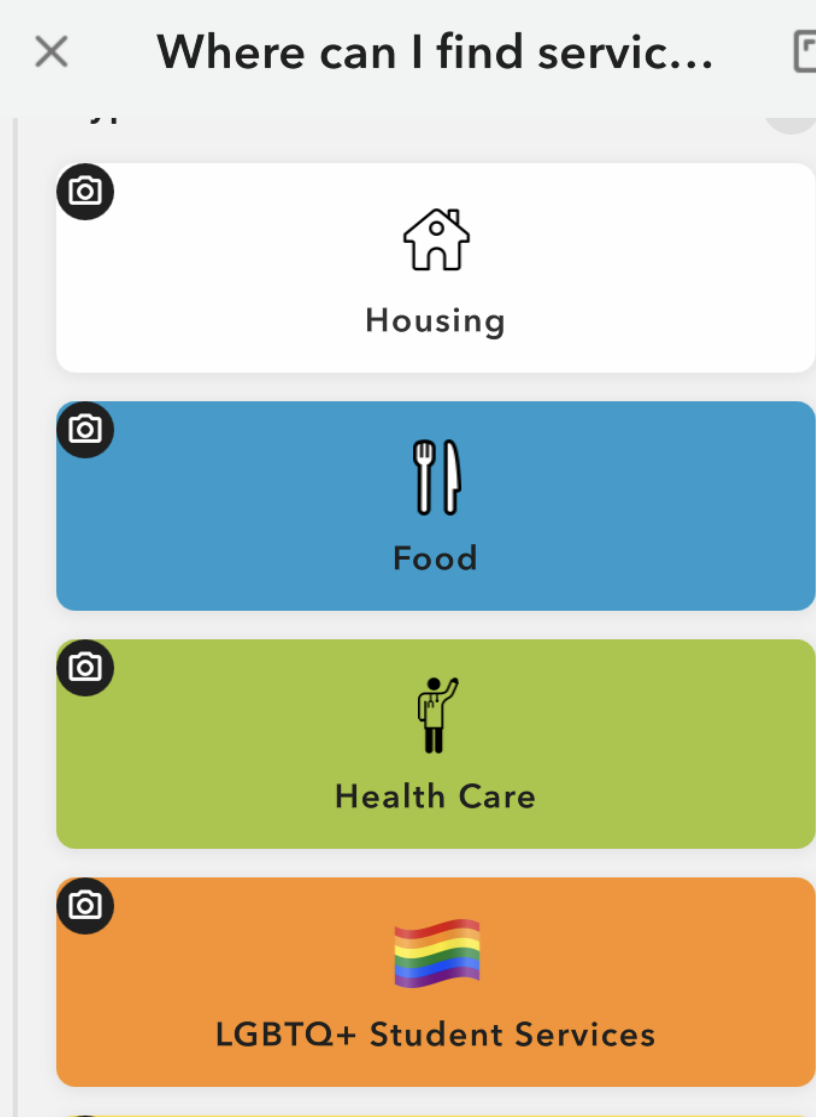

(a)

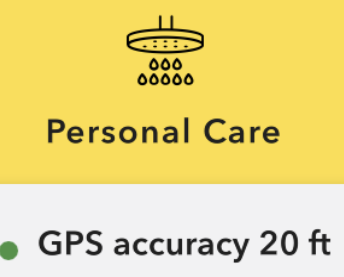

Figure 3. Second iteration of mobile application development using QuickCapture

When creating these applications, certain decisions were made with the objectives of decreasing the challenges, frustrations, and fears that can occur when using a technology for the first time and making the application accessible to a wide range of staff, administrative, and faculty providers. For example, the color contrasts of the icons and text were chosen to reflect the needs of visually impaired users (i.e., dark text on a light background or light text on a dark 
background). In addition, all of the images used on the icons in the QuickCapture application are public domain images attained from Wikimedia Commons, a collection of public domain media files that are "freely-licensed educational media content" (Wikimedia Commons 2004), so providers do not need to be concerned about copyright infringement issues.

The second tool for displaying the services and their locations, as well as information about how to access the services, for student users, was built using the Web AppBuilder on ArcGIS Online. The Web AppBuilder is a tool that allows users to develop their own 2D and 3D applications without writing code (Esri 2019). The Web AppBuilder was chosen as the tool used to build this application because it works symbiotically with QuickCapture and the hosted feature layers that are created in ArcGIS Online. Instructions on how users can utilize the tool to find services are included in Appendix 1. The web application for student users is displayed below in Figure 4.

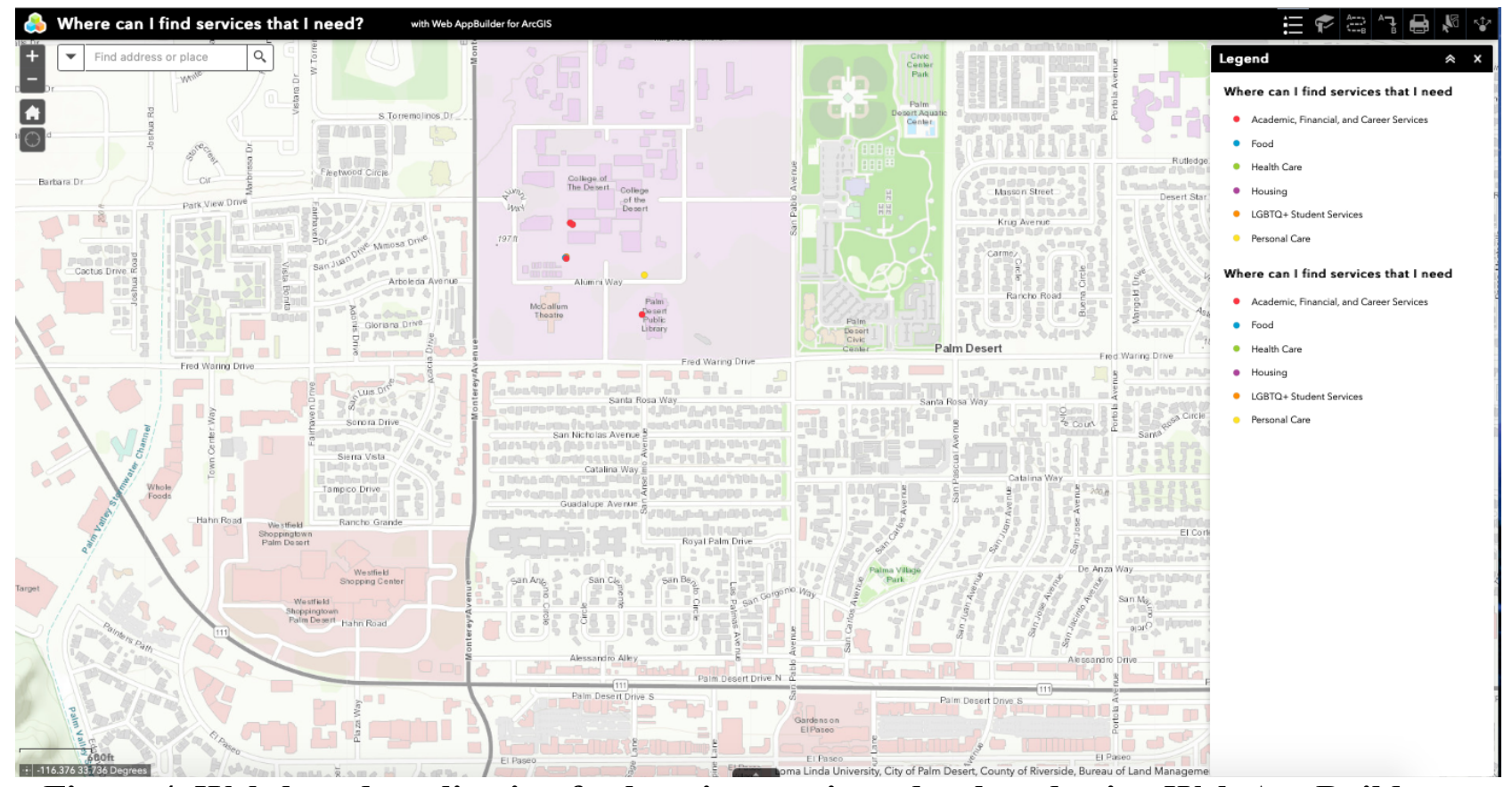

Figure 4. Web-based application for locating services, developed using Web AppBuilder 
Research about the experiences of students with basic needs insecurities has informed some of the features of the student application. For example, the directions widget was chosen for the student application because young adults who are experiencing homelessness use webbased technologies for directions (Woelfer and Hendry 2010). In addition, the title of the tool tries not to draw attention to student users' basic needs insecurity status, therefore decreasing further stigmatization of students experiencing basic needs insecurities (Crutchfield and Maguire 2018). The name for the application in this stage is "Where Can I Find Services that I Need?". This name keeps the application's emphasis on finding services but not on focusing on a student user's basic needs insecurity status.

\subsection{Evaluation}

Peffers et. al. (2018) notes that in design science research, "evaluation occurs concurrently with building" (p. 135). As such, the tools implemented during Cycle 1 have been informally assessed by stakeholders such as staff who work directly with college students who are experiencing basic needs insecurities, college students who have experienced basic needs insecurities, and the chairs and members of this dissertation committee as the tools have been developed. Feedback from these stakeholders has led to the inclusion of ideas for features to add to the application and ideas for making the application more accessible to student and staff users with a wide range of abilities, linguistic backgrounds, and familiarities with digital tools. Table 3 lists a sample of informal feedback shared by staff, students, and faculty advisors during Cycle 1. 
Table 3. Sample of informal feedback from users

\begin{tabular}{|l|}
\hline Include locations where students can print for free on campus \\
\hline Include locations where students can find peace and quiet \\
\hline Include locations with natural beauty and free recreation opportunities \\
\hline Include locations with free shower access \\
\hline Use color contrasts that are accessible to people with visual impairments \\
\hline Make information available in Spanish and/or additional languages, based on user's needs \\
\hline $\begin{array}{l}\text { Information about the services should be displayed in both .pdf and .jpeg formats to } \\
\text { accommodate best file compatibility with different phones and operating systems (Android vs. } \\
\text { Apple) }\end{array}$
\end{tabular}

The QuickCapture tool and the WebAppBuilder tool developed and implemented during the first iterative cycle show that a service navigation application for college students experiencing basic needs insecurities can be designed and implemented without extensive knowledge of processes such as computer coding. However, there are limitations to these tools that show that additional cycles of design, development, implementation, and evaluation are necessary. The features and functions that need improvement in future cycles of ideation are displayed in Table 4.

Table 4. Features to address in future iterative cycles Compressed map view impacts the user's ability to locate services on the mobile application. There is no way of accounting for the expiration date/time of a service. Service categories may not be clearly delineated and adequately descriptive. 
The student user side of this application contains a map that students can view easily in a web browser. However, the user application may not provide a clear view of the map and the information about the services in a mobile application format, as the mobile application form of the user application is just a compressed map version of the web browser view of the application. It may be difficult for student users to access the information about services that they need with a compressed view of the map in mobile applications.

Additionally, there is no way for accounting for the time and the locations of services simultaneously in either the QuickCapture tool for providers or the WebAppBuilder tool for users. Some services will be available to students on a permanent basis. For example, the student health center will likely remain in the same location with the same hours of operation for the entire semester, so students seeking free or reduced-cost healthcare services can be directed to the student health center on a regular basis. However, there may be services available on campus that are only available to students temporarily. For example, there may be a visiting food bank truck, such as the FIND Food Bank truck ${ }^{2}$, that is only available to students on a campus on a particular date and for a specific length of time and the service will disappear after that. If there is a service that is available temporarily in a certain location, there is no way for providers to designate an expiration date for the service in QuickCapture, so users will either continue to see out-of-date information about temporarily-available services, or providers will be required to manually add and delete the information about temporary services. Adding an expiration date to the provider and user tools could help enhance the utility of these tools.

Finally, the tool developed for providers in QuickCapture and the tool developed for users in the WebAppBuilder may be too confusing in their wording of the different service

\footnotetext{
${ }^{2}$ FIND Food Bank is a food bank based in the Coachella Valley in California that visits college campuses in the Coachella Valley on a rotating basis to distribute food (Find Food Bank 2020).
} 
categories. There are six categories of services included in the first cycle of design: Food, Housing, Healthcare, Personal Care, LGBTQ+ Services, and Academic, Career, \& Financial Support. The titles of these services may not provide a clear and accurate portrayal of the services displayed. For example, a variety of services are included in the "Personal Care" category ranging from free access to showers, to spaces where students can find peace, quiet, natural beauty, and/or recreation/exercise on campus or near campus. While all of these services are elements of personal care, the term may not clearly capture the variety of services in that category. Further consideration of the scope, terminology, and themes associated with the service categories is still required in order to present a tool that is user-accessible and ultimately results in optimal usability.

\section{Cycle 2}

\subsection{Design}

The second design cycle included the process of designing a brainstorming activity to solicit input from students, staff, faculty, and administrators about how to design an effective tool to support college students experiencing basic needs insecurities. Following DSR and PPGIS research methodologies, this brainstorming activity was designed with the objective of gaining information about the needs and preferences of users who would be engaging with the tool.

During the spring of 2020, the COVID-19 pandemic made conducting a large group, inperson brainstorming session impossible due to public health restrictions on conducting research involving the participation of human subjects. Instead of conducting an in-person brainstorming session, a remote brainstorming activity was designed using the "How Might We..." 
methodology. The "How Might We..." approach to designing a brainstorming session involves introducing participants to the problem using a problem statement, designing a central brainstorming question, and then breaking down this central brainstorming question into smaller and more specific actionable questions (Dam and Siang 2018).

This brainstorming activity was designed using the asynchronous remote brainstorming framework, described and evaluated by Williams (2013):

Remote brainstorming can be accomplished with synchronous (e.g., chat) and asynchronous (e.g., blogs, wikis, and other social media) communication technologies...Dennis and Williams (2003) compared electronic brainstorming to verbal (face-to-face) brainstorming [and] their research revealed that electronic brainstorming can be an efficient complement to verbal or nominal group brainstorming especially for large groups (p. 2).

The brainstorming activity questionnaire used in this cycle to solicit feedback from stakeholders is displayed in Table 5. This questionnaire deliberately uses open-ended questions to encourage participants to "think big" and to allow for a variety of ideas to emerge in responses, consistent with the "How Might We" brainstorming methodology (Dam and Siang 2018).

Table 5. Brainstorming Activity

Directions: Please consider and answer the questions below. You can type your answers directly into this document or you can answer them in another document if you prefer.

Problem Statement: In California, college students are experiencing basic needs insecurities such as homelessness, housing insecurity, and food insecurity at high rates.

Central Brainstorming Question: How might we support college students who are experiencing basic needs insecurities such as homelessness, housing insecurity, and food insecurity?

Actionable Question 1: How might we help students find housing, food, and personal hygiene services on campus? 
Actionable Question 2: How might we help students find housing, food, and personal hygiene services off campus?

Actionable Question 3: How might we use technology to support students who are experiencing homelessness, housing insecurity, and food insecurity?

Actionable Question 4: How might we envision a tool, strategy, or approach to helping students who are experiencing homelessness, housing insecurity, and food insecurity?

Actionable Question 5: How might we reduce stigma surrounding homelessness, housing insecurity, and food insecurity on college campuses?

\subsection{Implementation}

After receiving an exemption from the Institutional Review Board (IRB) at Claremont Graduate University (project \#3712) to complete this brainstorming activity, the survey was implemented. First, the brainstorming activity questionnaire was sent via e-mail to individual students, staff, faculty, and administrators at two community colleges and one graduate university, all located in Southern California. Seventeen (17) potential survey participants were identified based on their lived experience and expertise about this topic and the researcher's knowledge of their interest in contributing feedback to the project. In the first iteration of sharing the brainstorming questions, the questions and the IRB Informed Consent Form were sent to participants as fillable Microsoft Word documents. Participants then returned the completed brainstorming questionnaires with their own opinions, input, ideas, and feedback filled into the documents. In the second iteration of sharing the brainstorming questions, a Qualtrics survey was designed using the same Informed Consent form and the same brainstorming questions. The link to the Qualtrics survey was shared via e-mail. The Qualtrics survey was used to make the process of sharing the brainstorming activity more efficient, as one can share a Qualtrics survey link with many potential respondents simultaneously. A total of nine (9) respondents completed the brainstorming survey during the months of April 2020, May 2020, and June 2020. 


\subsection{Evaluation}

The nine responses to the brainstorming survey were evaluated using the general inductive approach for qualitative data analysis. "The primary purpose of the inductive approach is to allow research findings to emerge from the frequent, dominant, or significant themes inherent in raw data, without the restraints imposed by structured methodologies" (Thomas 2006, 238). The general inductive approach to analyzing qualitative data was used to assess responses to the brainstorming survey because the survey was designed to elicit expansive ideas and information from participants. The codes for the text of the survey responses could emerge inductively, after the survey was completed and during the analysis process. That is, the codes for the text of the survey responses did not have to be designed deductively, before the survey was assessed.

The inductive reasoning that grounds the general inductive approach is preferable to deductive reasoning approaches for evaluating this brainstorming survey because there are no preset or pre-generated codes or ideas being imposed on the transcripts of the brainstorming surveys. The researcher did not have any specific expectations or predictions about the content of the answers to the brainstorming questions before the survey was conducted because the objective of the survey was exploratory: to gather information and ideas from students, staff, faculty, and administration about how to best support students experiencing basic needs insecurities. Therefore, the general inductive approach is the best approach for analyzing the responses.

The stages that are included in the general inductive approach's textual evaluation process are: condensing raw text into a concise format, finding links between research goals and 
findings from the qualitative data, and describing a model or theory based on the responses from participants (Thomas 2003). The qualitative data analysis application, ATLAS.ti, was used to help facilitate the processes of condensing the text of the survey responses, organizing and coding the text, and exploring how the text of the survey responses can contribute ideas to the process of designing the tool to support students experiencing basic needs insecurities.

The initial inductive coding process produced 34 codes, at the units of sentences and phrases, that represent the most frequently cited themes of the interview responses. During the second stage of coding, redundancies were discovered, so some of the initial codes were merged together, leaving a total of 31 codes. The 31 codes were then organized into 5 thematic groups based on their content and associations: recommendations for colleges and universities, communicating with students, ideas for developing a tool, community engagement, and addressing stigma. The thematic groups and codes are displayed in Table 6.

Table 6. Brainstorming activity themes, codes, and quotation examples

\begin{tabular}{|l|l|l|}
\hline Themes & Codes & Quote Example \\
\hline $\begin{array}{l}\text { Recommendations for } \\
\text { colleges and universities }\end{array}$ & $\begin{array}{l}\text { college/university } \\
\text { advocates for better social } \\
\text { safety net for students }\end{array}$ & $\begin{array}{l}\text { "Organizing to advocate for more } \\
\text { safety nets for students would also } \\
\text { be a good stratedy [sic] because } \\
\text { this pandemic made it obvious } \\
\text { there is little to no security for a } \\
\text { college student" }\end{array}$ \\
\hline & plans for emergencies & $\begin{array}{l}\text { "An approach to helping students } \\
\text { experiencing this right now would } \\
\text { be making a plan for the future } \\
\text { instead of waiting till something } \\
\text { unprecedented such as Covid-19 } \\
\text { happens again." }\end{array}$ \\
\hline & $\begin{array}{l}\text { college/university provides } \\
\text { free or affordable food }\end{array}$ & $\begin{array}{l}\text { "Provide a free/reduced price meal } \\
\text { plan for at-risk students, depending } \\
\text { on need." }\end{array}$ \\
\hline
\end{tabular}




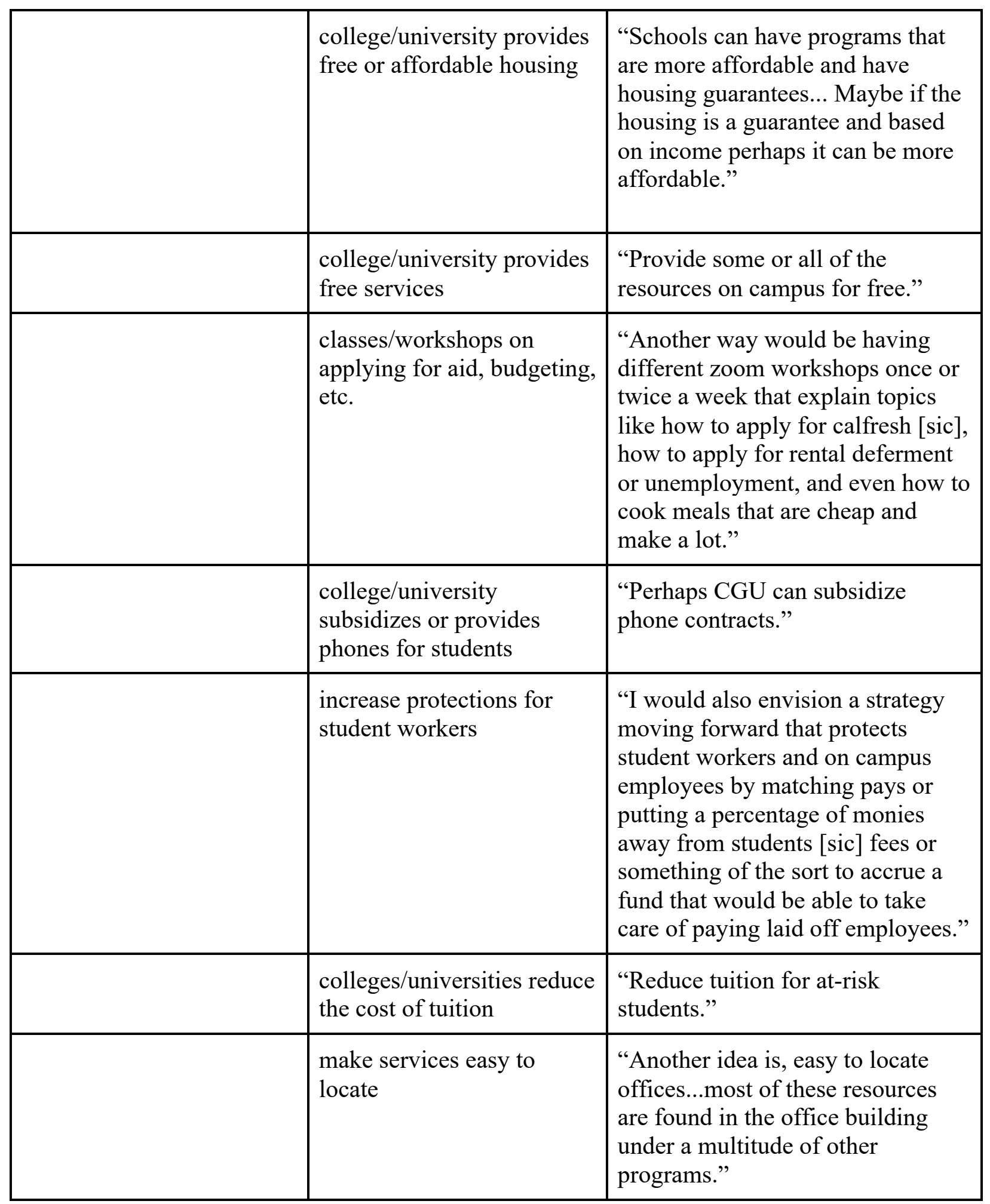

\begin{tabular}{|l|l|l|}
\hline $\begin{array}{l}\text { Communicating with } \\
\text { students }\end{array}$ & college/university website & $\begin{array}{l}\text { "By having a dedicated page } \\
\text { on the school website that is } \\
\text { easy to find listing all the }\end{array}$ \\
\hline
\end{tabular}




\begin{tabular}{|l|l|l|}
\hline & & $\begin{array}{l}\text { local food pantries } \\
\text { information, regional, state, } \\
\text { and federal programs and } \\
\text { non-profit organizations that } \\
\text { offered financial assistance } \\
\text { for housing and food." }\end{array}$ \\
\hline & e-mail & $\begin{array}{l}\text { "Email could be one of these } \\
\text { things to get information out } \\
\text { to all students." }\end{array}$ \\
\hline accessible information & $\begin{array}{l}\text { "Ensure that all people in the } \\
\text { college community know how } \\
\text { that the resources exist, and } \\
\text { also know how they may } \\
\text { access them." }\end{array}$ \\
\hline packets/fliers/posters & $\begin{array}{l}\text { "Another way would be } \\
\text { having packets or fliers with } \\
\text { information, which could } \\
\text { include more about fresh hub, } \\
\text { calfresh [sic], advertisements } \\
\text { for homeless shelters or rent } \\
\text { deferment, being put in the } \\
\text { residency halls or hung up on } \\
\text { the mailroom boards." }\end{array}$ \\
\hline survey students & $\begin{array}{l}\text { "Most students are in the age } \\
\text { range that like to use social } \\
\text { media. Social media can be a } \\
\text { powerful tool to reach out to } \\
\text { these people. Making posts } \\
\text { and trying to partner with } \\
\text { other schools on this to reach } \\
\text { larger audiences." }\end{array}$ \\
\hline text messages & $\begin{array}{l}\text { "Send out surveys..to see } \\
\text { what is needed more or less of } \\
\text { for them." }\end{array}$ \\
\hline & $\begin{array}{l}\text { "Send text reminders once in } \\
\text { a while." }\end{array}$ \\
\hline & & \\
\hline & &
\end{tabular}

\begin{tabular}{|l|l|l|}
\hline Ideas for developing a tool & confidentiality & $\begin{array}{l}\text { "Technology is valuable in } \\
\text { that it can provide for } \\
\text { confidentiality to students }\end{array}$ \\
\hline
\end{tabular}




\begin{tabular}{|l|l|l|}
\hline & & looking for these resources." \\
\hline & $\begin{array}{l}\text { cost barriers to using } \\
\text { technologies }\end{array}$ & $\begin{array}{l}\text { "It is not hard to imagine a } \\
\text { person who is homeless or on } \\
\text { the verge of losing their } \\
\text { apartment might be in the } \\
\text { situation of not having access } \\
\text { to a computer or even a cell } \\
\text { phone, since they wouldn't be } \\
\text { able to pay the bills for } \\
\text { internet service or cell } \\
\text { service." }\end{array}$ \\
\hline & location-based technologies & $\begin{array}{l}\text { "Perhaps even a 'in my area' } \\
\text { type off app." }\end{array}$ \\
\hline mobile application & $\begin{array}{l}\text { "Create a specific app for } \\
\text { students to request } \\
\text { assistance." }\end{array}$ \\
\hline & service directory & $\begin{array}{l}\text { "One way that admin can help } \\
\text { students find basic needs } \\
\text { services on campus is a } \\
\text { directory on the school's } \\
\text { site." }\end{array}$ \\
\hline & shower facilities & $\begin{array}{l}\text { "Let homeless students use } \\
\text { the gym facilities to shower." }\end{array}$ \\
\hline
\end{tabular}

\begin{tabular}{|l|l|l|}
\hline Community engagement & $\begin{array}{l}\text { off-campus community } \\
\text { engagement }\end{array}$ & $\begin{array}{l}\text { "Canvas Claremont } \\
\text { residents...Link students to } \\
\text { those who are willing to } \\
\text { volunteer lodging." }\end{array}$ \\
\hline & $\begin{array}{l}\text { on-campus community } \\
\text { engagement }\end{array}$ & $\begin{array}{l}\text { "Possibly crowd sourced } \\
\text { domain expertise from fellow } \\
\text { students attending campuses." }\end{array}$ \\
\hline
\end{tabular}

\begin{tabular}{|l|l|l|}
\hline Addressing stigma & Care & $\begin{array}{l}\text { "If we can ensure students are } \\
\text { taken care of by various } \\
\text { means, the stigma will be } \\
\text { much reduced or eliminated." }\end{array}$ \\
\hline & confusion & $\begin{array}{l}\text { "I think the stigma comes } \\
\text { from a place of uncertainty, or }\end{array}$ \\
\hline
\end{tabular}




\begin{tabular}{|l|l|l|}
\hline & & confusion." \\
\hline & non-judgmental attitude & $\begin{array}{l}\text { "Important to not judge or put } \\
\text { pressure onto users." }\end{array}$ \\
\hline & open, honest discussions & $\begin{array}{l}\text { "I feel if we have more open } \\
\text { discussions on this issue it } \\
\text { will bring awareness and help } \\
\text { realize the issue that press } \\
\text { many college students." }\end{array}$ \\
\hline & story telling & $\begin{array}{l}\text { "Create videos with faculty } \\
\text { and students sharing the } \\
\text { stories of their struggles that } \\
\text { they encounter." }\end{array}$ \\
\hline & the spectrum of need & $\begin{array}{l}\text { "I feel most people only know } \\
\text { housing insecurity and food } \\
\text { insecurity as extreme sorts of } \\
\text { the spectrum, but it can be as } \\
\text { easy as you don't know when } \\
\text { you will eat next, or you don't } \\
\text { know where you will sleep } \\
\text { tonight." }\end{array}$ \\
\hline
\end{tabular}

Responses from the brainstorming activity show that there is considerable support among participants for the usage of mobile applications and web-based applications to support students who are experiencing basic needs insecurities. The respondents' ideas and contributions to the brainstorming activity reflect many of the themes and findings that are presented in studies about the technological experiences of college students and young people who are experiencing homelessness (Woelfer and Hendry 2012, Guadagno et. al. 2013) and experiences of stigma associated with basic needs insecurities (Crutchfield and Maguire 2018).

Responses from the brainstorming activity participants, such as the response featured in Table 5 as the quote example for the code "cost barriers to using technologies", described potential financial accessibility concerns for students who are experiencing basic needs 
insecurities, which is consistent with the academic literature about the digital divide (Cooper 2006, Jones et. al. 2009, Goode 2010, Jesnek 2012). Participants in the brainstorming survey suggested that colleges and universities can help to address barriers to access by providing students with phones and providing students with access to computers and the Internet.

Participants shared ideas that can be incorporated into the design of the mobile application and the web application. For example, one participant suggested including “directions to local, state, and national government or other support programs and simple guides to applying for aid." Other participants recommended integrating the service location mobile application with a school's campus application and/or with the school's canvas application.

In addition, the participants also shared many ideas about how colleges, universities, and communities can better engage with, and care for, students who are experiencing basic needs insecurities. For example, participants suggested that colleges and universities provide free and affordable services to students, very clear information about services, and support for signing up for services on campus. One participant noted "for those that don't have access to computers or do not have smartphones provide an area like in the registration office or library where students can apply for programs." Another participant recommended that colleges and universities "can set up a food pantry on campus, a program that provides housing for those that cannot afford rent, counseling, and free meals with partnerships with local restaurants." Respondents also suggested that colleges and universities should be more assertive and intentional in their attempts to communicate with students about these services by sending students e-mails, texts, surveys about their needs, displaying posters about services in common areas, explaining how to apply for services, sharing a service directory on their websites, posting information about services to 
social media accounts, and providing accessible information about services that are easy to locate on campus.

Respondents to the brainstorming survey also noted that members of the on-campus and off-campus communities can provide support to students experiencing basic needs insecurities too. One participant shared that colleges should "provide for opportunities of awareness of these students to people and organizations that might be able to help them either financially or with job placements." Another participant highlighted the importance of building relationships between on-campus and off-campus organizations and entities to best support students experiencing basic needs insecurities. The participant recommends "building connections with the local community such as restaurants, laundry mat places, and local government."

Finally, participants shared ideas and recommendations about how to decrease the stigmatization of basic needs insecurities. Participants in the brainstorming survey noted that technologies such as mobile applications can provide students who are experiencing basic needs insecurities with the anonymity they need to feel confident exploring and accessing services. For example, one respondent shared that "the first thing to do is provide assistance anonymously, so that the students in those categories are not stigmatized." Another respondent notes: "I think this comes with some stigma and so there should also be a way of asking / seeking these resources confidentially. I think technology (a website or mobile app) would be appropriate tools for that."

All of the suggestions shared during the brainstorming activity represent significant ideation contributions to the design of the mobile application. These ideas will be incorporated into future iterative cycles.

\section{Cycle 3}


The third iterative cycle included the process of designing and implementing another version of a mobile application to support students experiencing basic needs insecurities using feedback from the evaluations that occurred in Cycle 1 and in Cycle 2. In the third cycle, a mobile application was designed, developed, and implemented using a collaborative process that included drawing on the technical skills and knowledge of two graduate student volunteers from the Center for Information Systems and Technology (CISAT) at Claremont Graduate University. A comprehensive evaluation of the Campus Cares Community App will be presented in the third chapter in this project, titled "Evaluating the Campus Cares Community Application". Therefore, this section contains a description of the design and implementation of the Campus Cares Community Application.

\subsection{Design}

The design of the mobile application occurred between April-August 2020. After surveying multiple options for mobile application templates, the mobile application template that was chosen was the Universal Listings React Native Template, developed by instamobile. A personal license for the Universal Listings React Native Template was purchased on March 29, 2020 for $\$ 99.00$. The author received a research materials award from the Claremont Graduate University Graduate Student Council during the Spring 2020 semester in the amount of $\$ 99.00$.

The Universal Listings Template was chosen for use in this mobile application because it offered design features that were discussed in the evaluation sections of Cycle 1 and Cycle 2, as well as functionalities necessary for testing the application. For example, the Universal Listings Template includes features such as "categories, map view, custom filters, reviews, [and] chat" and it is "optimized for both iOS \& Android" devices (instamobile 2020). By using this template, 
design features such as the creation of categories for services (i.e., separate categories for food services, housing services, health care services, etc.) and sharing a map view of the location of these services on-campus or off-campus with users were included in the application.

Additionally, the template's optimization for both iOS and Android devices supported the design idea of reaching a wide range of students who are using a variety of mobile devices.

The process of designing the user interface occurred between April-July 2020. The user interface was designed collaboratively, with input from two CISAT students and Professor Brian Hilton, dissertation co-chair. The tools that were used during this process include Axure RP, TeamViewer, and pen and paper for sketching the user's visual experience with the application. The service categories in this mobile application include: Food Services, Housing Services, Personal Care Services, Health Care Services, LGBTQ+ Student Services, and Financial Services. Figure 5 shows an early-stage sketch of the user interface design for the service category of food.
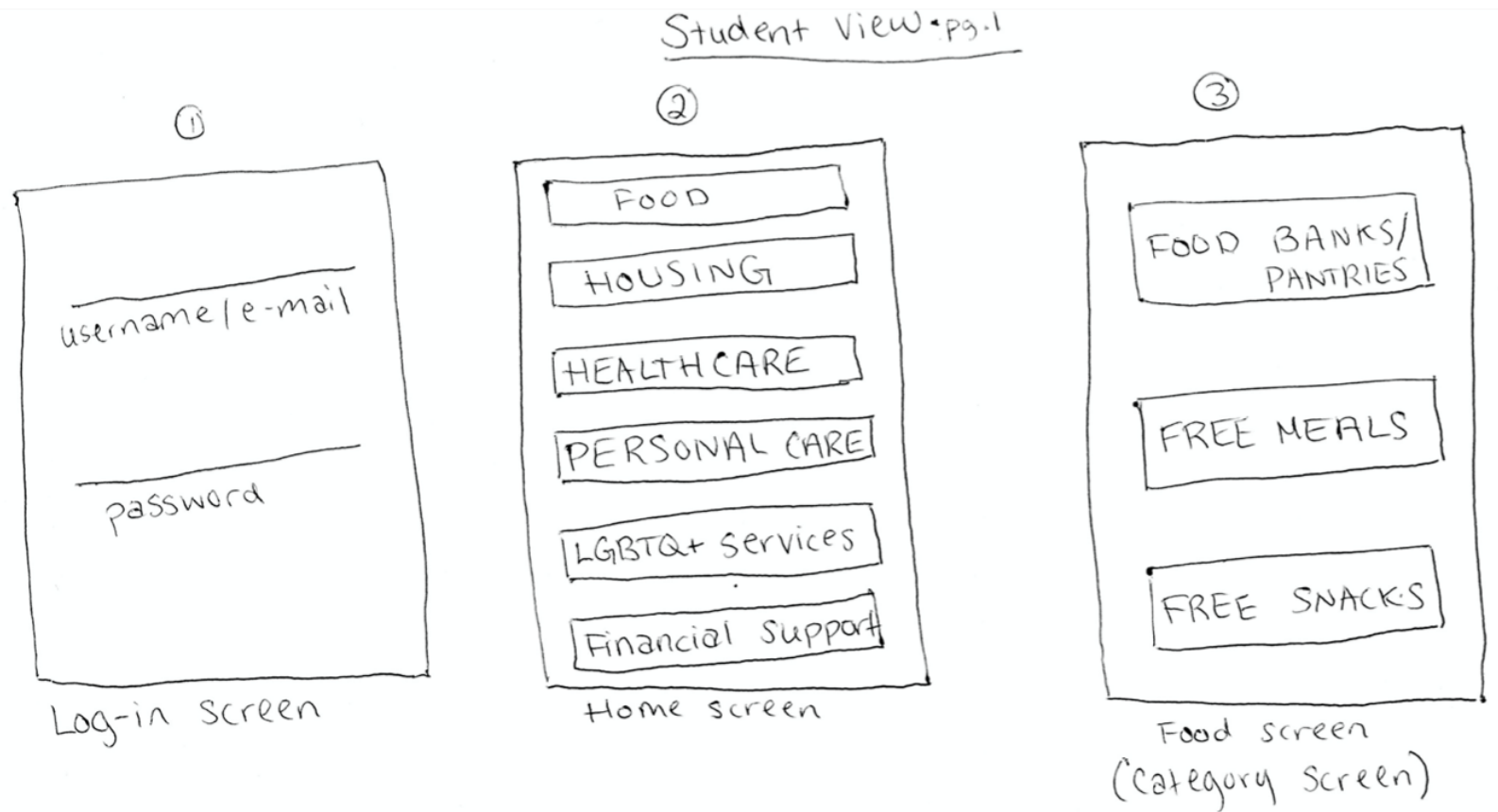

Figure 5. Sketch of the User Interface Design for Food Service Category 
Throughout the design process, data on basic needs insecurities services was shared and applied to the different service categories. For example, Hilton shared the Food Resources in California dataset, which includes a list of the locations of free food resources (e.g., food pantries and food banks) throughout the State of California. This comprehensive dataset includes services that could be accessed by students across California (Los Angeles Controller 2020).

Furthermore, the author shared information and a dataset about the locations of community fridges in the Los Angeles area. Community fridges, run by mutual aid societies and local business owners, are refrigerators that contain fresh and non-perishable food items that are accessible to everyone in a community at any time of the day or night. "Unlike more traditional forms of food aid, there are no forms to fill out, and no limit on how much food people can take or how often they can take it; the fridges are anonymous; their light is on 24/7; and they're not being policed or regulated by anyone" (James 2020). Information about where and how to access community fridges was added to this iteration of the mobile application because community fridges offer students who are experiencing basic needs insecurities the option of remaining anonymous while accessing food. The flexibility and the lack of reporting of one's food insecure status contribute to the utility of the community fridges for serving college students because accessing the fridges may decrease students' feelings of stigmatization associated with experiencing basic needs insecurities. The community fridges may also decrease students' fears of disclosing personal information. A quotation from an organizer with LA Community Fridges featured in the Los Angeles Times illustrates how the fridges may help decrease stigmatization and fear for students looking to access food resources: “A lot of people don't seek out aid 
because of their [immigration] status ... there's so much pride that people have, and seeking assistance strips that away" (James 2020).

Additional user interface design features were considered in July 2020, including appropriate and accessible color contrasts used in the mobile application, the application's icon Figure 6, and the name of the application. For example, the process of selecting a name for the mobile application considered names that convey care and community support for students experiencing basic needs insecurities. An initial list of names was presented by the author and included the following ideas: Campus Community App, Student Support App, Campus Cares App, Student Sites App, and Student Community App. After consultation with the design team, the name "Campus Cares Community App" was selected due to its thematic emphasis on care, community, and college campuses.

Figure 6 depicts the icon for the Campus Cares Community App. This icon was derived from Pixabay, a website that shares copyright-free images (Pixabay 2020). The icon was chosen due to its ability to convey support for students experiencing basic needs insecurities.

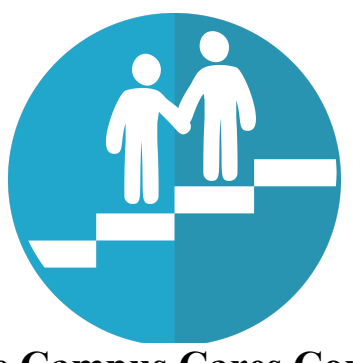

\section{Figure 6. Icon for the Campus Cares Community App}

The design of the application also included features suggested by participants in the Brainstorming Activity during Cycle 2. For example, participants in the Brainstorming Activity noted that it would be beneficial to connect the App to social media accounts for the purpose of making information accessible to users and connecting with users more efficiently. Users can log 
into the Campus Cares Community App using a Facebook account, an e-mail address, or a phone number. In addition, participants in the Brainstorming Activity recommended that students share information about services with each other (crowd-sourcing information about services). The Campus Cares Community App gives users the ability to add services and resources to the App, with the approval of the App administrator who is responsible for regulating content. Finally, participants in the Brainstorming Activity reiterated the importance of including certain types of services, such as shower services and food services, in any tool that is developed. The Campus Cares Community App includes these services.

\subsection{Implementation}

The Campus Cares Community App was developed by following four main steps: 1 . Connecting the React Native Universal Listings App to Firebase, a database; 2. Creating cloud storage for the application's data; 3. Creating an administrative approval function for monitoring content; and 4. Setting up a Gmail account and Facebook ID for the application. These four steps will be described in further detail below.

1. The first step that occurred in developing the prototype was connecting the React Native Universal Listings App to Firebase, a database. The iOS version of the app, the web app version, and the android version of the app are all connected to Firebase.

2. The next step in the development process involved choosing a cloud storage provider for the application. Since the application was already connected to Firebase and Firebase is associated with Google, the decision was made to use cloud storage supplied by Google to maintain continuity. 
3. Then, the function for administrator approval and regulation of content was developed so that administrators can monitor content (e.g., additional services) that is added by users.

4. A Gmail account and Facebook ID were created for the Campus Cares Community App so that the application could be submitted to the AppStore for approval. This step enables users to test the application in an evaluation. This stage in the development process also included writing a privacy policy for the application, which was modified from a privacy policy template composed by Termly, a company that supports privacy compliance.

Throughout the development process, additional actions were taken to improve the tool, such as working out bugs in the code and making changes to the icons in the application.

The unique features of this prototype include the icons and identifying images (attained from Creative Commons) for different service categories, the administrator approval feature that facilitates users sharing information about services while maintaining the regulation of content, and the feature that shows users pertinent information about the service (such as operating hours, contact information, etc.), where the service is located and provides directions on how to find that location. Additionally, the Campus Cares Community App can be used with iOS, Android, and web browsers.

The prototypes that were developed in Cycle 1 of this project included some, but not all, of these features. For example, while providers were able to use unique icons to navigate to different service categories in the application that was built using QuickCapture, users were only able to view a map with points showing different service locations in the WebApp Builder. Users would have had to double click on a point on the map in order to access information about the service (such as the hours of operation, contact information, and location of the service). The 
Campus Cares Community App presents users with all of the information they need to access a service clearly and efficiently. Figure 7 shows the list of service categories included in the Campus Cares Community App.

\section{Conclusion}

This chapter summarizes three iterative cycles of designing, developing, implementing, and evaluating a mobile application to support college students experiencing basic needs insecurities. During the first cycle, the design, implementation, and evaluation of tools to support students experiencing basic needs insecurities using Esri's QuickCapture and WebApp Builder was completed. During the second cycle, a Brainstorming Activity was designed, implemented, and evaluated to elicit feedback from participants and gain insights into how to improve the design of the tool. In the third cycle, a mobile application was designed and implemented using the Universal Listings React Native App template from instamobile. The iterative cycles described in this chapter show that there are multiple geospatial tools that can be used to support students experiencing basic needs insecurities. The Campus Cares Community App combines features of the mobile and web-based applications developed in Cycle 1 with feedback from potential users elicited in Cycle 2. The Campus Cares Community App, the development of which has been documented in Cycle 3 of this chapter, will be tested by potential users in a future chapter. 


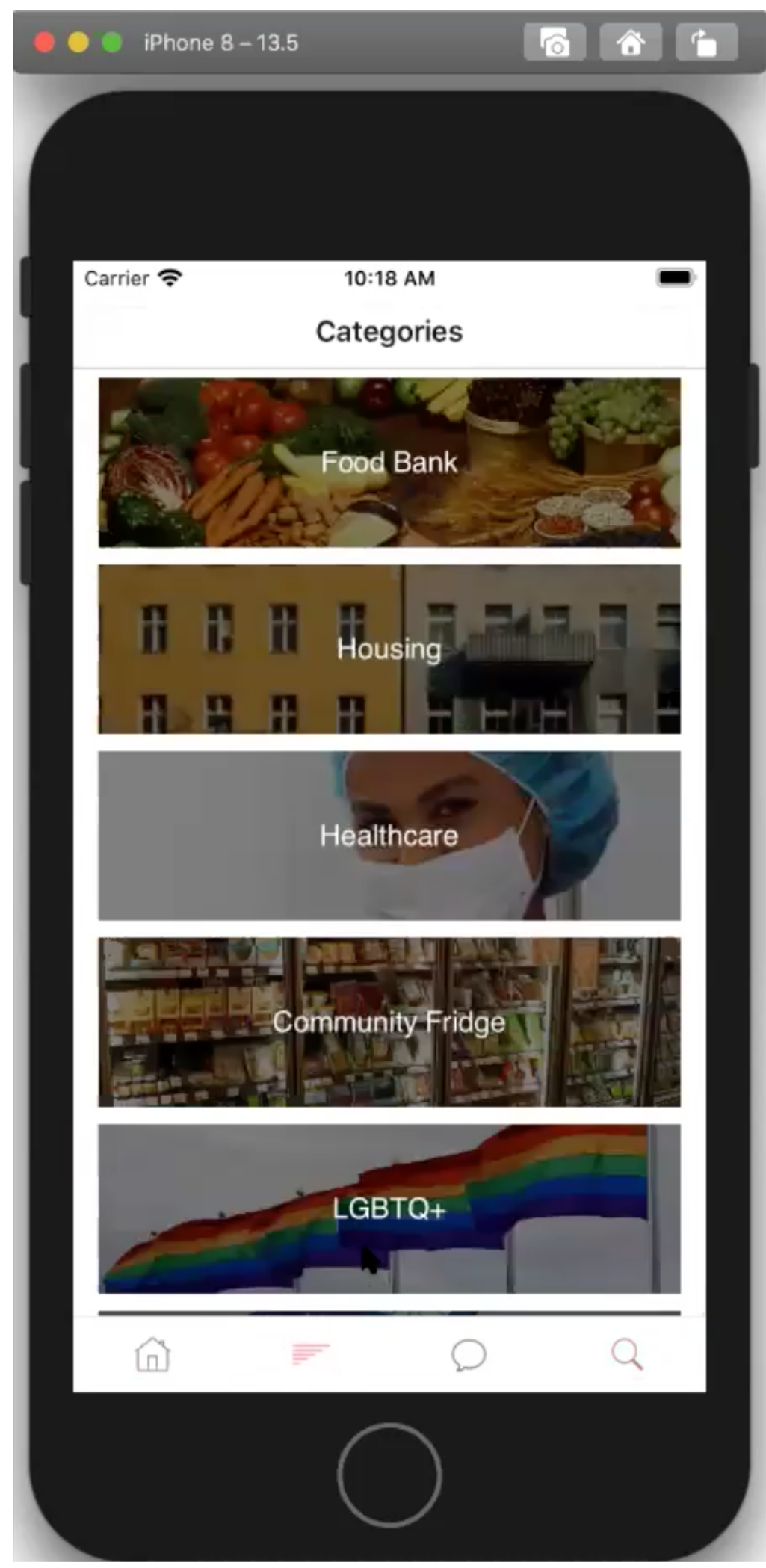

Figure 7. Campus Cares Community App 


\section{Evaluating the Campus Cares Community Application}

\section{Introduction}

This chapter presents the assessment results from a test of the mobile application titled “Campus Cares Community Application”, designed to support college students experiencing homelessness, housing insecurity, and food insecurity. The evaluation of the mobile application is driven by design science theory, critical GIS, and public participation GIS.

\section{Assessment Frameworks}

Evaluation of an artifact is a central part of the process iteration in design science theory because it gives researchers the opportunity to observe and measure the ability of the artifact to solve a problem (Peffers et. al. 2007, 56). Design science theory centers the evaluation of the tool on the utility of the application to the users who in this case are students experiencing basic needs insecurities and the staff, administrators, and faculty who work with them.

Practitioners of critical GIS assess the utility of an artifact by evaluating the degree to which the product or service reduces marginalization among vulnerable groups of people and contributes to the process of "chang[ing] social imaginaries in favour of non-hierarchical class, gender, and race relations" (Pavlovskaya 2018, 41). Since homelessness, housing insecurity, and

food insecurity are phenomena that are directly impacted by structural racism, classism, sexism, and heterosexism, it is necessary to center the evaluation of the tool around the experiences of college students from marginalized groups.

Public participation GIS (PPGIS) also provides a useful framework for assessing the Campus Cares Community App. PPGIS takes into account the impact that barriers to access can have on the use of geospatial artifacts. PPGIS assesses users' familiarities with GIS as well as 
the impact that geospatial tools have on decision-making processes (Tulloch 2008). In order to assess the strengths and weaknesses of the model, the Campus Cares Community App has been evaluated by stakeholders such as students who are experiencing homelessness, housing insecurity, and food insecurity and staff who work with - and support - students who are experiencing homelessness, housing insecurity, and food insecurity on college campuses.

\section{Evaluation Design}

The assessment of the Campus Cares Community App draws on participants' subjective assessments of usability with the System Usability Scale (SUS) along with participants' responses to five open-ended questions. Created in 1986 by John Brooke, the SUS is a reliable tool for measuring the usability of a system, application, or artifact which "consists of a 10-item questionnaire with five response options for respondents; from Strongly agree to Strongly disagree" (U.S. General Services Administration 2020, Brooke 2013, 30). The SUS evaluates systems, artifacts, and applications on their effectiveness in helping users complete activities, efficiency of resources (i.e., time, energy, etc.) expended while completing the activity, and the satisfaction of the user with the experience (Brooke 2013, 32).

This evaluation design was chosen because it is a reliable, valid measurement tool widely considered an "industry standard" for evaluating usability (Sauro 2011). While one of the disadvantages of using the SUS is that the SUS is considered complex to score (Sauro 2011, Sauro and Lews 2016, Klug 2017), one of the advantages of using the SUS is that it assesses the usability (or lack thereof) of a tool or artifact in a context-inclusive way. Brooke writes "given that usability in any given instance is defined by the context of the use of a system, it follows that in general, the way in which you measure usability will also necessarily be defined by that 
context" (Brooke 2013, 33). College students who are experiencing basic needs insecurities are operating in a variety of contexts that will shape the ways in which they interact with the Campus Cares Community App. For example, one student may use the application once while experiencing short-term homelessness to find housing, food, health care, or other services. Another student may use the application on a regular basis to find food because they are experiencing chronic, long-term food insecurity or homelessness. The centrality of context to the design and implementation of the SUS complements the needs of the potential users of this tool.

While the SUS is an effective assessment tool to use to measure the usability of a tool, it is not designed to capture qualitative feedback about usability (Sauro 2011, Brooke 2013). This evaluation also gives testers of the Campus Cares Community App the opportunity to provide qualitative feedback that may not have been elicited through the SUS by using a brief questionnaire containing five open-ended questions. The SUS used to assess the Campus Cares Community App is displayed in Table 7 and the five open-ended response questions are displayed in Table 8.

Table 7. System Usability Scale: Campus Cares Community Application

Directions: Please score the following 10 items with one of five responses that range from Strongly Agree to Strongly disagree:

I think that I would like to use this application frequently.

I found the application unnecessarily complex.

I thought the application was easy to use.

I think that I would need the support of a technical person to be able to use this application.

I found the various functions in this application were well integrated.

I thought there was too much inconsistency in this application.

I would imagine that most people would learn to use this application very quickly. 
I found the application very cumbersome to use.

I felt very confident using the application.

I needed to learn a lot of things before I could get going with this application.

\section{Table 8. Open Response Questions}

Directions: Please answer the following questions.

What do you like about this application?

What do you dislike about this application?

Is there anything that you would like to be added to this application?

Is there anything that you would like to be deleted from this application?

Are there any revisions that you would like to be made to this application?

\section{Evaluation Implementation}

The evaluation of the Campus Cares Community App was conducted during October-

December 2020. The SUS questionnaire and the five open-ended questions were compiled in a

Google Forms survey and disseminated via e-mail to staff who work with students who are

experiencing basic needs insecurities, faculty who are actively supportive of students

experiencing basic needs insecurities, and students at community colleges and public universities

in California. The survey included an informed consent form that preceded the SUS questions

and the qualitative questionnaire, approved by the Institutional Research Board at Claremont

Graduate University (IRB protocol \#3712). Participants were contacted and recruited to

participate in the assessment based on their professional expertise about students' needs and

lived experiences with basic needs insecurities. Five respondents participated in the evaluation. 


\section{Results \& Discussion}

The average (mean) SUS score of responses from the five SUS surveys administered to participants is 70 . Generally, an SUS score of 68 is average, with scores below 68 indicating lower than average usability and scores above 68 indicating higher than average usability (U.S. General Services Administration 2020). The results of the survey for the Campus Cares Community App suggest that the App has scored above average on the SUS and is therefore a potentially useful tool for stakeholders who need to find basic needs services. Table 9 shows the SUS scores associated with each participants' response and the average SUS score across participant responses.

Table 9. Evaluation Participants' System Usability Scale (SUS) Scores

\begin{tabular}{|l|l|}
\hline Participant ID & SUS score \\
\hline 1 & 90 \\
\hline 2 & 50 \\
\hline 3 & 90 \\
\hline 4 & 80 \\
\hline 5 & 40 \\
\hline & Mean $(\mu)$ SUS $=70$ \\
\hline
\end{tabular}

Sauro (2011) notes that "SUS scores are not percentages" and thus cannot be compared or analyzed until they are normalized or converted into letter grades. Sauro and Lewis (2016) and Klug (2017) suggest converting SUS scores into letter grades to present and communicate the meaning of the scores clearly and effectively to stakeholders who may not be familiar with results from SUS data. Table 10 shows the curved grading scale for interpreting SUS scores, as 
designed by Sauro and Lewis (2016). The SUS scores from the evaluation of the Campus Cares Community App have been converted into letter grades and displayed in Table 11.

Table 10. Grading Scale for SUS Scores

\begin{tabular}{|l|l|}
\hline Letter Grade & Numerical Score Range \\
\hline A + & $84.1-100$ \\
\hline A & $80.8-84.0$ \\
\hline A- & $78.9-80.7$ \\
\hline B + & $77.2-78.8$ \\
\hline B & $74.1-77.1$ \\
\hline B- & $72.6-74.0$ \\
\hline C + & $71.1-72.5$ \\
\hline C & $65.0-71.0$ \\
\hline C- & $62.7-64.9$ \\
\hline D & $51.7-62.6$ \\
\hline F & $0-51.6$ \\
\hline
\end{tabular}

Table 11. Evaluation SUS Scores Converted into Letter Grades

\begin{tabular}{|l|l|l|}
\hline Participant ID & SUS score & Letter Grade \\
\hline 1 & 90 & A + \\
\hline 2 & 50 & F \\
\hline 3 & 90 & A+ \\
\hline 4 & 80 & A- \\
\hline 5 & 40 & F \\
\hline & Mean $(\mu)$ SUS $=70$ & Mean $(\mu)$ Letter Grade: C \\
\hline
\end{tabular}


The average letter grade for the administered SUS surveys is a $\mathrm{C}$ which suggests that the participants who tested the Campus Cares Community App believe it is a tool that is usable. While these results show that the usability of the Campus Cares Community App is above average, these results do not provide specific recommendations about how to improve the usability of the tool. Table 12 illustrates the results from the five qualitative, open-response survey questions that appeared in the evaluation after the SUS survey questions were administered.

The answers to these questions provide us with more information about the strengths and weaknesses of the usability of the App. For example, one participant noted: "The App is simple and easy to navigate." Another participant shared: "I like the userface and the ability to include a map with the location of each place." These responses show which features of the App contributed to testers' positive experiences with usability.

Additionally, participants' responses to the open-ended questions illustrate ways to improve the usability of the App. For example, one participant wrote: "The only thing that was unclear to me was the messaging portion. Who are you able to message within the app? Service providers? Other users? Both?" This feedback shows that the usability of the messaging feature of the app can be further enhanced and clarified. Another participant expressed confusion over how to navigate through the home page and the categories page: "It seems like there are two different looks for the Categories page, and I saw one right after the other, though it is unclear to me how you go from one view to another." These comments show that some of the features of the App present challenges for users and require improvements. 
In addition to providing crucial insights about the usability of the App, the answers to the open-ended questions also illuminate ways in which the content and features of the App can be improved so that the utility of the App increases. For example, one participant shared the idea of adding "services for women, children/youth services" to the category filters. Another participant suggested adding a tutorial video with audio and visual instructions to teach new users how the App works.

Participants also posed thought-provoking questions in their responses that should be considered when planning the implementation of the App. For example, a respondent shared: "I am wondering how it will be populated when a school first purchases it." This is a very important question that would need to be addressed before beginning to administer the App to student users on campuses. Another participant posed questions about the growth of the App: "What happens as these lists become longer and longer? How will you navigate this? ... how will you orient people as the amount [of] data in the system grows?" As more services are added to the App and more users engage with the App, the data needs of the App will increase, potentially causing problems for users unless necessary adjustments are made. Anticipating changing data needs, storage needs, and an increased number of users is central to the implementation process as seen in Table 12.

Table 12. Participants' Answers to Open-Response Questions

\section{Question: What do you like about this application?}

I love that this will be at the student fingertips any time of the day.

I like the userface and the ability to include a map with the location of each place.

Students would benefit greatly from an app like this.

I love the services that this app focuses on. It is so clear to me that there is a need for an app 
like this one. I really like that the information is a crowd sourced with personal ratings. As people encounter more resources, they can share them within the application. The nature of the target audience, plus the nature of creating access to avenues of support, makes this application inherently community oriented and directed. I like the nature of the app and the categories covered. I can see service providers engaging with this app as well.

The App is simple and easy to navigate.

\section{Question: What do you dislike about this application?}

I wouldn't say I dislike anything. I am wondering how it will be populated when a school first purchases it.

I saw that the demo was on an iphone. Is it compatible with android and a web browser as well?

Nothing really it just needs to be finished and all resources added.

It seems like there are two different looks for the Categories page, and I saw one right after the other, though it is unclear to me how you go from one view to another.

Nothing

\section{Question: Is there anything that you would like to be added to this application?}

I think it covered everything. I am sure once it is up and running there will be more suggestions.

NA

A short and simple tutorial on how to use (visual and audio).

No. I'm glad that there are filters in the app. Can you filter for services for women, children/youth services? When you go into each category, you see the existing listings. Currently, they are short. What happens as these lists become longer and longer? How will you navigate this? Is this app meant to only be used in a certain area of the country, state, or all over the country? If so, how do you orient people in terms of their location, or, alternatively, how will you orient people as the amount data in the system grows?

No

Question: Is there anything that you would like to be deleted from this application?

No

Make sure resources are geared towards area and user. 
No. I appreciate the existing scope of the application.

Nonresponse

Nonresponse

Question: Are there any revisions that you would like to be made to this application?

No

At this point, no.

This is a great idea and will assist all who use it.

No. The only thing that was unclear to me was the messaging portion. Who are you able to message within the app? Service providers? Other users? Both?

Nonresponse

\section{Conclusion}

The design and assessment of the Campus Cares Community App presents an idea for using geospatial tools to connect college students experiencing basic needs insecurities with oncampus and off-campus services that they need, but may not use on their own without facilitation, encouragement, or assertive guidance (Crutchfield and Maguire 2018, Mello 2018). The evaluation demonstrates that, with continued improvements and iterations, the Campus Cares Community App presents users with a helpful, usable tool for navigating basic needs services. The design and evaluation of the Campus Cares Community App represents an example of how to use geospatial tools to shape "geographies of hope and care" (Pavlovskaya 2018) by supporting college students who are experiencing basic needs insecurities. 


\section{Conclusion}

College students who are experiencing basic needs insecurities in California face a myriad of challenges to engaging with educational, employment, and economic opportunities. The research agenda in academia and the public policy agenda in California are beginning to confront and address the realities faced by students who are experiencing these conditions. However, there have been very few uses of geospatial tools, applications, and methods in the academic literature and the policy research on this topic. This dissertation explores practical applications and potential uses of geospatial tools and technologies to enhance service delivery to college students who are experiencing basic needs insecurities. The objective of this research project is to design a tool to support students experiencing homelessness, housing insecurity, and food insecurity in California. Through three iterative design cycles and an assessment cycle, this objective was met with the design, development, and evaluation of the Campus Cares Community App.

The Campus Cares Community App differs from pre-existing tools designed to support students and other target populations experiencing basic needs insecurities, such as the Wellbeing Map, the Los Angeles Food Bank service locator, and the Homeless Service Locator App. The Campus Cares Community App differs from other tools because it offers one target population (college students) a mobile application for service navigation both on-campus and off-campus. The three aforementioned pre-existing tools were web-based applications, with two out of the three tools assuming a broad group of users composed of people at different stages in their lives experiencing different types of homelessness (e.g. chronic homelessness, couch surfing, living in a vehicle, camping, students experiencing homelessness, families experiencing homelessness, older adults experiencing homelessness, etc.). 
Additionally, the pre-existing tools would have presented college students experiencing basic needs insecurities with either on-campus service options (e.g. the Wellbeing Map) or offcampus service options (e.g. the Los Angeles Food Bank service locator or the Homeless Service Locator App), but not both simultaneously. The Campus Cares Community App presents student users with information about both on-campus and off-campus services in a mobile application with content that is targeting college students' needs specifically. This tool also differs from previously constructed service navigation tools in that it offers students experiencing basic needs insecurities more opportunities to participate in the design and development of the tool in consultation with the application's administrators at a particular campus. Also, students' agency is further enhanced because they can communicate with the App administrators through the chat feature of the app to ask questions, connect with a counselor or other campus staff member, or suggest adding services. They can also rate services and leave reviews so that their peers can learn more about other students' experiences with a service provider.

In future iterative cycles, it would be beneficial to develop Android and web browser versions of the App so that the tool can be tested on - and eventually reach - all users, and not just iPhone users. Additionally, the Campus Cares Community App is currently only available in English. However, in future design stages, it would be useful to expand the language options for the App so that more students can interact with the tool. It may also be helpful for users to revise or add to the existing service categories. For example, adding a category for services for women or adding a category for services for students who are parents may help direct students from these groups to services more efficiently and effectively.

The evaluation of the Campus Cares Community App found that the tool was userfriendly and appropriate for the target population, with an SUS score of 70 and positive feedback 
from the qualitative questionnaire. These findings are likely the result of the iterations that elicited feedback and ideas from students, and the staff and faculty who work with students who are experiencing basic needs insecurities. By asking students, and people who work closely with students, what they need or want to be included in the design of a tool, the application was able to effectively respond to the needs of the users. These findings imply that when designed in consultation with people who have knowledge of a condition based on their lived experiences of that condition (i.e. homelessness, food insecurity, etc.), geospatial tools can provide practical alternatives or supplements to traditional forms of service navigation.

While the iterations that included feedback and ideas from users were crucial for testing the application's usability, the sample sizes of participants in both the brainstorming survey cycle $(\mathrm{N}=9)$ and the evaluation cycle $(\mathrm{N}=5)$ were not large enough to draw firm conclusions about the tool's utility across a variety of institutional, temporal, and geographic contexts. Future research projects can include additional tests of the application with a larger sample size of testers, before implementation of the application occurs. After additional feedback from assessments has been collected and incorporated into the design of the tool, a plan for pilot testing and implementing the application on a campus should be developed in concert with service providers, college administrators, staff, faculty, and students.

Furthermore, this research project focused on developing a tool for students experiencing basic needs insecurities in California, so the findings may not be as relevant to stakeholders or institutions of higher education operating in other states, territories, or countries. As such, the findings from this study may not be externally valid. Future research projects can determine the usability of this type of tool in other contexts and for other target populations. For example, a modified version of this tool might be useful as a service navigation tool for people who are 
experiencing homelessness who are not college students. Or, a revised version of this application might be useful for connecting foster youth who are transitioning out of the foster care system to basic needs services.

This tool presents a new opportunity for service navigation for students that may reduce students' hesitancy or fear of seeking out services due to the stigmatization of basic needs insecurities. However, the use of this tool alone will not be able to adequately address the problem that many college students in California are unable to meet their basic needs for survival. Solving this problem in its entirety will involve significant resources such as financial resources, political resources, and resources such as time, energy, expertise, and personnel. Ameliorating college students' experiences with basic needs insecurities will also require cooperation and coordination among local, state, and federal policymakers, educators, administrators, students, service providers, and community members. In order to best support college students experiencing basic needs insecurities, it is imperative to dismantle the inequitable political, economic, and educational systems that have caused and perpetuated basic needs insecurities. 


\title{
Appendix 1 \\ Instructions for Staff, Faculty, and Administrative Providers - How to Build an Application for Service Navigation Using QuickCapture (Esri)
}

\begin{abstract}
*Please note: If you find any of the directions below confusing or if you are a visual learner, then please watch this brief tutorial produced by Adam Corcoran of Esri Ireland, available on Youtube: Click here to view a step-by-step instructional video about how to create the provider's tool for capturing data about services via QuickCapture.
\end{abstract}

Step 1: Log-in to your ArcGIS Online account.

Step 2: Click on "content" at the top of the page.

Step 3: Click on "Create" and then choose "Feature Layer".

Step 4: Create and configure your hosted feature layer. Create a new field within your hosted feature layer. The new field that you created in your hosted feature layer could be titled "type of service" or "student services", as it will encompass all of the service categories. Click on the title of the field and create a list. Each list item within the field represents a different service category that will have a different icon when your application is finished, so you can title each item on the list housing, food, health care, etc. For more information about what hosted feature layers are and how to create them, check out this tutorial prepared by Shannon Cox of Esri: "Working with Hosted Feature Layer Views in ArcGIS Online". You may also want to watch the brief video tutorial mentioned above, titled How to Configure ArcGIS QuickCapture to learn how to properly configure your hosted feature layer. Make sure that you have saved your hosted feature layer before continuing on to Step 5.

Step 5: On the web page titled "My projects" click on the orange and white rectangular icon in the top right of the page titled "+ New project".

Step 6: Select the feature layer that you would like to use for the project (the layer that you created and configured in Step 4).

Step 7: You will be directed to the page titled "Create project". Begin creating the project by clicking on the orange and white "create" icon in the bottom right corner of the page.

Step 8: To configure each label for each icon, click on the icon and edit the label, size, colors, images, and shapes on the right side of the screen. If you add images to your icons, make sure to use public domain images that will not violate copyright agreements, such as images found in Wikimedia Commons. You can also click on "Data" on the right side of the customizing page to add a phone camera's functionality to your icons. If you would like to be able to include a photo 
of the location that you are going to capture, then make the camera functional by clicking "Required" under "Take Photo".

Step 9: When the icons are configured to your preferences, click on the orange and white icon titled "save" in the top right corner of the screen.

Step 10: Download the QuickCapture application from your smart phone's AppStore by searching for "QuickCapture" in the Apple, Android, or Google AppStore.

Step 11: Log-in to your ArcGIS Online account in the application on your phone.

Step 12: You can scan the QR code on your desktop or laptop screen (still open with your QuickCapture project up on the screen) to download your project directly to the mobile QuickCapture application. Or, if you already see your project on the "My workspace" screen, touch the icon with your project's title. You should see your project and all of the icons and categories will appear, looking the way that you designed them to look.

Step 13: When you are ready to capture a location, touch the icon for the category of the location you are trying to capture (e.g., housing, food, etc.). The screen should turn into a camera.

Step 14: To take the photo and capture the location of the service, tap the white circle. You should see the image that you just captured frozen on the screen.

Step 15: If you are satisfied with the image, touch the orange and white "Done" icon in the bottom right corner of the screen. If you are unsatisfied with the image and you would like to retake the photo, touch the white " $\mathrm{X}$ " in the top left hand corner of the screen and take the photo again.

Step 16: After you have touched the "Done" icon, you should be automatically redirected to the main page of the application where you can see all of the icons with their different categories. In the top right corner of the screen, touch the white and gray square box. You will be redirected to a screen that says "Records on device". If this screen says "All records sent" then you do not have to do anything else - your locations have been captured. If this screen lists records of locations captured, touch the icon titled "Send".

Step 17: Return to ArcGIS Online. Make sure that you are logged in and then click on "content" on the top of the screen.

Step 18: Return to your project's hosted feature layer by clicking on the title of your hosted feature layer to open it. Click on "Open in Map Viewer" . 
Step 19: When your hosted feature layer has opened, click on "Save". A box titled "Save Map" will open.

Step 20: Choose a title, tags, summary, and saving location for your map. Then click the blue "save map" icon.

Step 21: Return to "My Content".

Step 22: Click on the title of the map that you just created.

Step 23: Click on "Create Web App". Choose the "Web AppBuilder" option for configuring your application.

Step 24: Create a title, tags, summary, and save location for your application. Then click "Ok".

Step 25: Return to "My Content". Click on your newly created application. Click "View Application". You should be able to view the locations that you captured using the QuickCapture Mobile Application on your Web App.

Step 26: In order to edit your Web App and configure the styles and functions, click on "Edit Application" to begin adding to, and revising, your application. For more information on configuring your Web App, check out the online reference guide titled "WebApp Builder for ArcGIS" produced by Esri. For more information about, and examples of, WebApps for ArcGIS Online, visit the Web AppBuilder for ArcGIS website: Web AppBuilder for ArcGIS.

Step 27: You can continue to capture locations using your QuickCapture application on your mobile device. You can delete locations of services that are no longer available or out of date by deleting the point on the map in your hosted feature layer or in your Web App by editing your hosted feature layer or application.

\section{Instructions for Student Users:}

Directions for using the application with a web browser (e.g., Google Chrome, Explorer, Safari, etc.):

Step 1: Click on the shared link to open the Web App

(http://agis.maps.arcgis.com/apps/webappviewer/index.html?id=e75038415fe2454d8e2fl ba2d7f $\underline{16 \mathrm{~b} 73})$.

Step 2: On the right side of the page, you will see color-coded circles that represent locations for different service categories such as food, housing, etc. 
Step 3: On the map, click on the point that corresponds with the color of the service that you are looking for. For example, if you are looking for access to showers, click on a yellow dot representing "Personal Care".

Step 4: When you click on the point on the map, a box will appear that contains three links to attached files. The first file is a .jpeg that displays a photograph of the location of the service. The second link is a .jpeg that contains information about how, when, and where to access the service (e.g., opening hours and days, need to bring a student ID, etc.). The third link is a .pdf that contains the same exact information as the second link, just in .pdf format. You can also click on "zoom to" to zoom into that location on the map.

Step 5: When you have found the service that you would like to use, you can print information about that service using the print icon in the top right hand corner of the page. Or, you can get directions from your location to the service location using the ${ }_{\mathrm{B}}^{\mathrm{A}} \mathrm{Z}_{\mathrm{B}}$ icon in the top right hand corner of the page. 


\section{Appendix 2 \\ Workflow images}

Figure 8 shows the administrator's view of the QuickCapture application. Administrators can edit, add, or delete photos associated with different points on the map that were captured using the QuickCapture mobile application. Also, administrators can upload a PDF and/or JPEG containing pertinent information about the service (e.g. name of service, address, contact phone number, hours of operation, what to bring, whether or not an appointment is necessary, etc.).

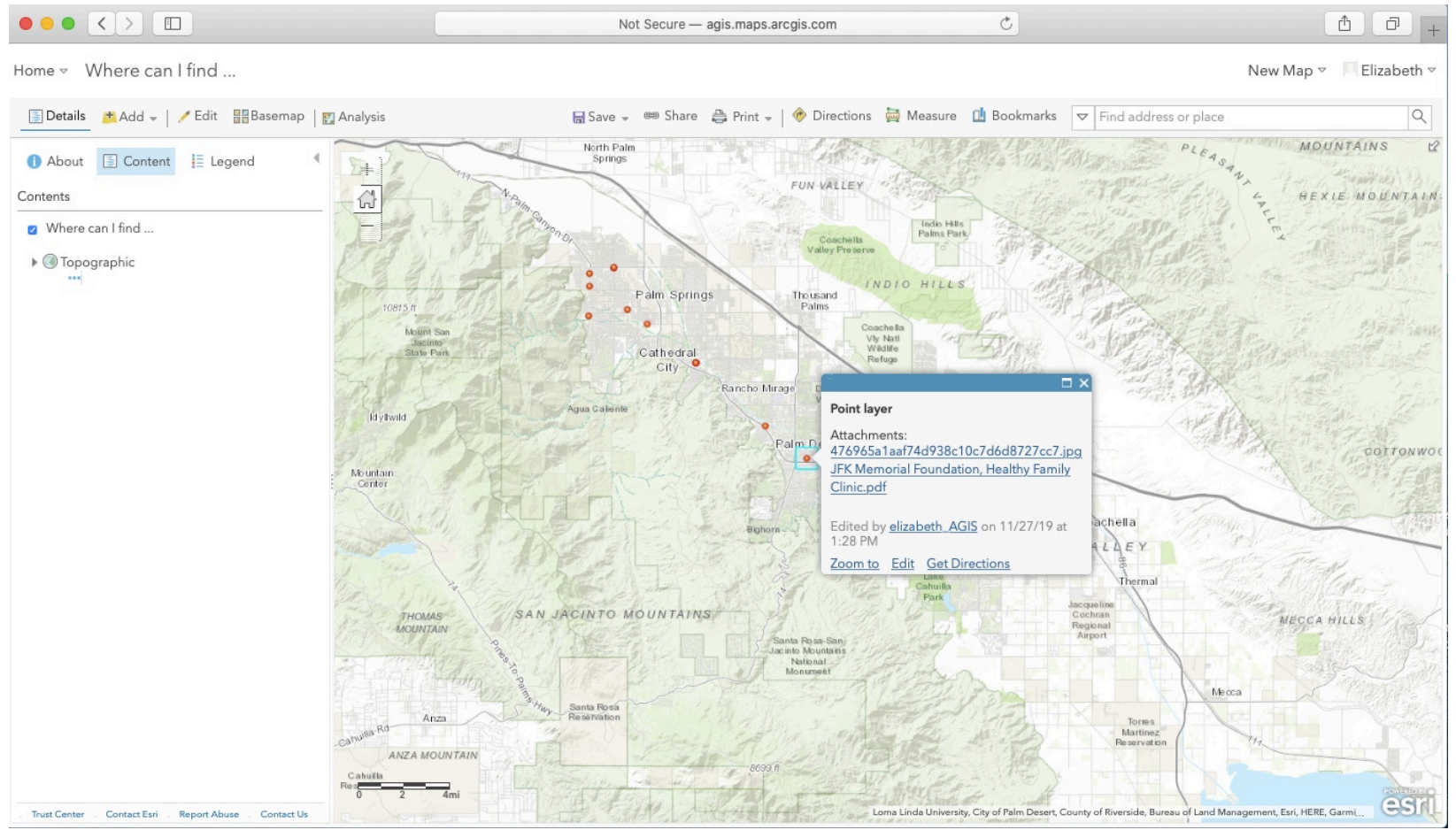

Figure 8. QuickCapture Administrator's View

The point layer that was created from capturing locations of services using the QuickCapture mobile application can also be used to develop a web-based application using the WebApp Builder in ArcGISOnline. Figure 9 shows the first iteration of this web-based application and Figure 10 shows the second iteration of this web-based application. Additionally, Figure 10 displays the web-based application's directions tool that helps users find directions to a location within the application. 


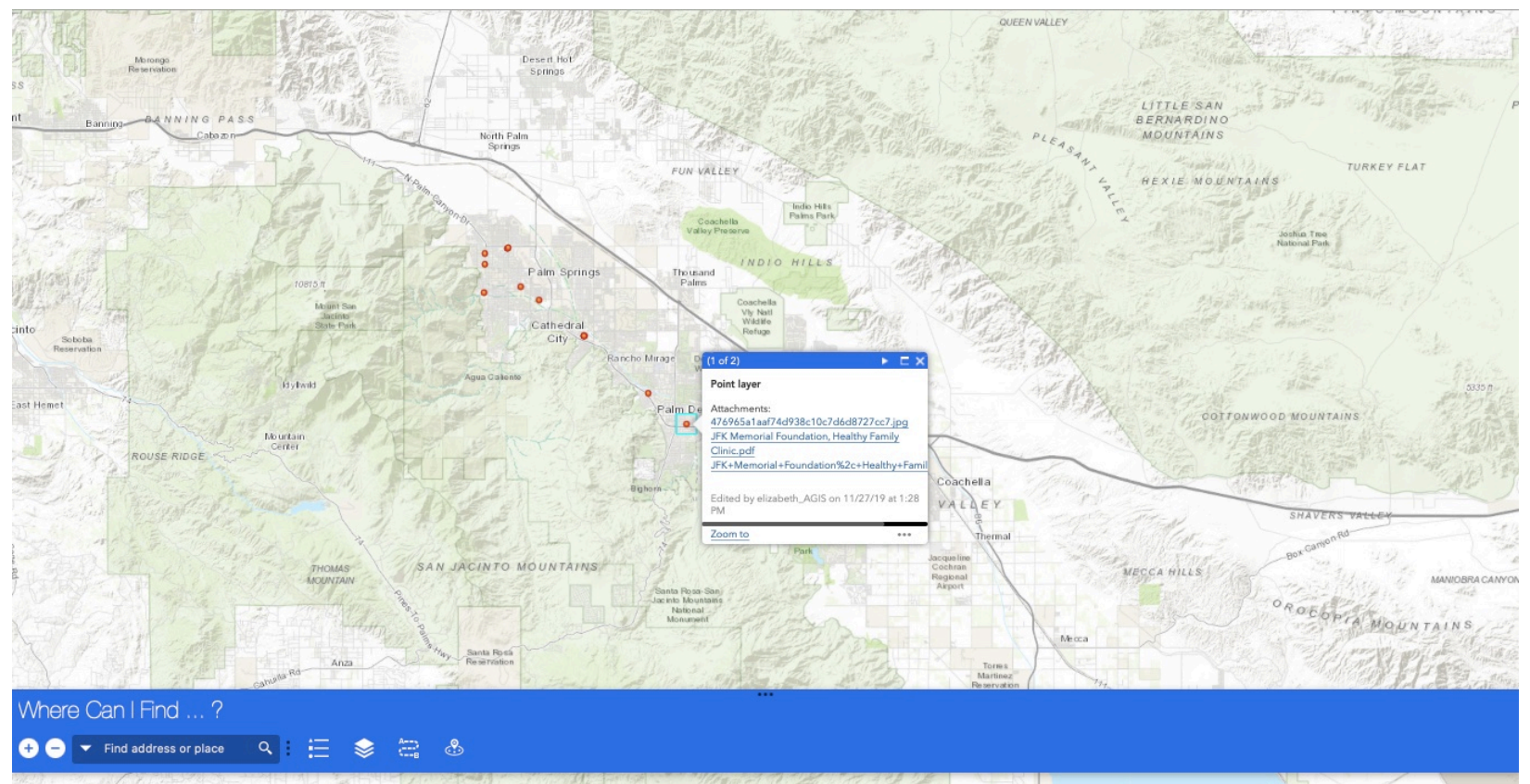

Figure 9. Early Stage of Design of Web-Based Application

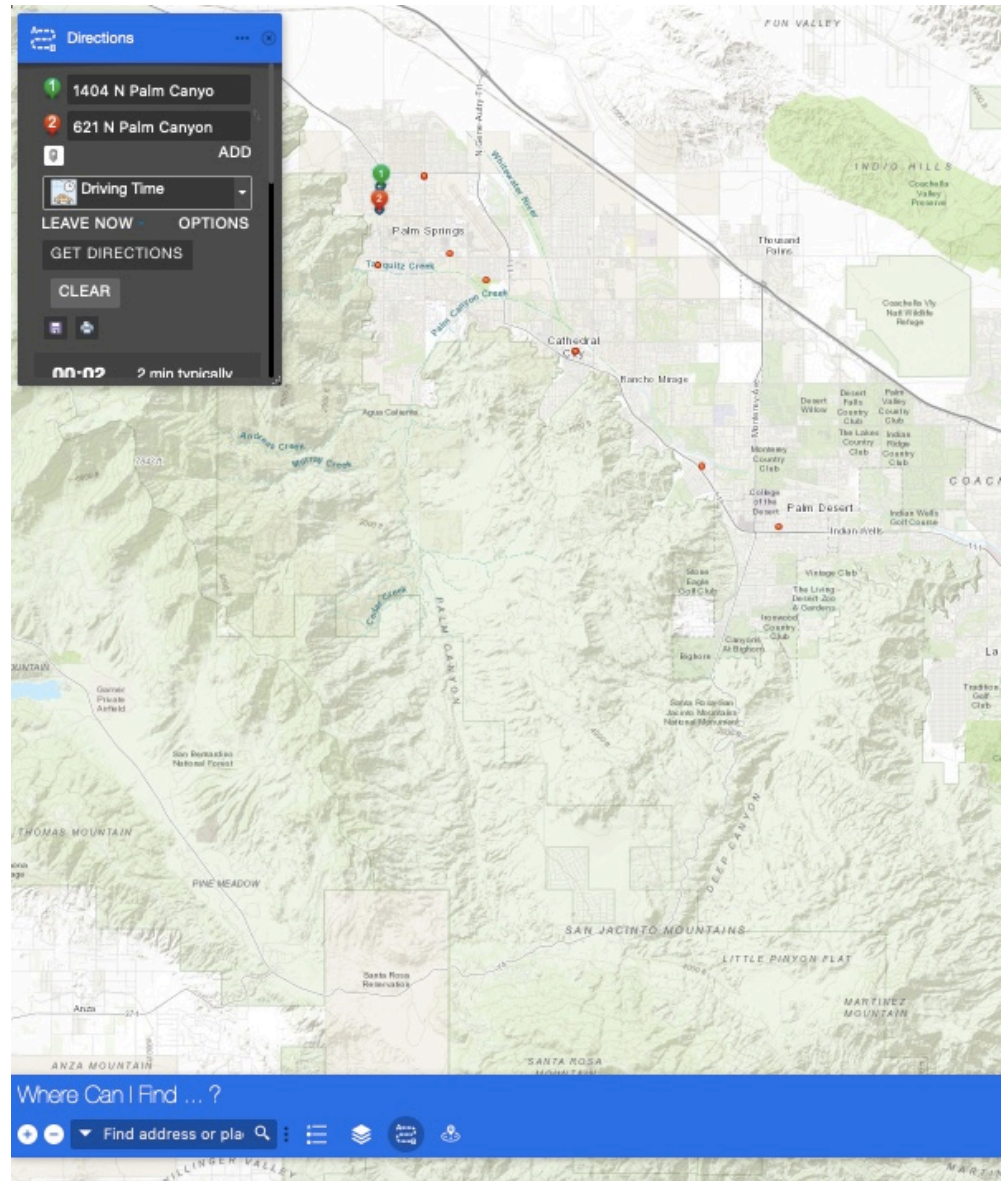

Figure 10. Web-Based Application with 'Directions' Feature

Figures 11-22 display screen views of the Campus Cares Community App. 


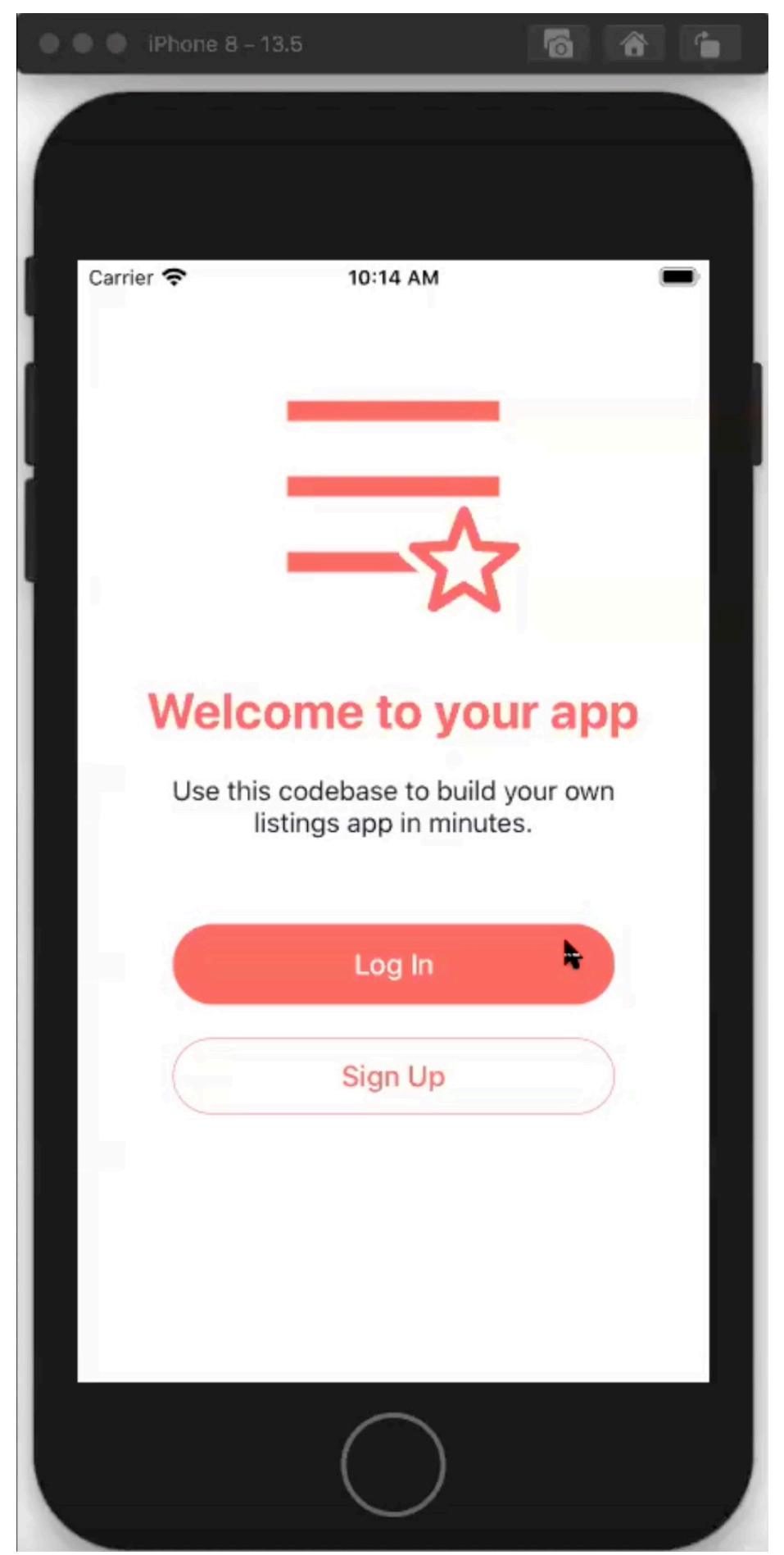

Figure 11. Campus Cares Community App Log In Screen 


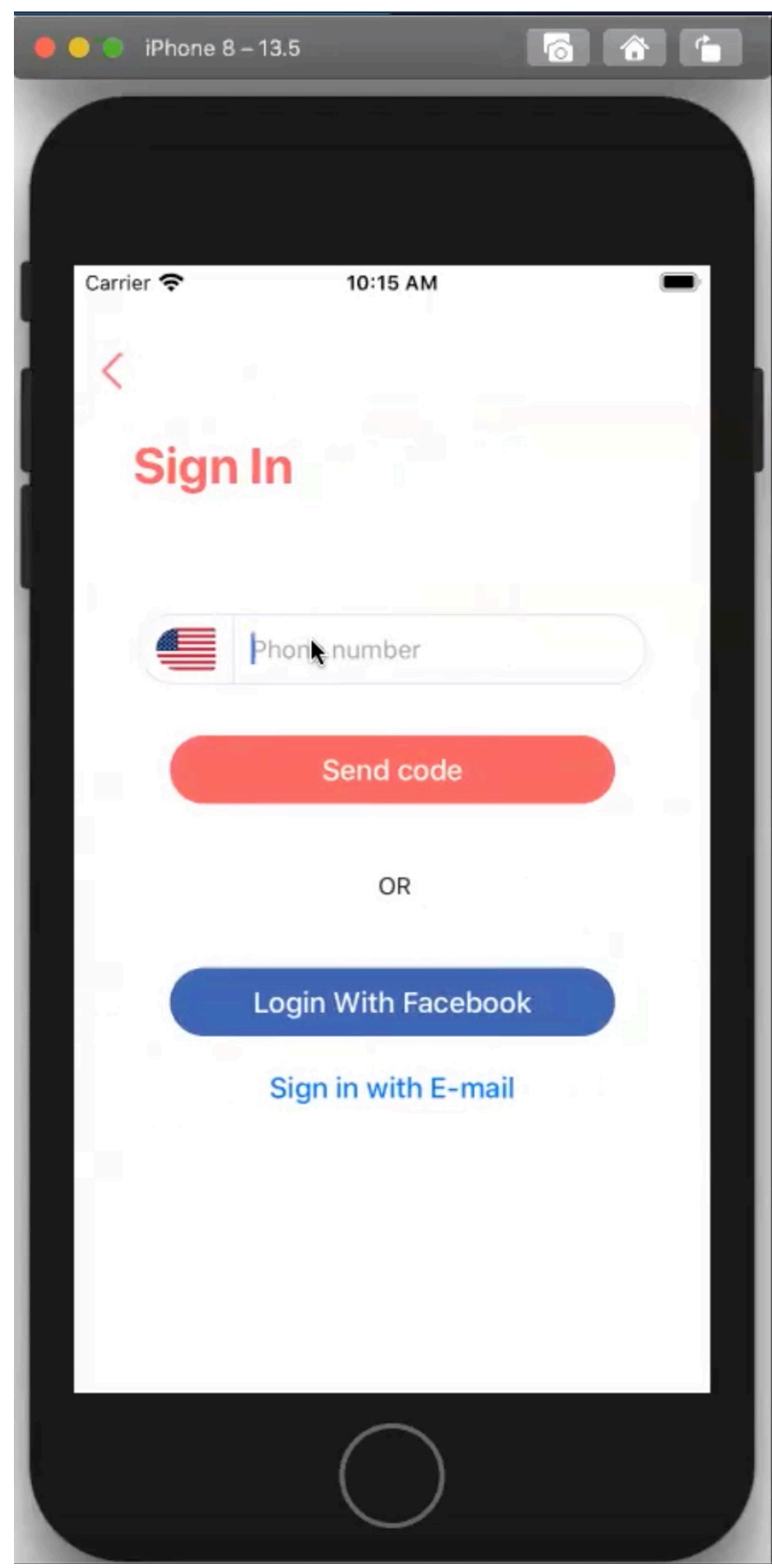

Figure 12. Campus Community Cares App Sign In Screen 


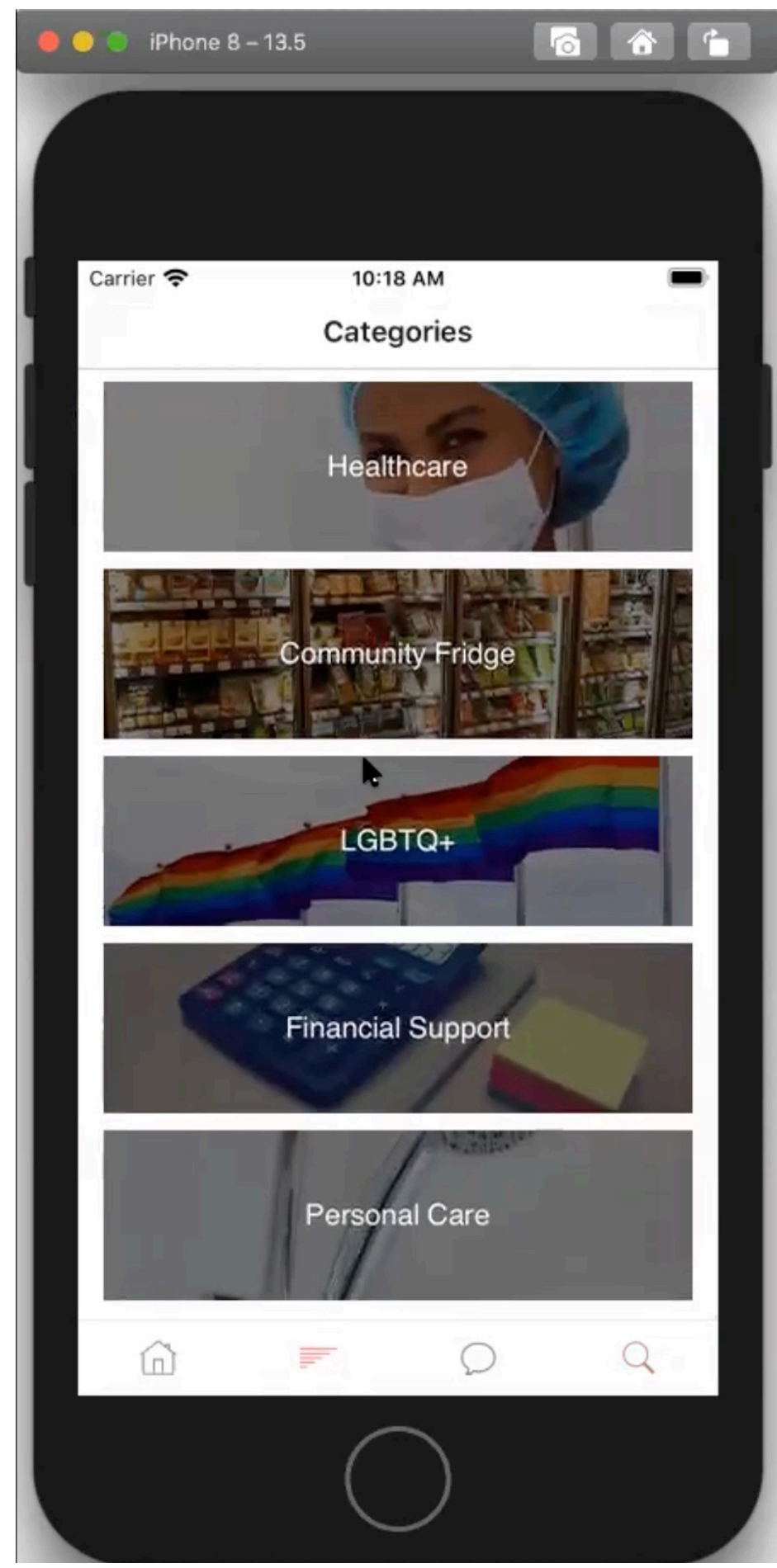

Figure 13. Campus Cares Community App Service Category Selection Screen 


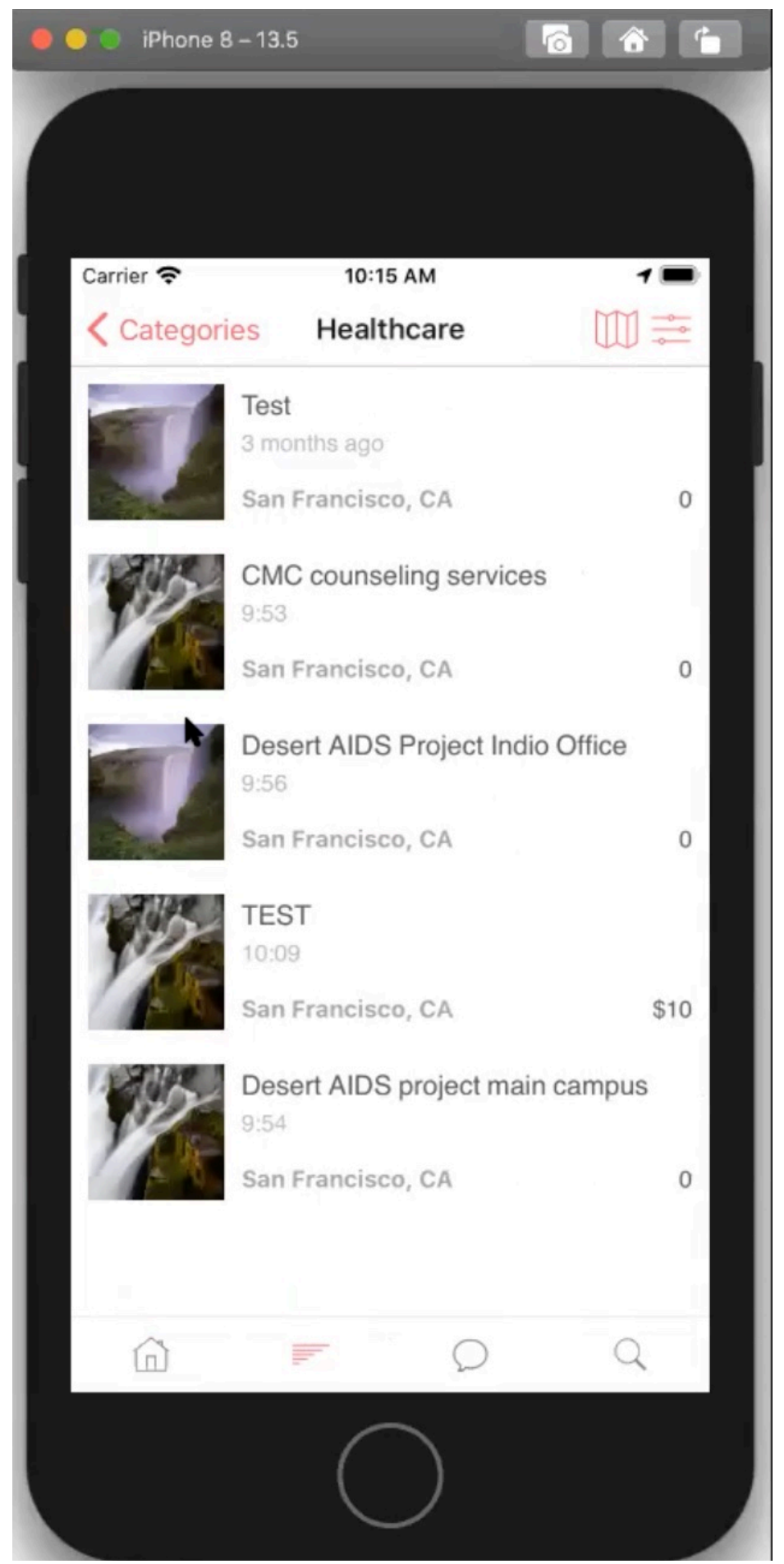

Figure 14. Healthcare Category Screen Showing List of Healthcare Services 


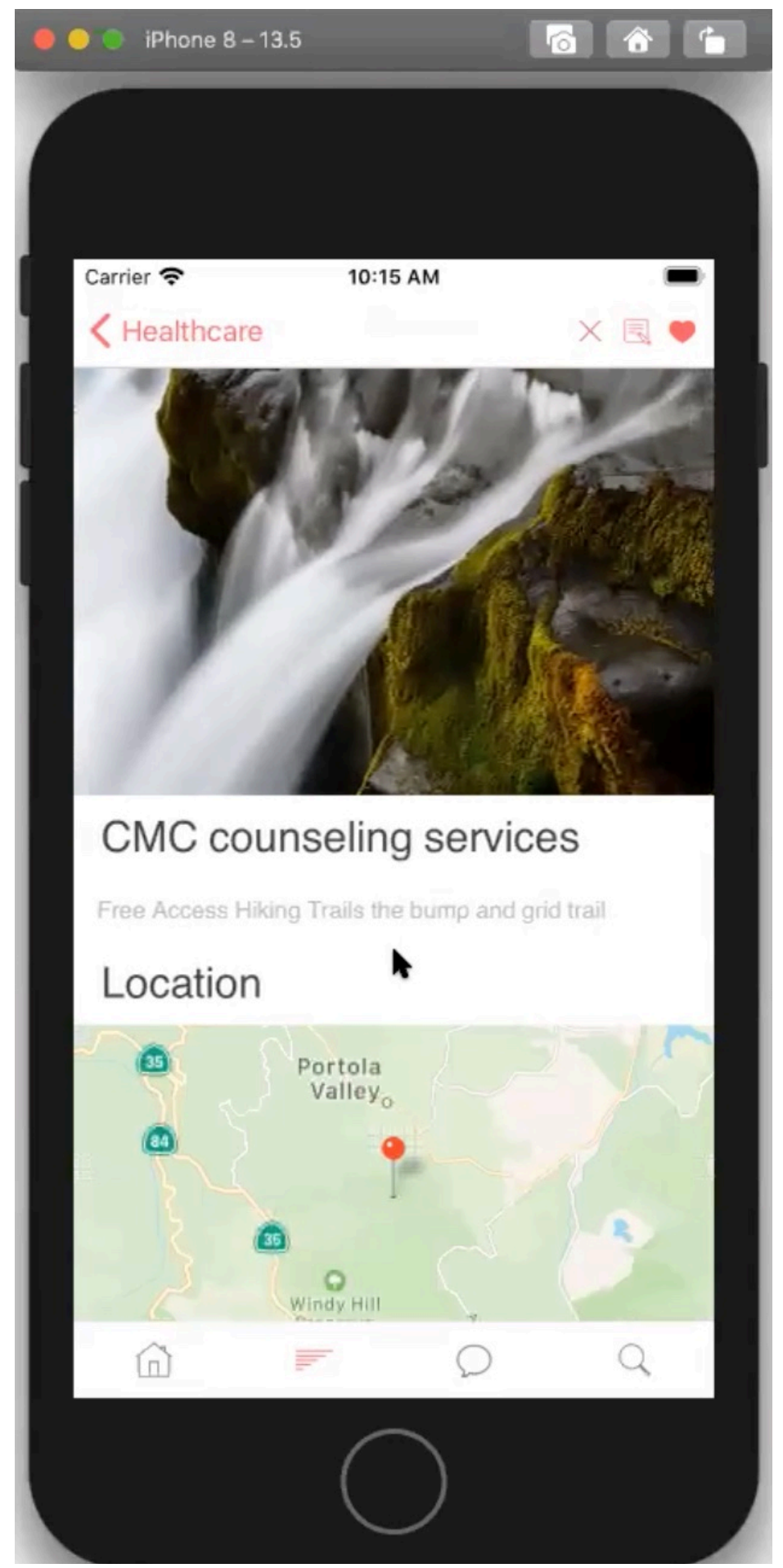

Figure 15. Healthcare Service Screen with Name of Service, Location, and Information 


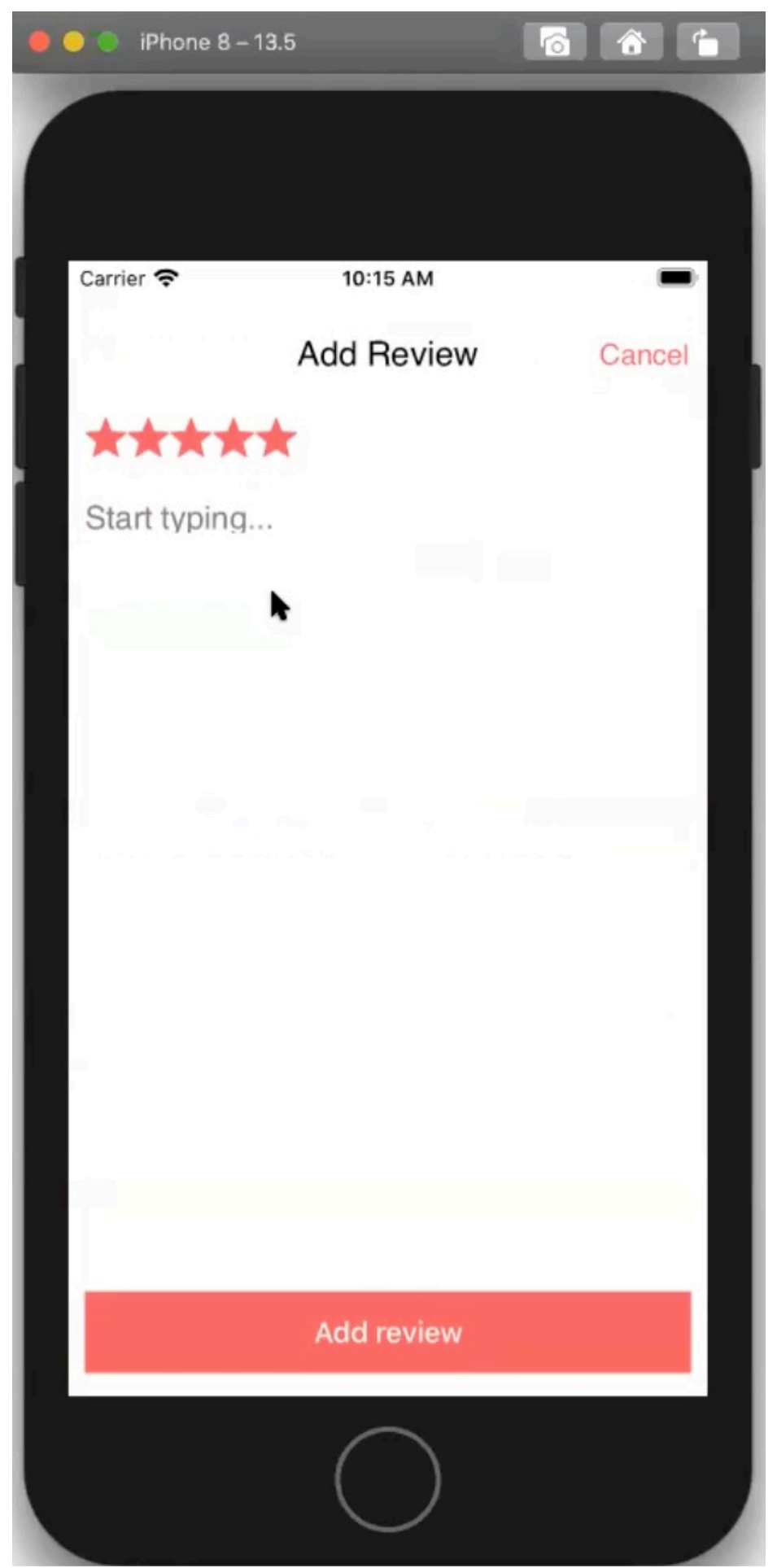

Figure 16. Service Review Screen 


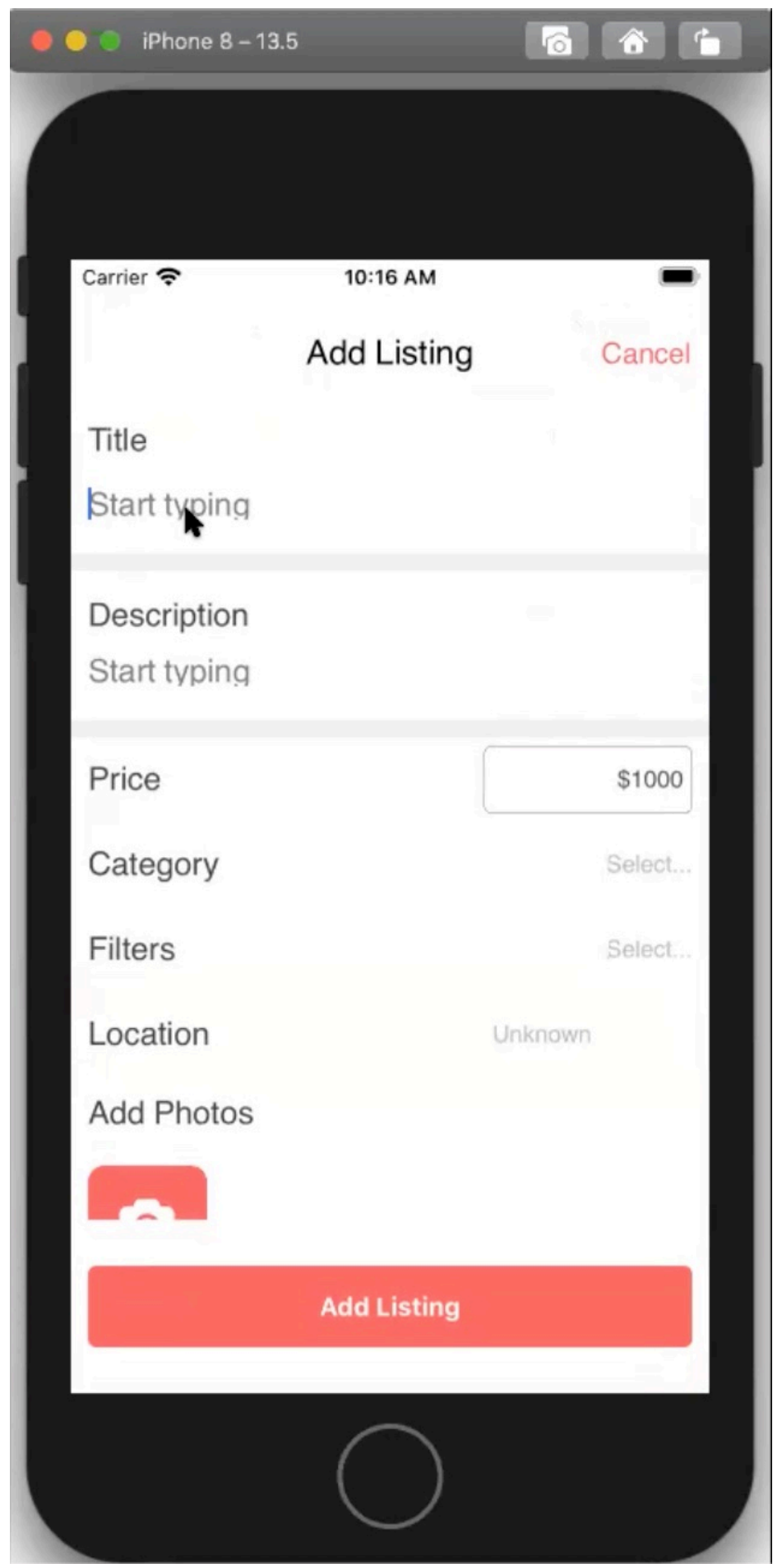

Figure 17. Add Listing Screen 


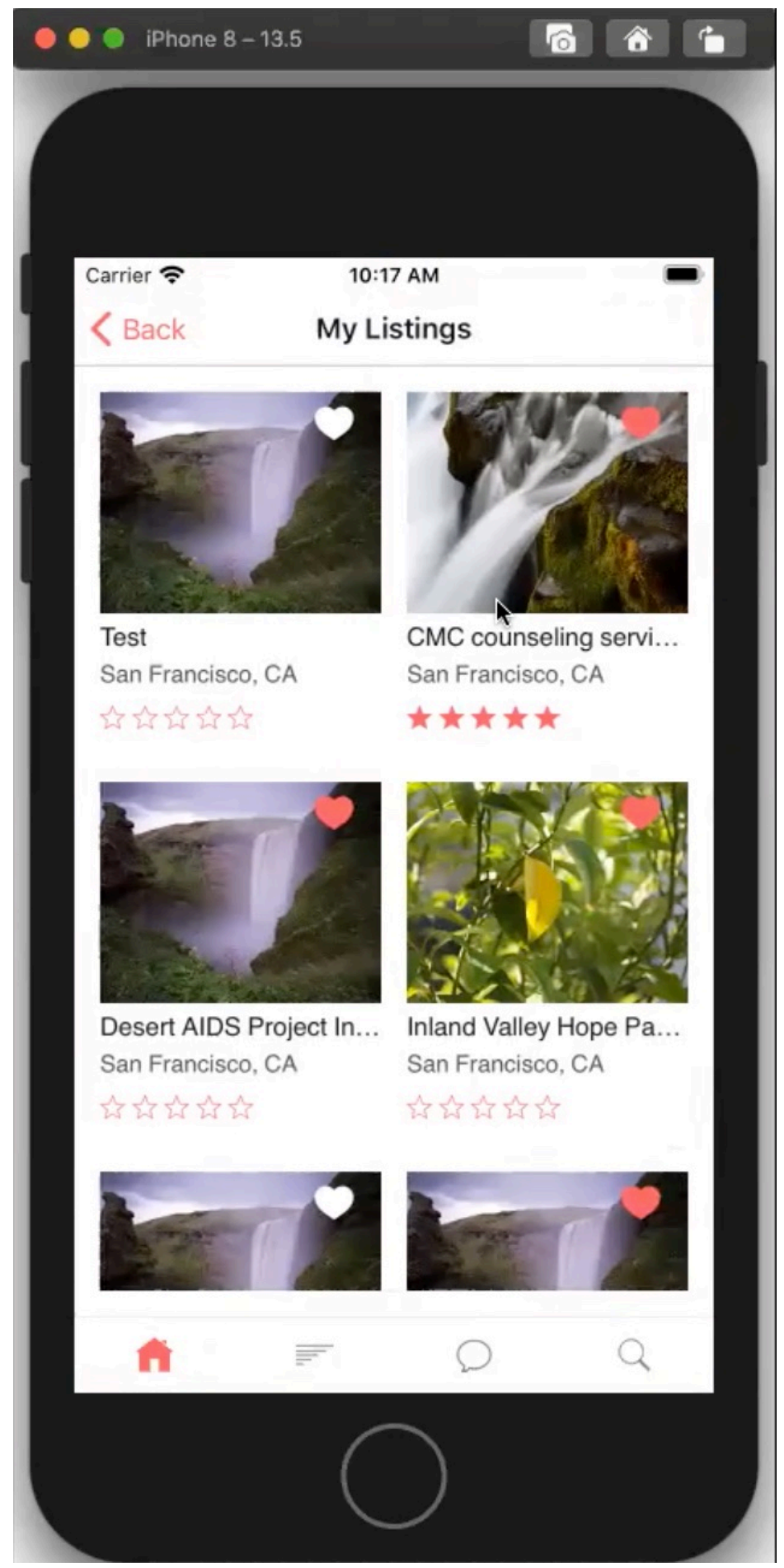

Figure 18. User Favorites Screen 


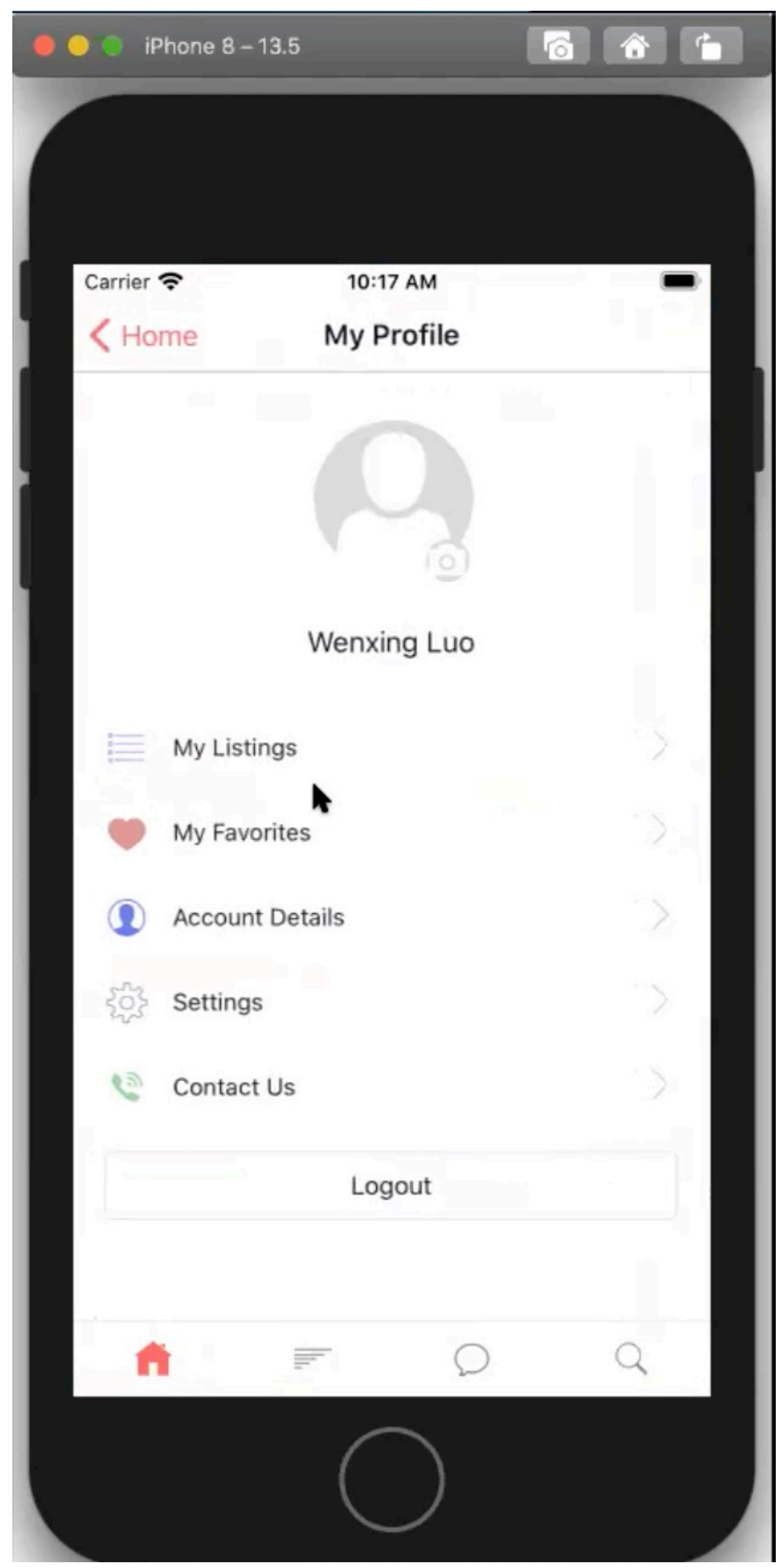

Figure 19. User Profile Screen 


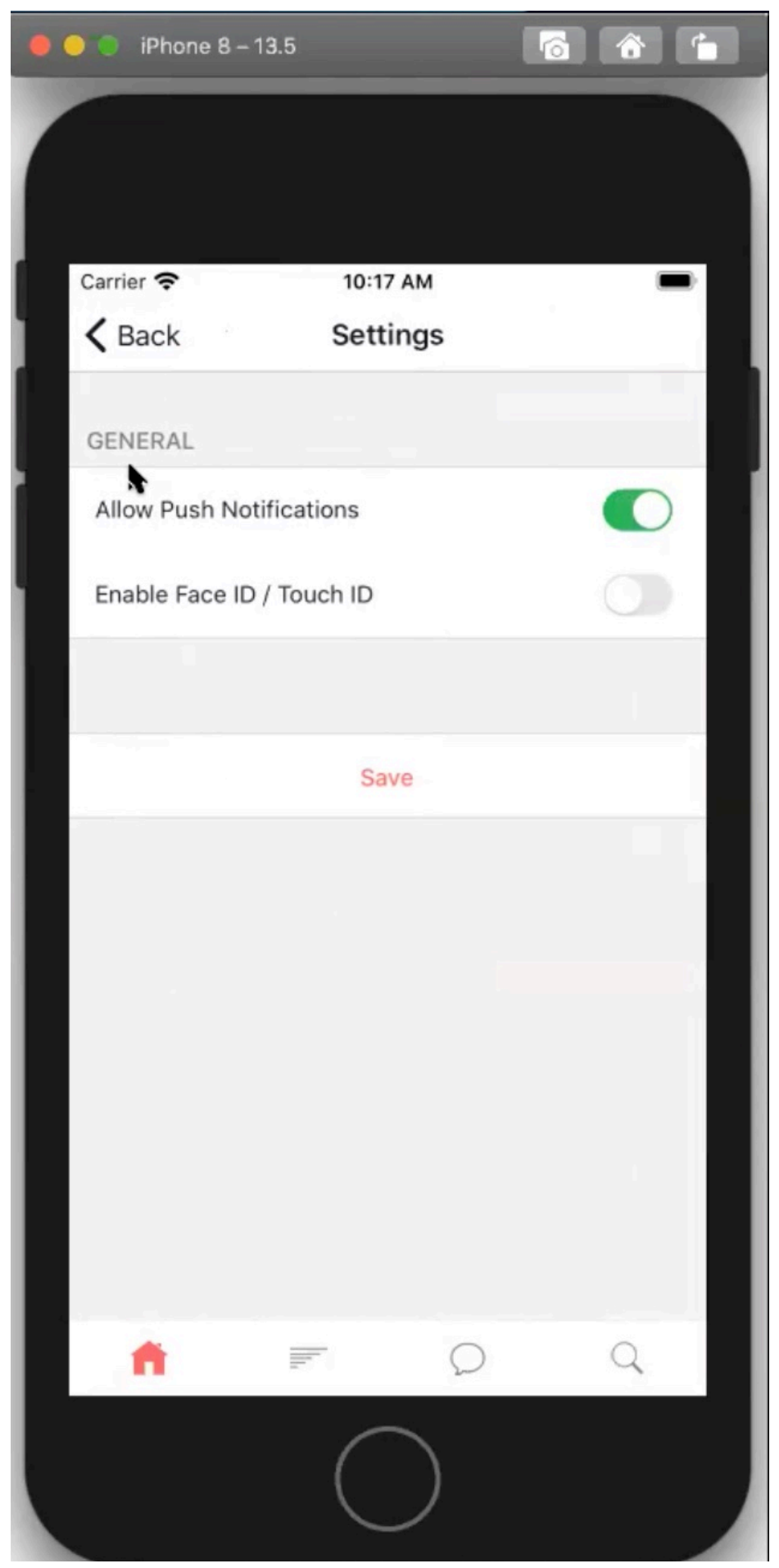

Figure 20. User Settings Screen 


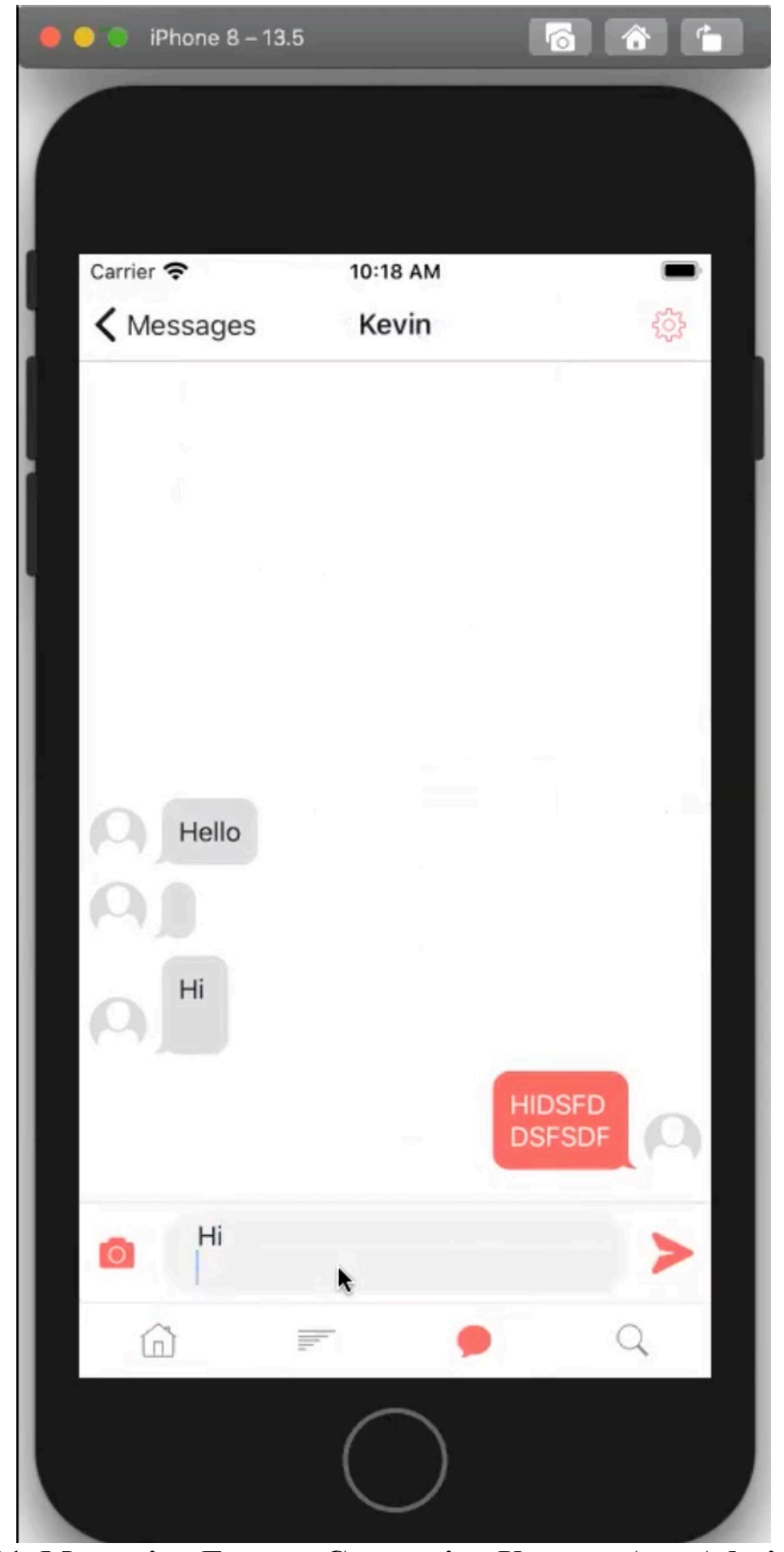

Figure 21. Messaging Feature Connecting Users to App Administrator 


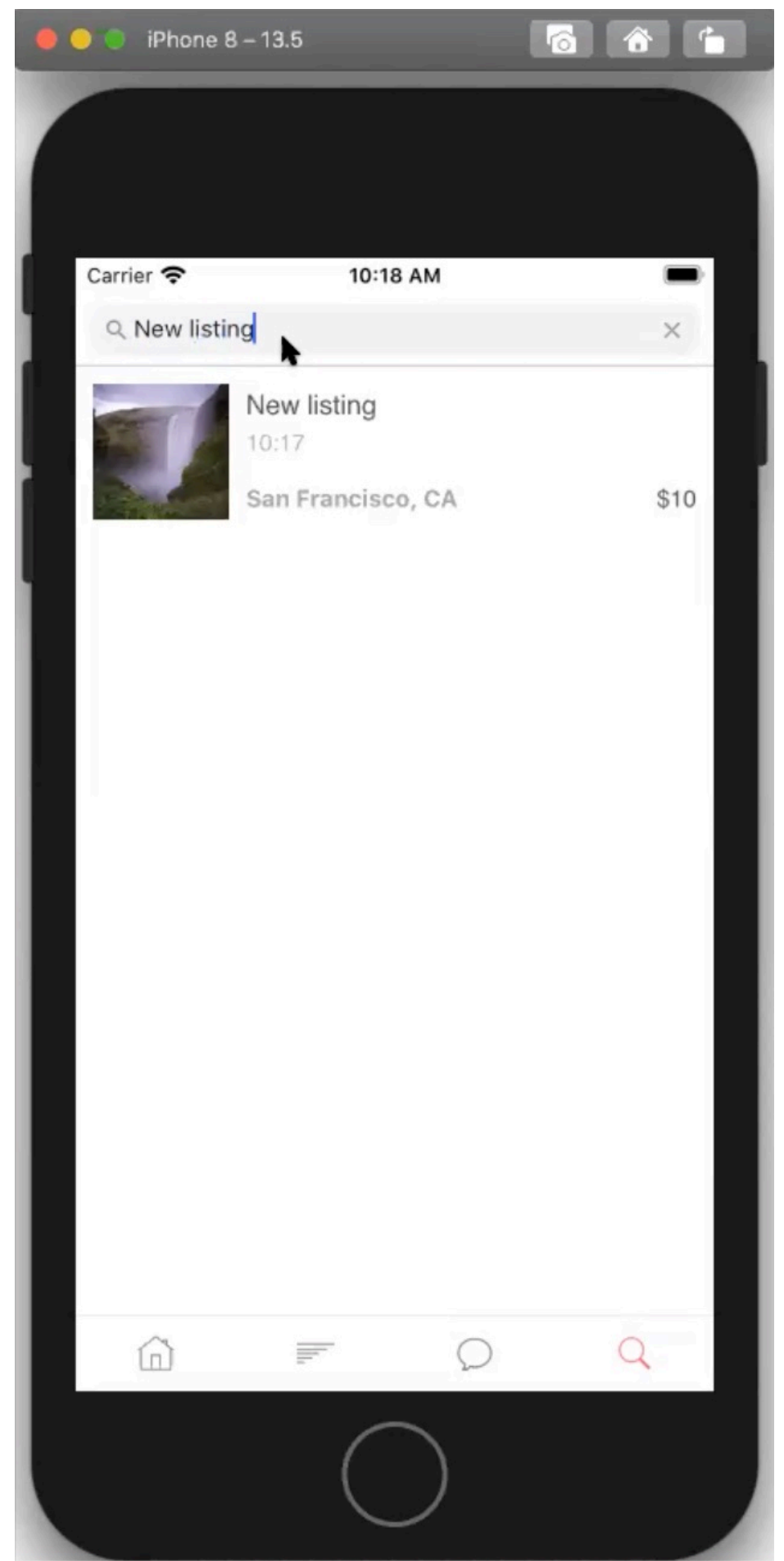

Figure 22. Search Feature for Finding Services by Name or Key Words 


\section{Bibliography}

A.B. 302 "Parking: Homeless Students" (California 2019):

https://leginfo.legislature.ca.gov/faces/billTextClient.xhtml?bill_id=201920200AB302

A.B. 1747 "Food Assistance: Higher Education Students" (California 2016):

https://leginfo.legislature.ca.gov/faces/billTextClient.xhtml?bill_id=201520160AB1747

A.B. 1995 "Community colleges: homeless students: access to shower facilities" (California 2016): https://leginfo.legislature.ca.gov/faces/billNavClient.xhtml?bill_id=201520160AB1995

Albouy, D. \& Zabek, M. (2016). "Housing Inequality," National Bureau of Economic Research [Working Paper 21916]: http://davidalbouy.net/housinginequality.pdf

Allison, T. (2018). Rethinking SNAP Benefits for College Students. Young Invincibles [policy brief].

Anderson, B. (July 24, 2018). "Starving students" Sacramento Bee:

https://www.sacbee.com/news/politics-government/capitol-alert/article215360060.html

Annan, K. (April 26, 2000). "Secretary-General Kofi Annan to the World Education Forum, delivered in Dakar, Senegal." United Nations:

https://www.un.org/press/en/2000/20000426.sgsm7369.doc.html

Assistant Secretary for Planning and Evaluation (2004). "Measures of Material Hardship: Final Report." Office of the Assistant Secretary for Planning and Evaluation:

https://aspe.hhs.gov/report/measures-material-hardship-final-report/basic-needs-and-foodinsecurity

Au, N. \& Hyatt, S. (April 2017). "Resources Supporting Homeless Students at California's Public colleges and universities". CA Homeless Youth Project:

http://cahomelessyouth.library.ca.gov/docs/pdf/collegesupportsreportpdf4-27-17.pdf

Berg-Cross, L., \& Green, R. (2009). The impact of the recession on college students. Journal of College Student Psychotherapy, 24(1), 2-16.

Bowen, H. (2018) Investment in learning: The individual and social value of American higher education. Routledge.

Brooke, J. (2013). SUS: A Retrospective. Journal of Usability Studies, 8(2), 29-40.

Broton, K., Frank, V., \& Goldrick-Rab, S. (2014). Safety, security, and college attainment: An investigation of undergraduates' basic needs and institutional response. Wisconsin Hope Lab.

Broton, K. M., \& Goldrick-Rab, S. (2018). Going without: An exploration of food and housing insecurity among undergraduates. Educational Researcher, 47(2), 121-133. 
Broton, K., \& Goldrick-Rab, S. (2016). The dark side of college (un) affordability: Food and housing insecurity in higher education. Change: The Magazine of Higher Learning, 48(1), 16-25.

Broton, K., \& Goldrick-Rab, S. (2015). Public Testimony on Hunger in Higher Education Submitted to the National Commission on Hunger.

Broton, K., \& Goldrick-Rab, S. (2013). Housing instability among college students. Center for Financial Security. Madison, WI: University of Wisconsin. Retrieved from https://wiscape. wisc. edu/docs/WebDispenser/wiscapedocuments/hcm-housing-policy-memo. pdf.

Brown, E. G. (January 10, 2017). “2017-2018 Governor’s Budget Summary,” California:http://www.ebudget.ca.gov/2017-18/pdf/BudgetSummary/FullBudgetSummary.pdf

Buch, K., Langley, S., Johnson, T., \& Coleman, N. (2016). A university-community partnership to combat food insecurity among college students. Partnerships: A Journal of Service-Learning and Civic Engagement, 7(1), 16-26.

California Community Colleges (2018). Guidelines for California Community College Homeless Youth Liaisons. URL: http://www.cccstudentmentalhealth.org/docs/Homeless-Primer-2018.pdf

California Community Colleges Chancellor's Office (2018). Basic Needs Survey Report. URL: http://extranet.cccco.edu/Portals/1/ExecutiveOffice/Board/2018_agendas/March/4.4-Attachment2-Basic-Needs-Survey-Report.pdf

California Department of Housing and Community Development (2018). "People Experiencing Homelessness": http://www.hcd.ca.gov/policy-research/specific-policyareas/homelessness.shtml

California Homeless Youth Project and SchoolHouse Connection (2018). 5 Practical Guides to Support Homeless and Low-Income College Students in California. Issue Brief. URL: https://www2.calstate.edu/impact-of-the-csu/student-success/basic-needsinitiative/Documents/5GuidesToHelpHomelessCollegeStudents.pdf

California Legislative Information (2019). "A Glossary of Legislative Terms": http://leginfo.ca.gov/glossary.html

California Legislative Information (2019). “AB-302 Parking: Homeless Students, Bill History.”: https://leginfo.legislature.ca.gov/faces/billHistoryClient.xhtml?bill_id=201920200AB302

Calvez, K., Miller, C., Thomas, L., Vazquez, D., \& Walenta, J. (2016). The university as a site of food insecurity: Evaluating the foodscape of Texas A\&M University's main campus. The Southwestern Geographer, 19(2016), 1-14. 
Chaparro, M. P., Zaghloul, S. S., Holck, P., \& Dobbs, J. (2009). Food insecurity prevalence among college students at the University of Hawai'i at Mānoa. Public health nutrition, 12(11), 2097-2103.

Chappelle, N. (2015). Food insecurity at Humboldt State University (Doctoral dissertation, Humboldt State University).

Cinderby, S., Snell, C., \& Forrester, J. (2008). Participatory gis and its application in governance: The example of air quality and the implications for noise pollution. Local Environment, 13(4), 309-320.

Coady, D. \& Dizioli, A. (2017). "Income Inequality and Education Revisited: Persistence, Endogeneity, and Heterogeneity.” International Monetary Fund [working paper 17/126].

Coady, D. \& Dizioli, A. "Income inequality and education revisited: persistence, endogeneity and heterogeneity." Applied Economics 50.25 (2018): 2747-2761.

Cooper, J. (2006). The digital divide: The special case of gender. Journal of Computer Assisted Learning, 22(5), 320-334.

Crampton, J. (2010). Mapping : A critical introduction to cartography and gis (Critical introductions to geography ser, v. 11). Chicester: John Wiley \& Sons, Incorporated.

Crutchfield, R. and Maguire, J. (January 2018). "Study of Student Basic Needs." The California State University Office of the Chancellor: https://www2.calstate.edu/impact-of-the-csu/studentsuccess/basic-needsinitiative/Documents/BasicNeedsStudy_phaseII_withAccessibilityComments.pdf

Dam, R.F. and Siang, T. Y. (2018). "What is Ideation - and How to Prepare for Ideation Sessions." Interaction Design Foundation: https://www.interaction$\underline{\text { design.org/literature/article/what-is-ideation-and-how-to-prepare-for-ideation-sessions }}$

Elwood, S. (2006). Beyond cooptation or resistance: Urban spatial politics, community organizations, and GIS-based spatial narratives. Annals of the association of American geographers, 96(2), 323-341.

Elwood, S. (2006). Critical issues in participatory GIS: Deconstructions, reconstructions, and new research directions. Transactions in GIS, 10(5), 693-708.

Espinoza, A. (2013). Assessing differences in food security status among college students enrolled at a public California state university campus (Doctoral dissertation).

Environmental Systems Research Institute (2019). “ArcGIS QuickCapture”: https://www.esri.com/en-us/arcgis/products/arcgisquickcapture/overview?rmedium=esri_com_redirects01\&rsource=/en-us/landingpage/product/2019/arcgis-quickcapture 
Environmental Systems Research Institute (2019). "What is Web AppBuilder for ArcGIS?": https://doc.arcgis.com/en/web-appbuilder/create-apps/what-is-web-appbuilder.htm

Farahbakhsh, J., Hanbazaza, M., Ball, G. D., Farmer, A. P., Maximova, K., \& Willows, N. D. (2017). Food insecure student clients of a university-based food bank have compromised health, dietary intake and academic quality. Nutrition \& dietetics, 74(1), 67-73.

FIND Foodbank (2020). “The Desert's Regional Food Bank”: http://www.findfoodbank.org

Freudenberg, N., Manzo, L., Jones, H., Kwan, A., Tsui, E., \& Gagnon, M. (2011). Food Insecurity at CUNY: Results from a Survey of CUNY Undergraduate Students. Healthy CUNY Initiative, City University of New York.

Garcia, M. (2019). 2018-2019 Student Expenses and Resources Survey: Initial Insights. California Student Aid Commission.

Gaines, A., Robb, C. A., Knol, L. L., \& Sickler, S. (2014). Examining the role of financial factors, resources and skills in predicting food security status among college students. International Journal of Consumer Studies, 38(4), 374-384.

Geis, Q. D. (2015). Exploring the academic and social experiences of homeless college students. Master's thesis, University of Nebraska, Lincoln.

Grabmeier, J. (June 30, 2015). “70 percent of college students stressed about finances.” Ohio State News: https://news.osu.edu/70-percent-of-college-students-stressed-about-finances/

Goldrick-Rab, S., Baker-Smith, C., Coco, V., \& Looker, E. (2019). California Community Colleges \#RealCollege Survey. The Hope Center, pp. 1-48.

Goldrick-Rab, S., Richardson, J., and Kinsley, P. (2017). Guide to Assessing Basic Needs Insecurity in Higher Education. The Hope Lab.

Goldrick-Rab, S., Richardson, J., \& Hernandez, A. (2017). Hungry and homeless in college: Results from a national study of basic needs insecurity in higher education.

Goode, J. (2010). The digital identity divide: how technology knowledge impacts college students. New media \& society, 12(3), 497-513.

Griffin, S. (February 6, 2012). "What does gender have to do with housing?" Bridge the Gulf: https://bridgethegulfproject.org/blog/2012/what-does-gender-have-do-housing $\% \mathrm{E} 2 \% 80 \% \mathrm{~A} 8$

Guadagno, R. E., Muscanell, N. L., \& Pollio, D. E. (2013). The homeless use Facebook?! Similarities of social network use between college students and homeless young adults. Computers in Human Behavior, 29(1), 86-89. 
Gundersen, C., \& Ziliak, J. P. (2015). Food insecurity and health outcomes. Health affairs, 34(11), 1830-1839.

Gupton, J. T. (2017). Campus of opportunity: A qualitative analysis of homeless students in community college. Community College Review, 45(3), 190-214.

Hallett, R. E., \& Crutchfield, R. (2017). Homelessness and Housing Insecurity in Higher Education: A Trauma-Informed Approach to Research, Policy, and Practice: ASHE Higher Education Report. John Wiley \& Sons.

Hallett, R. E., \& Freas, A. (2018). Community college students' experiences with homelessness and housing insecurity. Community College Journal of Research and Practice, 42(10), 724-739.

Haney, M. (January 2015). The Impact of Financial Burden and Employment on Student Employment Turnover and Dropout Intentions (Honors Thesis, East Carolina University). Retrieved from the Scholarship: http://hdl.handle.net/10342/4800

Harvey, F. (2018). Critical gis: Distinguishing critical theory from critical thinking. The Canadian Geographer / Le Géographe Canadien, 62(1), 35-39. doi:10.1111/cag.12440

Hill, J. (2019). “Biography.”: https://sd13.senate.ca.gov/biography

Huang, H., Fernandez, S., Rhoden, M. A., \& Joseph, R. (2018). Serving former foster youth and homeless students in college. Journal of Social Service Research, 44(2), 209-222.

Humboldt State University (Nov. 6, 2018). "Housing Liaison Aims to Help Students Avoid Homelessness," Humboldt State Now: http://now.humboldt.edu/news/housing-liaison-aims-tohelp-students-avoid-homelessness/

Humboldt State University (Dec. 10, 2020). "Wellbeing Map.” Student Health and Wellbeing Services: https://wellbeing.humboldt.edu/wellbeing-map-0

Instamobile (2020). "React Native Listings App” template: $\underline{\text { htps://www.instamobile.io }}$

James, J. (July 14, 2020). "Community fridges show up in LA neighborhoods to feed those in need," Los Angeles Times: https://www.latimes.com/california/story/2020-07-14/in-1-aneighborhoods-struggling-under-pandemic-well-stocked-fridges-turn-up-to-help

Jesnek, L. M. (2012). Empowering the Non-Traditional College Student and Bridging the" Digital Divide". Contemporary Issues in Education Research, 5(1), 1-8.

Jones, S., Johnson-Yale, C., Millermaier, S., \& Perez, F. S. (2009). Everyday life, online: US college students' use of the Internet. First Monday, 14(10).

Jones, S., Johnson-Yale, C., Millermaier, S., \& Pérez, F. S. (2009). US college students' Internet use: Race, gender and digital divides. Journal of Computer-Mediated Communication, 14(2), 244-264. 
Kattari, S. K., Whitfield, D. L., Walls, N. E., Langenderfer-Magruder, L., \& Ramos, D. (2016). Policing gender through housing and employment discrimination: comparison of discrimination experiences of transgender and cisgender LGBQ individuals. Journal of the Society for Social Work and Research, 7(3), 427-447.

Klug, B. (2017). An Overview of the System Usability Scale in Library Website and System Usability Testing. Weave, 1(6).

Koller, K. (2014). Extent of BGSU student food insecurity and community resource use. Honor's thesis, Bowling Green State University.

Lareau, A. (2014). Schools, housing, and the reproduction of inequality. Choosing homes, choosing schools, 169-206.

LePage, N. and Hyatt, S. (Sept. 2019). Measuring our success: campus supports for college students experiencing food \& housing insecurity. California Homeless Youth Project. California Research Bureau, California State Library.

Los Angeles Controller (Aug. 10, 2020). "Food Resources in California" [dataset]: https://controllerdata.lacity.org/dataset/Food-Resources-in-California/v2mg-qsxf

Los Angeles Food Bank (2020). "Pantry Locator.” County of Los Angeles: https://foodresources-lacounty.hub.arcgis.com/datasets/fd1770204f5348f7b1bef01aae0afa8a

Maroto, M. E., Snelling, A., \& Linck, H. (2015). Food insecurity among community college students: Prevalence and association with grade point average. Community College Journal of Research and Practice, 39(6), 515-526.

Maroto, M. E. (2013). Food insecurity among community college students: Prevalence and relationship to GPA, energy, and concentration (Doctoral dissertation, Morgan State University).

Martinez, S. M., Webb, K., Frongillo, E. A., \& Ritchie, L. D. (2018). Food insecurity in California's public university system: What are the risk factors?. Journal of Hunger \& Environmental Nutrition, 13(1), 1-18.

Martinez, S. M., Frongillo, E. A., Leung, C., \& Ritchie, L. (2018). No food for thought: Food insecurity is related to poor mental health and lower academic performance among students in California's public university system. Journal of health psychology, 1359105318783028.

Mello, F. (May 2018). "California campuses confront a growing challenge: homeless students." CAL matters: https://calmatters.org/articles/homeless-college-students-california/

Mello, F. (May 2019). "The soul-crushing cost of college in California, explained." CalMatters: https://calmatters.org/explainers/california-cost-of-college-explained/ 
Mercado, V. (2017). Food and housing insecurity among students at a community college district (Doctoral dissertation, San Francisco State University).

Mirabitur, E., Peterson, K. E., Rathz, C., Matlen, S., \& Kasper, N. (2016). Predictors of collegestudent food security and fruit and vegetable intake differ by housing type. Journal of American College Health, 64(7), 555-564.

Mukherjee, F. (2015). Public participatory GIS. Geography Compass, 9(7), 384-394.

National Alliance to End Homelessness (2018). “2018 Point-in-Time Counts":

https://endhomelessness.org/resource/2018-point-in-time-counts/

National Alliance to End Homelessness (2012). "What is a Point-in-Time Count?”:

https://endhomelessness.org/resource/what-is-a-point-in-time-count/

Nazmi, A., Martinez, S., Byrd, A., Robinson, D., Bianco, S., Maguire, J., ... \& Ritchie, L. (2018). A systematic review of food insecurity among US students in higher education. Journal of Hunger \& Environmental Nutrition, 1-16.

Nielsen, K. (2015). 'Fake It'til You Make It'” Why Community College Students' Aspirations ' 'Hold Steady'. Sociology of Education, 88(4), 265-283.

Paden, N. (2012). Homeless students? Not at my university: The reality of homeless college students. ASBBS Proceedings, 19(1), 669.

Pavlovskaya, M. (2018). Critical GIS as a tool for social transformation. The Canadian Geographer/Le Géographe canadien, 62 (1), 40-54.

Payne-Sturges, D. C., Tjaden, A., Caldeira, K. M., Vincent, K. B., \& Arria, A. M. (2018). Student hunger on campus: food insecurity among college students and implications for academic institutions. American Journal of Health Promotion, 32(2), 349-354.

Pickles, J. (2006). Ground Truth 1995-2005. Transactions in GIS, 10(5), 763-772.

Pickles, J. (1997). Tool or science? GIS, technoscience, and the theoretical turn.

Pixabay (2020). “Mentor Icon”: https://pixabay.com/illustrations/mentor-icon-tutor-icon-mentortutor-2895941/

Rall, E., Hansen, R., \& Pauleit, S. (2018). The added value of public participation GIS (PPGIS) for urban green infrastructure planning. Urban Forestry \& Urban Greening.

Restmeyer, N. (2018). College Ready, Hungry, and Homeless. Speaker's Office of Research and Floor Analysis, California State Assembly. 
Ringer, B. D. "College students experiencing homelessness: The consequence of failed macro policies." McNair Scholars Research Journal 8.1 (2015): 9.

Rossi, P.H., Lipsey M.W., Freeman, H.E. (2004). Evaluation: A Systematic Approach. Sage Publications.

Sackett, C., Goldrick-Rab, S., \& Broton, K. (2016). Addressing housing insecurity and living costs in higher education. US Department of Housing and urban Development, Office of Public Development and Research.

Sauro, J. (2011) SUStisfied? Little-known System Usability Scale facts. User Experience: The Magazine of the User Experience Professionals Association, 10(3). Retrieved from http://uxpamagazine.org/sustified/

Sauro, J., Lewis, J. (2016). Quantifying the user experience: Practical statistics for user research. Amsterdam; Waltham, MA: Elsevier/Morgan Kaufmann.

Sen, A. K. (2009). "The Idea of Justice,” pp. 1-27, Cambridge: Belknap Press of Harvard University Press.

Sieber, R. (2004). Rewiring for a gis/2. Cartographica: The International Journal for Geographic Information and Geovisualization,39(1), 25-39. doi:10.3138/T6U8-171M-452W$516 \mathrm{R}$

Silva, M. R., Kleinert, W. L., Sheppard, A. V., Cantrell, K. A., Freeman-Coppadge, D. J., Tsoy, E., ... \& Pearrow, M. (2017). The relationship between food security, housing stability, and school performance among college students in an urban university. Journal of College Student Retention: Research, Theory \& Practice, 19(3), 284-299.

Termly (2020). "Privacy Policy Generator”: https:/termly.io/products/privacy-policy-generator/

The U.S. Department of Housing and Urban Development (2015). "Point-in-Time Count Methodology Guide": https://www.hudexchange.info/resource/4036/point-in-time-countmethodology-guide/

Thomas, D. R. (2003). A general inductive approach for qualitative data analysis.

Thomas, D. R. (2006). A general inductive approach for analyzing qualitative evaluation data. American journal of evaluation, 27(2), 237-246.

Tsui, E., Freudenberg, N., Manzo, L., Jones, H., Kwan, A., \& Gagnon, M. (2011). Housing instability at CUNY: Results from a survey of CUNY undergraduate students. Healthy CUNY Initiative, City University of New York.

Tulloch, D. (2008). Public participation GIS (PPGIS). Encyclopedia of geographic information science, 352-355. 
University of California (UC) Global Food Initiative (Dec. 2017). "Global Food Initiative: Food and Housing Security at the University of California". Report: https://www.ucop.edu/globalfood-initiative/ files/food-housing-security.pdf

Uehara, E. S. (1994). Race, gender, and housing inequality: an exploration of the correlates of low-quality housing among clients diagnosed with severe and persistent mental illness. Journal of Health and Social Behavior, 35(4), 309.

U.S. General Services Administration (2020). "System Usability Scale (SUS)” Technology Transformation Services: https:/www.usability.gov/how-to-and-tools/methods/system-usabilityscale.html

U.S. Interagency Council on Homelessness (2018). "Key Federal Terms and Definitions of Homelessness Among Youth." Discussion of Subtitle VII-B of the McKinney-Vento Homeless Assistance Act: https://www.usich.gov/resources/uploads/asset library/Federal-Definitions-ofYouth-Homelessness.pdf

Warren, S. (2004). The utopian potential of GIS. Cartographica: The International Journal for Geographic Information and Geovisualization, 39(1), 5-16.

Wikimedia Commons (2004). "Images". Accessed January 2020:

https://commons.wikimedia.org/wiki/Main_Page

Williams, C. (2013). Brainstorming and Design: A User-Centered Design Method. Morgan Kaufmann.

Wilson, W. J. (2006). The geography of opportunity: Race and housing choice in metropolitan America. Brookings Institution Press.

Woelfer, J. P., \& Hendry, D. G. (2010, April). Homeless young people's experiences with information systems: life and work in a community technology center. In Proceedings of the SIGCHI Conference on Human Factors in Computing Systems (pp. 1291-1300). ACM.

Woelfer, J. P., \& Hendry, D. G. (2012, May). Homeless young people on social network sites. In Proceedings of the SIGCHI Conference on Human Factors in Computing Systems (pp. 28252834). ACM. 